Florida International University FIU Digital Commons

3-24-2014

\title{
Two Adaptation Mechanisms Regulate Cellular Migration in Dictyostelium discouideum
}

Marbelys Rodriguez

mrodr126@fiu.edu

DOI: $10.25148 /$ etd.FI14040813

Follow this and additional works at: https://digitalcommons.fiu.edu/etd

Part of the Biology Commons

\section{Recommended Citation}

Rodriguez, Marbelys, "Two Adaptation Mechanisms Regulate Cellular Migration in Dictyostelium discouideum" (2014). FIU

Electronic Theses and Dissertations. 1144.

https://digitalcommons.fiu.edu/etd/1144

This work is brought to you for free and open access by the University Graduate School at FIU Digital Commons. It has been accepted for inclusion in FIU Electronic Theses and Dissertations by an authorized administrator of FIU Digital Commons. For more information, please contact dcc@fiu.edu. 


\section{FLORIDA INTERNATIONAL UNIVERSITY}

Miami, Florida

\section{TWO ADAPTATION MECHANISMS REGULATE CELLULAR MIGRATION IN DICTYOSTELIUM DISCOIDEUM}

A dissertation submitted in partial fulfillment of

the requirements for the degree of

DOCTOR OF PHILOSOPHY

in

BIOLOGY

by

Marbelys Rodriguez

2014 
To: Dean Kenneth G. Furton

College of Arts and Sciences

This dissertation, written by Marbelys Rodriguez, and entitled Two Adaptation Mechanisms Regulate Cellular Migration in Dictyostelium discoideum, having been approved in respect to style and intellectual content, is referred to you for judgment.

We have read this dissertation and recommend that it be approved.

Alejandro Barbieri

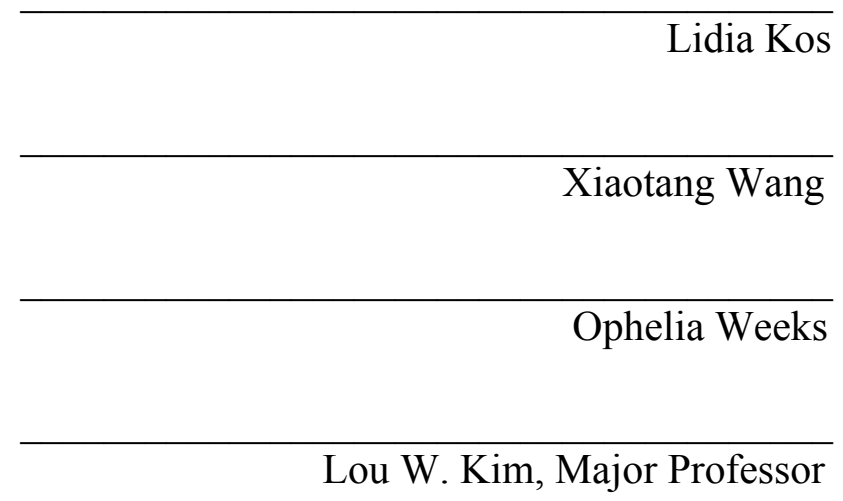

Date of Defense: March 24, 2014

The dissertation of Marbelys Rodriguez is approved.

\begin{tabular}{c}
\hline $\begin{array}{c}\text { Dean Kenneth G. Furton } \\
\text { College of Arts and Sciences }\end{array}$ \\
\hline $\begin{array}{c}\text { Dean Lakshmi N. Reddi } \\
\text { University Graduate School }\end{array}$
\end{tabular}

Florida International University, 2014 


\section{ABSTRACT OF THE DISSERTATION \\ TWO ADAPTATION MECHANISMS REGULATE CELLULAR MIGRATION IN \\ DICTYOSTELIUM DISCOIDEUM}

by

Marbelys Rodriguez

Florida International University, 2014

Miami, Florida

Professor Lou W. Kim, Major Professor

Dictyostelium discoideum is a simple model organism widely used to study many cellular functions, including differentiation, gene regulation, cellular trafficking and directional migration. Adaptation mechanisms are essential in the regulation of these cellular processes. The misregulation of adaptation components often results in persistent activation of signaling pathways and aberrant cellular responses. Studying adaptation mechanisms regulating cellular migration will be crucial in the treatment of many pathological conditions in which motility plays a central role, such as tumor metastasis and acute inflammation. I will describe two adaptation mechanisms regulating directional migration in Dictyostelium cells.

The Extracellular signal Regulated Kinase 2 (ERK2) plays an essential role in Dictyostelium cellular migration. Extracellular Signal Regulated Kinase 2 stimulates intracellular cAMP accumulation in chemotaxing cells. Aberrant ERK2 regulation results in aberrant cAMP levels and defective directional migration. The MAP Phosphatase with Leucine-rich repeats (MPL1) is crucial for ERK2 adaptation. Cells lacking, MPL1 (mpll cells) displayed higher pre-stimulus and persistent post-stimulus ERK2 phosphorylation, 
defective cAMP production and reduced cellular migration. Reintroduction of a full length $\mathrm{Mpll}$ into $\mathrm{mpll}^{-}$cells restored aggregation, ERK2 regulation, random and directional motility, and cAMP production similar to wild type cells $(W t)$. These results suggest Mpl1 is essential for proper regulation of ERK2 phosphorylation and optimal motility in Dictyostelium cells.

Cellular polarization in Dictyostelium cells in part is regulated by the activation of the AGC-related kinase Protein Kinase Related B1 (PKBR1). The PP2A regulatory subunit, B56, and the Glycogen Synthase Kinase 3 (GSK3) are necessary for PKBR1 adaptation in Dictyostelium cells. Cells lacking B56, psrA cells, exhibited high basal and post-stimulus persistent phosphorylation of PKBR1, increased phosphorylation of PKBR1 substrates, and aberrant motility. PKBR1 adaptation is also regulated by the GSK3. When the levels of active GSK3 are reduced in $W t$ and $p s r A^{-}$cells, high basal levels of phosphorylated PKBR1 were observed, in a Ras dependent, but B56 independent mechanism. Altogether, PKBR1 adaptation is regulated by at least two independent mechanisms: one by GSK3 and another by PP2A/B56. 


\section{DEDICATION}

I dedicate this dissertation to David and to my parents, Maria and Sebastian. Thanks for believing in me unconditionally, even at times where I did not believe in myself. I love you all very much.

Yo quiero dedicar esta Tesis de Doctorado a David y a mis padres, Maria y Sebastian. Muchas gracias por creer en mi incondicionalmente, aun en ocaciones cuando yo no creia en mi. Los amo muchisimo. 


\section{ACKNOWLEDGMENTS}

First and foremost, I would to thank my mentor, Dr. Lou W. Kim, for all the guidance I received throughout these years. Next, I would like to thank all my committee members, Dr. Alejandro Barbieri, Dr. Lidia Kos, Dr. Xiaotang Wang and Dr. Ophelia Weeks for their insightful suggestions. I would like to acknowledge Lorraine S. Acevedo, Boris Castillo, Dr. Seon-Hee Hwang, Adwait Kabra, Bohey Kim, Dr. Nam-Sihk Lee, Dr. Erasmo Perera, Maria Pulido, Amy Saldana, Mujataba Sharief, Dr. Tong Sun and Dr. Sudhakar Veeranki for their technical help and support. Lastly, I would like to thank the MBRS/RISE Graduate program for its sponsorship. 


\section{TABLE OF CONTENTS}

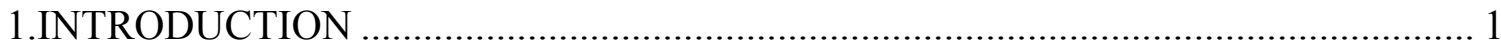

1.1 Dictyostelium discoideum as a model system for cellular motility............................. 1

1.2 An overview of some of the signaling pathways regulating directional motility in

Dictyostelium. 2

1.2.2 The family of small GTPases Ras regulates leading edge formation in

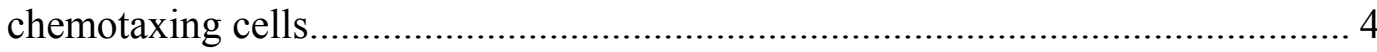

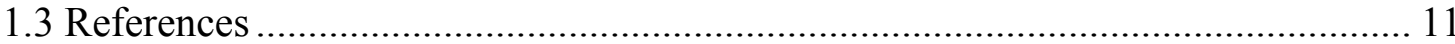

2.MPL1, THE NOVEL PHOSPHATASE WITH LEUCINE-RICH-REPEATS, IS ESSENTIAL FOR PROPER ERK2 PHOSPHORYLATION AND CELL MOTILITY. 15

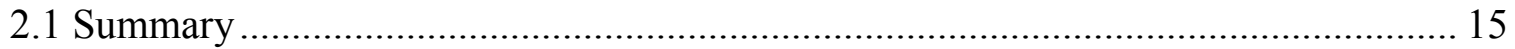

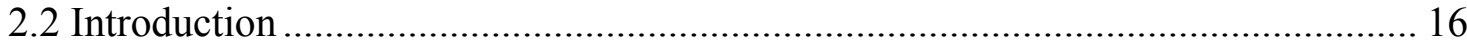

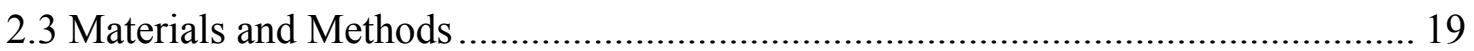

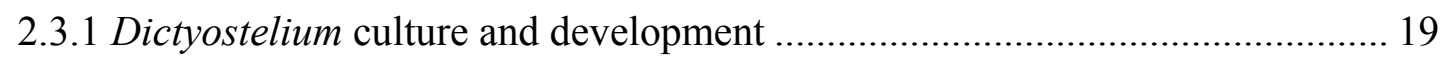

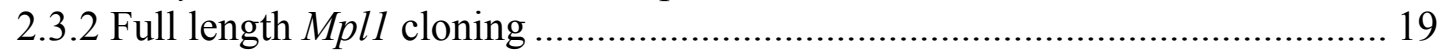

2.3.3 Generation of $\mathrm{mpll}^{-}$cells and northern blot analysis of $\mathrm{Mpll}$......................... 20

2.3.4 Recombinant Mpl1-Phosphatase and Phosphatase Assay ............................... 21

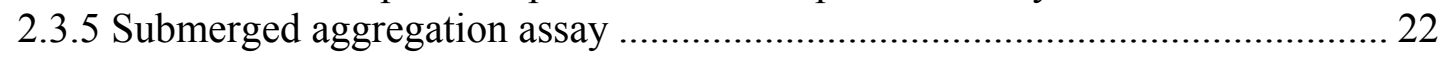

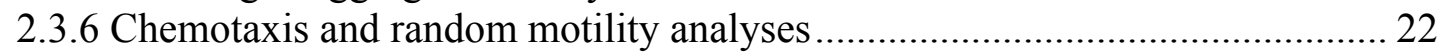

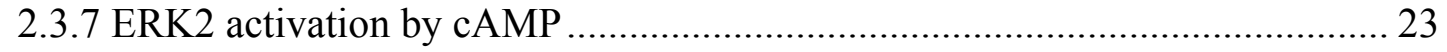

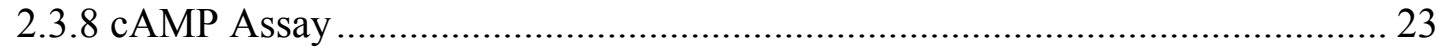

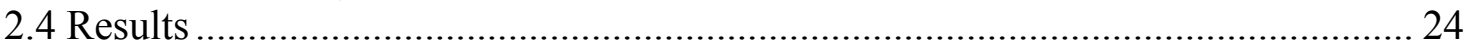

2.4.1 Mpl1 is an active phosphatase with Leucine-Rich Repeats. ........................... 24

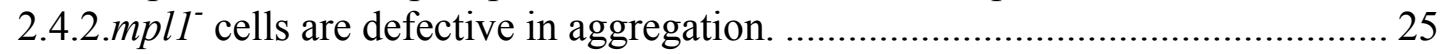

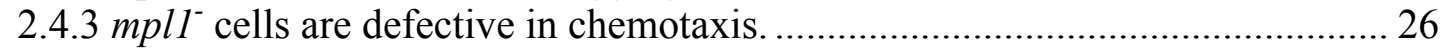

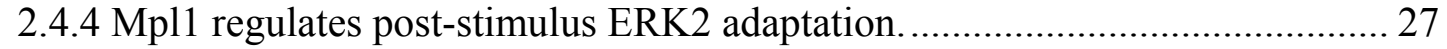

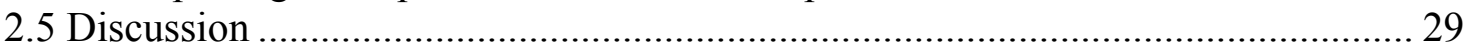

2.5.1 Phosphatases similarly architected to Mpl1 exist in other unicellular

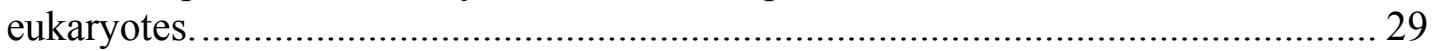

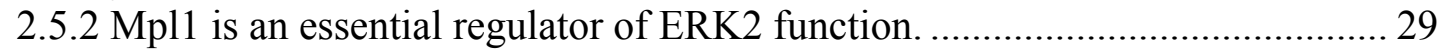

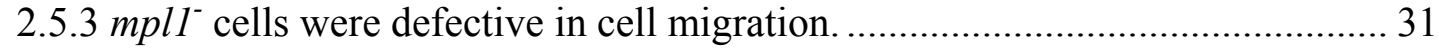

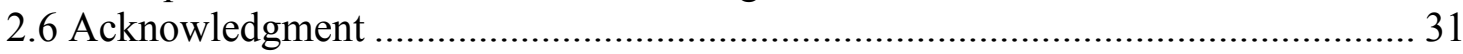

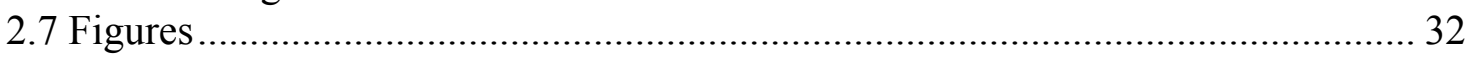

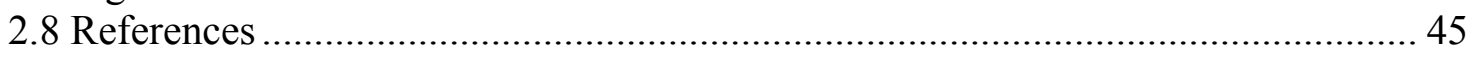

3.THE PP2A REGULATORY SUBUNIT, B56, AND THE GLYCOGEN SYNTHASE KINASE-3 REGULATE PROTEIN KINASE B-RELATED 1

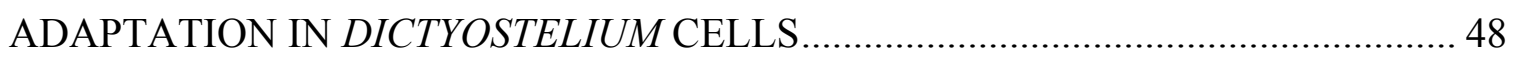

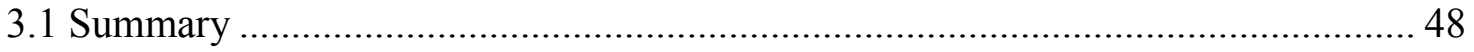

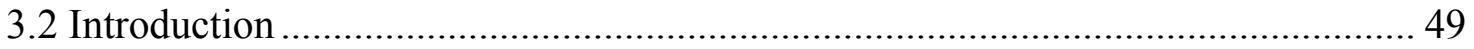




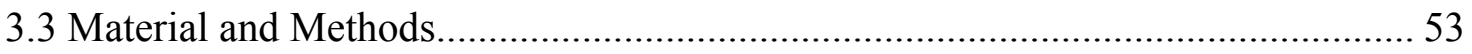

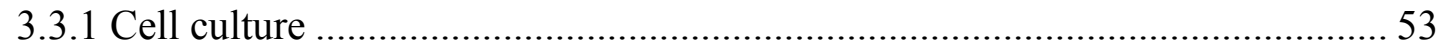

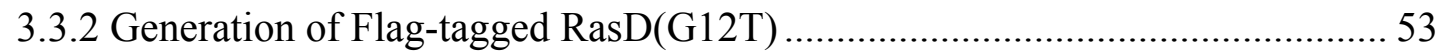

3.3.3 Determining Ras Activation in response to cAMP stimulation ........................55

3.3.4 Determining PKBR1 activation in response to cAMP stimulation ................... 56

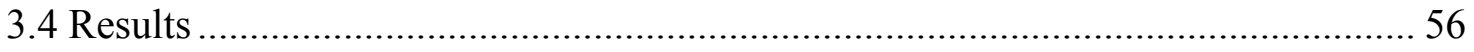

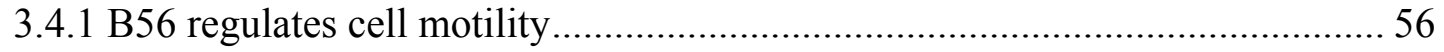

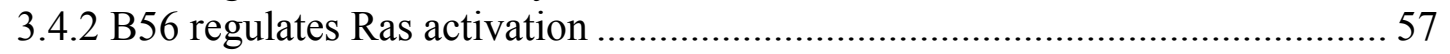

3.4.3 B56 is important for PKBR1 regulation ..................................................... 58

3.4.4 Repairing Ras activation in $p s r A^{-}$cells does not restore PKBR1 adaptation

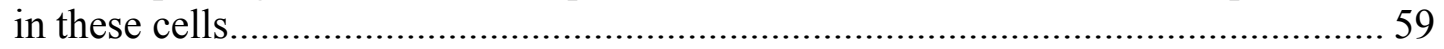

3.4.5 RasD regulates PKBR1 and PKBA activation .............................................5 59

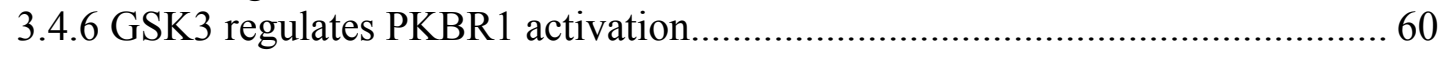

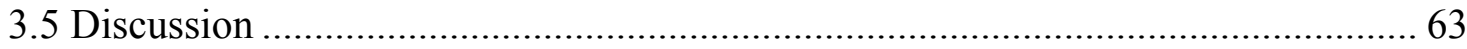

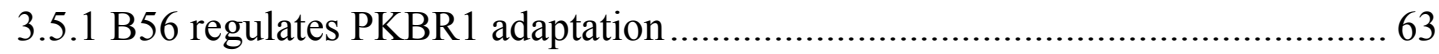

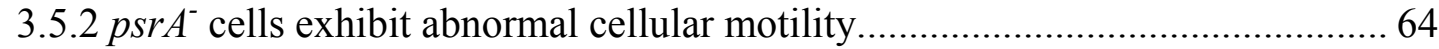

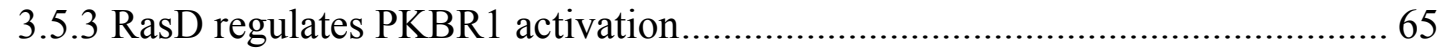

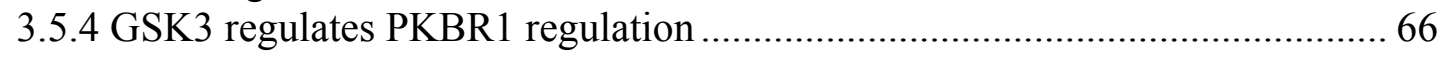

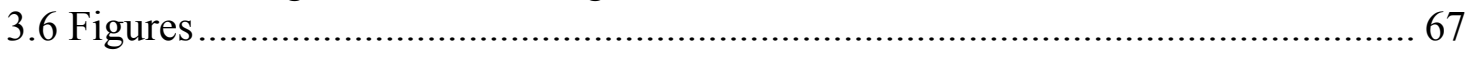

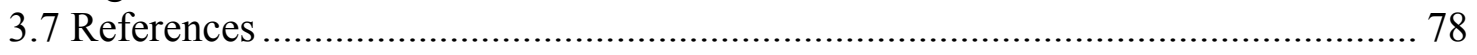

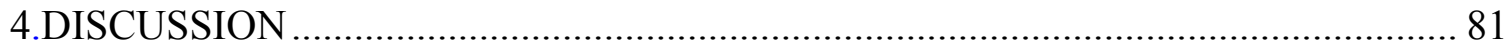

4.1 MPL1 plays an essential role in ERK2 adaptation............................................. 81

4.2 The PP2A regulatory subunit, B56, and GSK3 play an essential role in PKBR1

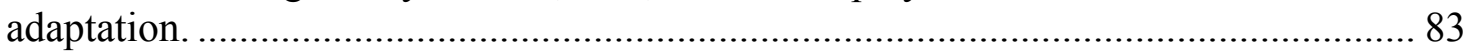

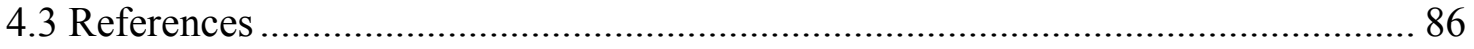

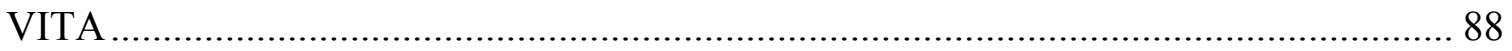




\section{LIST OF FIGURES}

FIGURE

PAGE

1. Dual specificity phosphatases with Leucine-Rich Repeats. ................................... 33

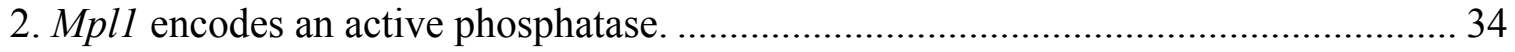

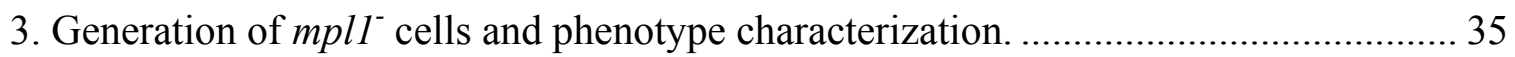

4. $\mathrm{mpll}^{-}$cells are inefficient in chemotaxis under $0.1 \mu \mathrm{M}$ cAMP gradient. ..................... 38

5. $\mathrm{mpll}^{-}$cells displayed aggravated chemotactic responses toward $2 \mu \mathrm{M}$ cAMP gradient compared to $0.1 \mu \mathrm{M}$ cAMP gradient. ...................................................... 41

6. $\mathrm{mpll}^{-}$cells were also defective in random motility. ......................................... 42

7. Mpl1 regulates ERK2 phosphorylation in Dictyostelium ....................................... 43

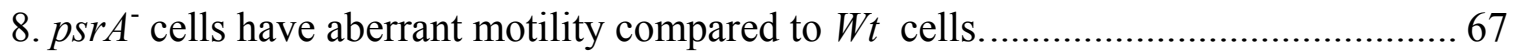

9. RasG, D and C activation in response to cAMP stimulation is defective in $p s r A^{-}$

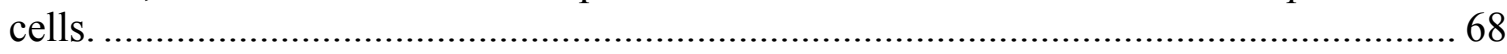

10. pr $^{-}$cells aberrantly high levels of active PKBR 1 ............................................ 71

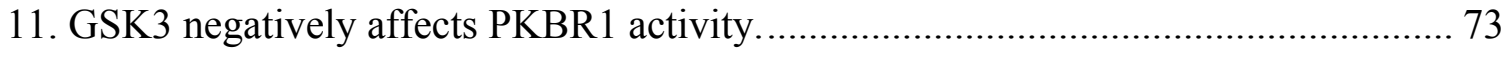

12. Lithium chloride $(\mathrm{LiCl})$ treatments to cells results in increased PKBR1 activation... 75

13. B56 and GSK3 regulate PKBR1 adaptation and chemotaxis............................... 77 
$\mathrm{ACA}$ Adenylyl Cyclase A

$\mathrm{AL}$ Active Loop B56. PP2A regulatory B subunit cAMP adenosine 3', 5'-monophosphate

CI . Chemotactic Index RasCG13T Constitutively Active Form of RasC

RasDG12T Constitutively Active Form of RasD

$\cot \mathrm{B}$ Spore Coat protein B CRAC Cytosolic Regulator of Adenylyl Cyclase DAG Diacylglycerol DSP Dual Specific Phosphatases ecmA Extracellular Matrix Protein A ecmB Extracellular Matrix Protein B

ERK2 Extracellular signal Regulated Kinase 2

GPCR G protein-Coupled Receptor GSK3 Glycogen Synthase Kinase 3 GSK3DN Dominant Negative form of GSK3 GST-RBD Byr2 Ras Binding Domain from Schizosaccharomyces pombe Byr2 GST-RBD Raf1 $_{1}$ Ras Binding Domain of mammalian Raf1

HM Hydrophobic Motif $\mathrm{IP}_{3}$ Inositol-1,4,5-Triphosphate 
$\mathrm{LiCl}$ Lithium Chloride

LRR Leucine Rich Repeats

MAP Mitogen Activated Protein MHCK Myosin Heavy Chain Kinase MKB MAP Kinase Binding Domain MKP MAP Kinase Phosphatase

PAKa p21 Activated Protein A PDK1 Phosphoinositide dependent kinase 1

PH Pleckstrin homology PI3K Phosphoinositide 3-Kinase $\mathrm{PIP}_{2}$ ..Phosphatidylinositol 4,5-Biphosphates

PKA Protein Kinase A

PKBA Protein Kinase BA

PKBR1 Protein Kinase B-related 1

PLC .Phospholipase C PP2A Protein Phosphatase 2A PTEN Phosphatase Tensin homolog deleted ten PTP Protein Tyrosine Phosphatases

RasGEFA Ras guanine exchange factors A

RasGEFH Ras guanine exchange factors $\mathrm{H}$ $\operatorname{RegA}$ Response Regulator-A TEY threonine ${ }^{176}$ and tyrosine ${ }^{178}$ motif TorC2 Target of Rapamicin Complex 2 


\section{CHAPTER 1: INTRODUCTION}

\subsection{Dictyostelium discoideum as a model system for cellular motility}

Dictyostelium discoideum cells, for a great deal of time, have been used as a model system to study several cellular processes including motility, differentiation, cytokinesis and cellular trafficking. Dictyostelium popularity as an organism model is a result of several reasons. Firstly, the generation of single and serial knockouts is less challenging than in other model systems. Secondly, cell culturing is well established in Dictyostelium cells. Lastly, many of the metazoan signaling pathways are conserved in Dictyostelium cells, possibly since it is more closely related to metazoans than other simple models systems like yeast, making Dictyostelium the preferred simple model system of study (Eichinger, L., et al. 2005; Cai, H. and Devreotes, P. 2011; MüllerTaubenberger, A. et al. 2013).

Dictyostelium cells in nature are usually found in the forest soil as single cells feeding off bacteria and yeast cells (Eichinger, L. et al. 2005; Müller-Taubenberger, A. et al. 2013). However, when nutrients are depleted, cells stop growing and start a developmental module that results in the formation of fruiting body composed mainly of stalk cells and spore cells; the latter germinate when conditions are favorable once again (Chilsholm, R. and Firtel, R. 2004; Müller-Taubenberger, A. et al. 2013).

Dictyostelium development does not involve cellular proliferation, but requires multicellular aggregation. As such, cell motility is crucial for development (Chisholm, R.

and Firtel, R. 2004). During development, cells come together guided by a gradient of adenosine 3', 5'-monophosphate (cAMP) resulting in the formation of an aggregate. The 
generation of cAMP is thought to originally be generated from "aggregation centers", thought to be composed of starved cells (Chilsholm, R. and Firtel, R. 2004). The cAMP waves generated by the cells in the aggregation centers stimulate another wave of cAMP generation in the following layers of cells and thus propagate the cAMP waves outwardly. Because many of the signaling pathways regulating chemotaxis in Dictyostelium cells are conserved in metazoan cells (Chilsholm, R. and Firtel, R. 2004; Cai, H. and Devreotes, P. 2011), aggregating cells have been widely used as a chemotactic model to further understand many of the signaling pathways regulating directional motility.

\subsection{An overview of some of the signaling pathways regulating directional motility in Dictyostelium}

In response to cAMP stimulation, the cAMP receptor 1 (CAR1), which is a seventransmembrane G protein-coupled receptor (GPCR), stimulates the dissociation of heterotrimeric G-proteins into $G_{\alpha}$ and $G_{\beta \gamma}$ subunits, which in turn activate several signaling pathways that regulate cAMP relay, cell polarization and directional motility.

\subsection{1 cAMP relay regulation is mediated by ERK2 and PKA}

Activation of CAR1 receptor stimulates the production and secretion of cAMP, resulting in the stimulation of nearby cells, which in turn, can produce and secrete more cAMP, resulting in the generation of a cAMP gradient (Maeda, M. et al. 2004). The Extracellular signal Regulated Kinase 2 (ERK2), formerly known to regulate cellular proliferation, differentiation, cell cycle regulation and oncogenic transformation in mammalian cells (Camps, M. et al. 1999), plays an essential role in regulating internal 
level of cAMP in Dictyostelium cells (Aubry, L. et al. 1997, Wang, Y. et al. 1998, Madea, M. et al. 2004 and Brzostowski, J. and Kimmel, A., 2006).

In response to cAMP stimulation, the $\mathrm{G}_{\beta \gamma}$ subunits stimulates the cAMP production by activating the cytosolic regulator of adenylyl cyclase (CRAC), ERK2 and adenylyl cyclase A (ACA), which catalyzes the synthesis of cAMP from ATP (Laub, M.T. and Loomis, W. 1998; Tsujioka, M. et al. 2001 and Kimmel, A. and Parent, C., 2003). High intracellular levels of cAMP activate Protein Kinase A (PKA), which is a heterotetramer composed of two catalytic subunits and two regulatory subunits; the latter binds to cAMP resulting in its dissociation from the regulatory subunits resulting in PKA activation (reviewed in Laub, M.T. and Loomis, W.F. 1998). Cells lacking the catalytic subunit of PKA, have been shown to have defective aggregation, ACA expression and cAMP relay (Schulkes, C., and Schaap, P. 1995; Knetsch, M.L.W., et al. 1996; Aubry, L. et al. 1997). The intracellular cAMP levels are rapidly degraded by the phosphodiesterase Response Regulator-A (RegA) (Tsujioka, M. et al. 2001). Studies suggest ERK2 regulates cytosolic cAMP levels mediating RegA activity; ERK2 have been suggested to phosphorylate RegA resulting in RegA inactivation and degradation (Chilsholm, R. and Firtel, R. 2004; Madea, M. et al. 2004). Reduced levels of active RegA result in cAMP cytosolic accumulation and further increase in PKA activity (Laub, M.T. and Loomis, W. 1998, Tsujioka, M. et al. 2001, Maeda, M. et al. 2004 and Brzostowski, J. et al. 2006). Persistent activation of the GPCR receptor resulting in increased cAMP production and ERK2 activation results in lateral pseudopod formation and deficient chemotaxis (Brzostowski, J. et al. 2013). 
Extracellular signal Regulated Kinase 2 deactivation is not completely understood, but several studies suggest its activation is non-adaptive, since ERK2 remains activated as long as cAMP levels remain high (Brzostowski, J.A. and Kimmel, A.R. 2006; Swaney, K.F. et al. 2010; Brzostowski, J.A., et al. 2013). There is conflicting evidence regarding the negative regulators of ERK2; some studies suggest ERK2 activity can be inhibited through a negative feedback mechanism mediated by PKA (Laub, M.T and Loomis, W., 1998; Maeda, M. et al. 2004), however, another study suggests ERK2 deactivation occurs independently of PKA, since ERK2 deactivation can occur in cells lacking ACA ( $\mathrm{aca}^{-}$cells), which cannot produce cAMP and as a result, are unable to active PKA (Brzostowski, J. and Kimmel, A. 2006). The existence of additional negative ERK2 regulators, which can be activated independently of ACA, may provide an alternative explanation for the observed ERK2 adaptation in $a c a^{-}$cells.

Dual specific phosphatases (DSP), members of the phosphatase family of Protein Tyrosine Phosphatases (PTP), have been shown to be involved in the dephosphorylation of ERK2 in mammalian cells (Camps, M. et al. 1999). A Dictyostelium dual specific phosphatase, MPL1, further discussed in chapter 2, can provide valuable insight into ERK2 adaptation. Cells lacking MPL1 ( $\mathrm{mpll}^{-}$cells) exhibit persistent ERK2 activation, increased cAMP production and defective chemotaxis; altogether suggesting MPL1 may be an essential component in ERK2 adaptation.

\subsubsection{The family of small GTPases Ras regulates leading edge formation in chemotaxing cells}

Dictyostelium cells are able to sense the receptor occupancy both through time and space along the cell's length and use that information to selectively activate/inhibit 
certain proteins in response to the chemoattractant gradient (Swaney, K.F. et al. 2010). In other words, cellular polarization and thus chemotaxis require the localized activation and deactivation of proteins in different regions of the cell; this can be accomplished by the local regulation of kinases and phosphatases resulting in the enrichment or exclusion of certain proteins in the different areas of the cell. Several proteins, including members of the family of small GTPases Ras and Rac, the phosphoinositide 3-kinase (PI3K), the Target of Rapamicin Complex 2 (TorC2) and members of the family of AGC kinases, Protein Kinase BA (PKBA) and Protein Kinase B-related 1 (PKBR1), become rapidly activated in response to cAMP stimulation at the leading edge of the cell; whereas other proteins are activated or recruited to the lateral and rear sides of the cell, such as the Phosphatase Tensin homolog deleted ten (PTEN), p21 Activated Protein A (PAKa) and assembled myosin II (Chung, C. et al. 2001; Futamoto, S. et al. 2002; Park, K.C. et al. 2004; Sasaki, A. et al. 2004; Sasaki, A. and Firtel, R. 2006; Kortholt, A. and van Haastert, P. J.M 2008; Swaney, K.F et al. 2010). Polarizing cells involve localized Factin polymerization and hence pseudopod formation at the leading edge and not the lateral sides of the cell, as well as limited myosin II assembly and contraction to the rear of the cell to aid propelling the cell forward.

A member of the Dictyostelium Ras superfamily, RasG, has been shown to transiently become activated in response to cAMP stimulation at the leading edge of chemotaxing cells. Upstream regulators of RasG include the RasGEFR (Kae, H. et al. 2007) and the RasGAP, DdNF1, (Zhang, S. et al. 2008), since disruptions in any of these genes produce abnormal RasG activation and adaptation, respectively, resulting in abnormal directional motility. The activation of RasG results in the activation of PI3K, 
which phosphorylates phosphatidylinositol 4,5-biphosphates $\left(\mathrm{PIP}_{2}\right)$ generating the phosphatidylinositol $(3,4,5)$-triphosphate $\left(\mathrm{PIP}_{3}\right)$ at the membrane. Although the RasG activation was shown to occur independently of PI3K and actin polymerization, it has been proposed the presence of a positive feedback loop between RasG, PI3K and F-actin polymerization resulting in the amplification of the signal (Sasaki, A. et al. 2004). The accumulation of $\mathrm{PIP}_{3}$ serves as docking sites for many Pleckstrin homology (PH) domain-containing proteins, such as PKBA, that are important for cell polarity, cAMP relay and directional motility (Kae, H. et al. 2004; Sasaki, A. et al. 2006; Kortholt, A. and van Haastert, P. J.M 2008; Cai, H. and Devreotes, P. 2011; Kortholt, A. et al. 2011).

The accumulation of $\mathrm{PIP}_{3}$ at the leading edge of the cell is also regulated by PTEN, which catalyzes the dephosphorylation of $\mathrm{PIP}_{3}$ at the third position; because $\mathrm{PIP}_{3}$ is a PI3K product, PTEN have been suggested to antagonize PI3K activity and regulate $\mathrm{PIP}_{3}$ accumulation at the front of chemotaxing cells. In response to cAMP, PTEN dissociates from the membrane at the front of the cell and localizes on the cytoplasm and to the lateral and rear regions of the cell resulting in the accumulation of $\mathrm{PIP}_{3}$ at the leading edge of the cell (Futamoto, S. et al. 2002; Iijima, M., et al. 2004). Cells lacking PTEN (pten cells) exhibited high levels of $\mathrm{PIP}_{3}$ and lateral pseudopod formation suggesting PTEN along PI3K play an essential role regulating proper PIP $_{3}$-mediated signaling and directional migration (Iijima, M. and Devreotes, P. 2002). The localization of PTEN have been suggested to be regulated in part by the $\mathrm{PIP}_{2}$ binding domain localized in the N-terminal region of PTEN since mutations on this binding motif severely impairs PTEN membrane localization (Iijima, M. et al. 2004). Additionally, PTEN membrane localization seems to be regulated by the Phospholipase C (PLC), 
which shown to hydrolyzes PIP $_{2}$ forming diacylglycerol (DAG) and inositol-1,4,5triphosphate $\left(\mathrm{IP}_{3}\right)$; cells lacking PLC ( $p l c^{-}$cells) exhibited a more generalized localization of PTEN around the membrane in contrast to the usual lateral and rear localization observed in Wild type (Wt) cells (Kortholt, A. et al. 2007). Altogether, RasG and PI3K mediated pseudopod formation at the front of chemotaxing cells results from the temporal activation of PI3K, PTEN and PLC.

Another member of the Ras superfamily, Rap1, has been shown to regulate cellular polarity and myosin II assembly in Dictyostelium cells (Kortholt, A. et al. 2006; Jeon, T. et al. 2007; Kortholt, A. and van Haaster, P.J.M. 2008). The activation of Rap1 has been shown to be mediated by the Rap1 GEF, GbpD, resulting in the activation the serine/threonine kinase, Phg2 (Kortholt, A. et al. 2006). The Rap1 mediated activation of Phg2 plays an important role in the regulation of myosin II assembly in chemotaxing cells, thus regulating cell polarity and cell adhesion (Jeon, T.J. et al. 2007). In order for cells to extend a pseudopod, myosin II disassembly needs to occur at areas of F-actin polymerization; as a result, chemotaxing cells mainly contain polymerizing F-actin at the leading edge of the cell and restrict the myosin II assembly to the lateral and posterior regions of the cell (Swaney, K. et al. 2010). Upon cAMP stimulation, myosin II is phosphorylated by the myosin heavy chain kinase (MHCK) in three different threonine residues, $\mathrm{Thr}^{1823} \mathrm{Thr}^{1833}$ and $\mathrm{Thr}^{2029}$, preventing myosin II assembly at the leading edge of the cell (Egelhoff, T.T et al. 1993;Bosgraaf, L. and van Haastert, P.J.M. 2006). The activation of Phg2 was suggested to regulate myosin II phosphorylation at the cell's leading edge; $W t$ cells overexpressing a constitutively active form of Rap1 (Rap1G12V) exhibited extended myosin II assembly; similarly, cells lacking Phg2 (phg2- cells), 
accumulate higher levels of assembled myosin II at the cell cortex; altogether, these results suggest Rap1 and Phg2 prevent myosin II assembly at front of the chemotaxing cell, thus regulating cell polarity, pseudopod formation and directional migration (Jeon, T.J.et al. 2007).

Another member of the Dictyostelium Ras superfamily is RasC; similarly to RasG and Rap1, RasC becomes activated in response to cAMP stimulation resulting in the activation of TorC2, which along with Phosphoinositide dependent kinase 1 (PDK1) phosphorylates and activates members of the AGC family of kinases, PKBA and PKBR1 (Kae, H., et al. 2004; Lee, S. et al. 2005; Kamimura, Y., et al. 2008; Liao, X. et al. 2010; Cai, H., et al. 2010). The activation of RasC was suggested to be regulated by a complex composed of the scaffolding protein Scal, two RasGEF proteins, RasGEFA and RasGEFH, and the catalytic and scaffolding subunits of the Protein Phosphatase 2A (PP2A) complex; in response to cAMP stimulation the Scal complex was shown to rapidly translocate to the membrane of chemotaxing cells resulting in the activation of RasC, thus stimulating the activation of PKBA and PKBR1 (Charest, P. et al. 2010). Protein Kinase BA and PKBR1 have been suggested to regulate directional migration and cellular polarity through the phosphorylation of several downstream proteins including Talin and PAKa, which have been shown to regulate cellular adhesion and myosin II assembly, respectively (Chung, C., et al. 2001; Kamimura, Y. et al. 2008; Charest, P. et al 2010; Tang, M. et al. 2010).

A prerequisite for PKBA activation is its translocation to the membrane through its PH-domain that binds to $\mathrm{PIP}_{3}$ (Meili, R. et al. 1999); in contrast, PKBR1 is 
permanently found at the membrane through a myristoylation at its $\mathrm{N}$-terminal region, instead of the PH domain commonly found in other members of the AGC protein kinase family (Meili, R. et al. 1999; Meili, R. et al. 2000). Therefore, it has been suggested, PKBA activation is under RasG-PI3K control while PKBR1 occurs independently of PI3K activation (Kamimura, Y. et al. 2008; Liao, X. et al. 2010), supporting the notion that parallel pathways in many instances have redundant roles regulating cell polarity and directional motility.

The adaptation of PKBR1 is not fully understood; recent evidence suggests the presence of a negative feedback mechanism between PKBR1 and Sca1 resulting in decreased RasC activation and subsequently decreased PKBR1 activation; Sca1 is possibly a PKBR1 substrate and when phosphorylated by PKBR1, Sca1 is unable to promote RasC activation ultimately reducing PKBR1 further activation (Charest, P. et al 2010). In chapter 3, two novel PKBR1 negative regulators, the Glycogen Synthase Kinase 3 (GSK3) and the PP2A regulatory subunit, B56, will be discussed. The role of GSK3 in PKBR1 regulation has been previously reported by Teo, R. and his colleagues; cells lacking GSK3 ( $g s k 3^{-}$cells) exhibited undetected levels of PKBR1 activation and defective chemotaxis (Teo, R. et al. 2010; see chapter 3 below). In chapter 3, evidence suggesting GSK3 also plays a negative role in PKBR1 activation will be presented. Also, in chapter 3, the role of the PP2A regulatory subunit, B56, in PKBR1 adaption will be discussed. It was suggested that B56 negatively regulate PP2A catalytic activity in mammalian cells and in Dictyostelium cells because cells lacking B56 exhibited persistent phosphorylation of PP2A substrates (Ito, A. et al. 2000; Lee, N. et al. 2008). Similarly to GSK3, B56 negatively regulates PKBR1 activation in Dictyostelium cells. 
Cells lacking B56 ( $p s r A^{-}$cells) exhibited abnormal high basal levels of active PKBR1 resulting in defective directional migration. Altogether, PKBR1 adaptation seems to be complex, possibly being regulated by multiple signaling pathways. 


\subsection{References}

Aubry, L., Maeda, M., Insall, R., Devreotes, P. and Firtel, R. 1997, The Dictyostelium Mitogen-activated Protein Kinase ERK2 is Regulated by Ras and cAMP-dependent Protein Kinase (PKA) and Mediates PKA Function. Journal of Biological Chemistry, 272:3883-3886

Bosgraaf, L. and van Haastert, P.J.M. 2006 The regulation of myosin II in Dictyostelium 2006 European Journal of Cell Biology, Vol. 85, pp969-979

Brzostowski, J. and Kimmel, A. 2006, Nonadaptive Regulation of ERK2 in Dictyostelium: Implications for Mechanisms of cAMP Relay. Molecular Biology of the Cell, 17: 4220-4227.

Brzostowski, J. A., Sawai, S. Rozov, O., Liao, X., Imoto, D., Parent, C.A. and Kimmel, A. 2013 Phosphorylation of chemoattractant receptors regulates chemotaxis, actin reorganization and signal relay. Journal of Cell Science, Vol. 126, pp4614-4626

Cai, H., Das, S., Kamimura, Y., long, Y., Parent, C. and Devreotes, P. 2010 Ras-mediated activation of the TORC2-PKB pathway is critical for chemotaxis. The Journal of Cell Biology, Vol. 190, pp233-245

Cai, H. and Devreotes, P. 2011 Moving in the right direction: How eukaryotic cells migrate along chemical gradients. Seminars in Cell \& Developmental Biology, Vol. 8, p834-41

Camps, M., Nichols, A. and Arkinstall, S., 1999, Dual Specificity Phosphatase: a Gene Family for Control of MAP Kinase Function. FASEB J. Vol. 14, pp. 6-16.

Charest, P., Shen, Z., Lakoduk, A., Sasaki, A., Briggs, S. and Firtel, R. 2010 A Ras signaling complex controls the RasC-TORC2 pathway and directed cell migration. Developmental Cell, Vol. 18, p737-749

Chisholm, R. and Firtel, R., 2004, Insights Into Morphogenesis From a Simple Developmental System. Nature Reviews, 5:531-541

Chung, C. Y., Potikyan, G. and Firtel, R. 2001 Control of cell polarity and chemotaxis by Akt/PKB and PI3 Kinase through the regulation of PAKa. Molecular Cell, Vol. 7, pp937947

Egelhoff, T.T., Lee, R.J. and Spudich, J.A. 1993 Dictyostelium myosin heavy chain phosphorylation sites regulate myosin filament assembly and localization in vivo. Cell, Vol. 75, pp363-371

Eichinger, L., Pachebat, J. A., Glöckner, G., Rajandream, M.-A., Sucgang, R., Berriman, M., Song, J., Olsen, R., Szafranski, K., Xu, Q., Tunggal, B., Kummerfeld, S., Madera, 
M., Konfortov, B.A. Eicwe, D., Bankier, A.T., Lehmann, R., Hamlin, N., Davies, R., Gaudet, P., Fey, P., Pilcher, K., Cheng, G., Suanders, D., Sodergren, E., Davis, P., Kerhornou, A., Nier, X., Hall, N., Anjard, C., Hempill, L., Bason, N., Farborher, P., Desany, B., Just, E., Morio, T., Rost, R., Churcher, C., Cooper, J., Hyadock, S., van Diessche, N., Cronin, S, Goodhead, I., Muzny, D., Mourier, T., Pain, A., Lu, m., Harper, D., Lindsay, R., Hauser, H. James, K., Quiles, M, Madan Babu, M., Saito, T., Buchrieser, C., Wardroper, A., Felder, M., Thangavelu, M., Johnson, D., Knights, A., Loulseged, H., Mungall, K., Oliver, K., Price, C., Quail, M.A., Urushihara, H., Hernandez, J., Rabbinowitsch, E., Steffen, D., Sanders, M., Ma, J., Kohara, Y., Sharp, S., Simmonds, M., Spiegier, S., Tivey, A., Sugano, S., White, B., Walker, K., Woodward, J., Winckler, T., Tanake, Y., Schleicher, M., Weinstock, G., Rosenthal, A., Cox, E.C., Chisholm, R.L., Gibbs, R., Loomis, W.F., Platzer, M., Kay, R.R., Williams, J., Dear, P.H., Noegel, A.A., Barrel, B. and Kuspa, A. 2005 The genome of the social amoeba Dictyotelium discoideum. Nature, Vol 435, p43-57

Futamoto, S., Meili, R., Lee, S., Parry, L. and Firtel, R.A. 2002 Spatial and temporal regulation of 3-phosphoinositides by PI3K and PTEN mediates chemotaxis. Cell, Vol. 109, pp611-623

Iijima, M. and Devreotes, P. 2002 Tumor Suppresor PTEN mediates sensing of chemoattractant gradients. Cell, Vol. 109, pp599-610

Iijima, M., Huang, E., Luo, H.R., Vazquez, F. and Devreotes, P.N. 2004 Novel mechanism of PTEN regulation by its phosphatidylinositol 4,5-bisphosphate binding motif is critical for chemotaxis. Journal of Cell Science, Vol. 279, pp16006-16613

Ito, A., Kataoka, T., Watanabe, M., Nishiyama, K., Mazaki, Y., Sabe, H., Kitamura,Y. and Nojima,H. 2000 A truncated isoform of the PP2A B56 subunit promotes cell motility through paxillin phosphorylation. The EMBO Journal, Vol. 19, pp562-571

Jeon, T. J., Lee, D., Merlot, S., Weeks, G. and Firtel, R. 2007 Rap1 controls cell adhesion and cell motility through the regulation of myosin II. The Journal of Cell Biology, Vol. 176, pp1021-1033

Kae, H., Lim, C.J., Spiegelman, G.B., and Weeks, G. 2004 Chemoattractant-induced Ras activation during Dictyostelium aggregation. EMBO Reports, Vol. 5, pp602-606

Kae, H., Kortholt, A., Rehmann, H., Insal, R.H., Van Haastert, P.J.M., Spiegelman, G. and Weeks, G. 2007 Cyclic AMP signaling in Dictyostelium: G-proteins activate separate Ras pathways using specific RasGEFs. EMBO Reports, Vol. 8, pp477-482

Kamimura, Y., Xiong, Y., Iglesias, P., Hoeller, O., Bolourani, P. and Devreotes, P. 2008 PIP3-Independent activation of TORC2 and PKB at the cell's leading edge mediates chemotaxis. Current Biology, Vol. 18, p1034-1043

Kimmel, A. and Parent, C., 2003. The Signal to Move: D. discoideum Go Orienting.Science, 300:1525-1527 
Knetsh, M.L.W., Epskamp, S.J.P., Schenk, P.W., Wang, Y., Segall, J.E. and SnaarJagalka, B.E. 1996 Dual role of cAMP and involvement of both G-proteins and Ras in regulation of ERK2 in Dictyostelium discoideum. The EMBO Journal, Vol. 15, pp33613368

Kortholt, A., Rehmann, H., Kae, H., Bosgraff, L., Keizer-Gunnink, I., Weeks, G., Wittinghofer, A. and van Haastert, P.J.M. 2006 Characterization of the GbpD-activated Rap1 pathways regulating adhesion and cell polarity in Dictyostelium discoideum. Journal of Biological Chemistry, Vol.281, pp23367-76

Kortholt, A., King,J.S., Keizer-Gunnink, I., Harwood, A.J. and van Haastert, P.J.M. 2007 Phospholipase C regulation of phosphatidylinositol 3,4,5-triphosphate mediated chemotaxis. Molecular Biology of the Cell, Vol. 18, pp4772-4779

Kortholt, A. and van Haastert, P. J.M 2008. Highlighting the role of Ras and Rap during Dictyostelium chemotaxis. Cellular Signaling, Vol. 20, pp1415-1422

Kortholt, A., Kataria, R., Keizer-Gunnink, I., Van Egmond, W.N., Khanna, A. and Van Haaster, P.J.M. 2011 Dictyostelium chemotaxis: essential Ras activation and accessory signaling pathways for amplification. EMBO Reports Vol. 12, pp1273-1279

Laub, M.T. and Loomis, W. 1998. Role of PKA in the Timing of Developmental Events in Dictyostelium Cells. Microbiology and Molecular Biology Reviews, 62:684-694

Lee, S., Comer, F.I., Sasaki, A., McLeod, I.X., Duong, Y., Okumura, K., Yates III, J.R., Parent, C. and Firtel, R. 2005 TOR Complex 2 integrates cell movement during chemotaxis and signal relay in Dictyostelium. Molecular Biology of the Cell, Vol. 16, pp4572-4583

Lee, N., Veeranki, S., Kim, B. and Kim, L. 2008 The function of PP2A/B56 in nonmetazoan multicellular development. Differentiation, Vol. 76, pp1104-1110

Liao, H.X., Buggey, J., Kimmel, A.R. 2010 Chemotactic activation of Dictyostelium AGC-family kinases AKT and PKBR1 requires separate but coordinated functions of PDK1 and TORC2. Journal of Cell Science, Vol. 123, pp983-992

Madea, M., Lu, S., Shaulsky, G., Miyazaki, Y., Kuwayama, H., Tanaka, Y., Kuspa, A. and Loomis, W., 2004, Periodic Signaling Controlled by an Oscillatory Circuit That Includes Protein Kinases ERK2 and PKA. Science 304: 875-878

Meili, R., Ellsworth, C., Lee, S., Reddy, T.B.K., Ma, H. and Firtel, R. 1999 Chemoattractant-mediated transient and membrane localization of $\mathrm{Akt} / \mathrm{PKB}$ is required for efficient chemotaxis to cAMP in Dictyostelium. The EMBO Journal, Vol. 18, pp20922105

Meili, R., Ellsworth, C. and Firtel, R. 2000 A novel Akt/PKB-related kinase is essential for morphogenesis in Dictyostelium. Current Biology, Vol. 10, pp708-717 
Müller-Taubenberger, A., Kortholt, A. and Eichinger, L. 2013 Simple system substantial share: The use of Dictyostelium in cell biology and molecular medicine. European Journal of Cell Biology, Vol. 92, P45-53

Park, K. C., Rivero, F., Meili,R., Lee, S., Apone, F. and Firtel, R. 2004 Rac Regulation of chemotaxis and morphogenesis in Dictyostelium. EMBO Journal Vol. 23 p4177-4189

Sasaki, A. T., Chun, C., Takeda, K., and Firtel, R. 2004. Localized Ras signaling at the leading edge regulates PI3K, cell polarity, and directional cell movement. JCB, Vol. $167: 505-518$

Sasaki, A. and Firtel, R. 2006 Regulation of chemotaxis by the orchestrated activation of Ras, PI3K and TOR. European Journal of Cell Biology, Vol. 85, p873-895

Schulkes, C., and Schaap, P. 1995 cAMP-dependent protein kinase activity is essential for preaggregative gene expression in Dictyostelium. FEBS Letters, Vol. 368, pp381-384

Swaney, K.F., Huang, C.H. and Devereotes, P. 2010 Eukaryotic chemotaxis: A network of signaling pathways control molity, directional sensing and polarity. Annu. Rev. Biophys. Vol. 39 p265-89

Tang, M., Iijima, M., Kamimura, Y., Chen, L., Long, Y. and Devreotes, P. 2010. Disruption of PKB signaling restores polarity to cells lacking tumor suppressor PTEN. Molecular Biology of the Cell, Vol. 22, pp437-447

Teo, R., Lewis, K., Forde, J.E., Ryves, W.J., Reddy, J.V., Rogers, B.J. and Harwood, A.J. 2010. Glycogen Synthase Kinase 3 is required for efficient Dictyostelium chemotaxis. Molecular Biology of the Cell, Vol. 21, pp. 2788-2796

Tsujioka, M., Yokayama, M., Nishio, K., Kuwayama, H., Morio, T., Katoh, M., Urushihara, H., Saito, T., Ochiai, H., Tanaka, Y., Takeuchi, I. and Madea, M. 2001. Spatial Expression Patterns of Genes Involved in Cyclic AMP Responses in Dictyostelium discoideum. Development. Developmental Growth and Differentiation, 43:275-283.

Wang, Y., Liu, J., and Segall, J. 1998, MAP Kinase Function in Amoeboid Chemotaxis. Journal of Cell Science 111:373-383

Zhang, S., Charest, P. and Firtel, R. 2008 Spatiotemporal regulation of Ras activity provides directional sensing. Current Biology, Vol. 18, pp1587-1593 


\section{CHAPTER 2: MPL1, THE NOVEL PHOSPHATASE WITH LEUCINE-RICH- REPEATS, IS ESSENTIAL FOR PROPER ERK2 PHOSPHORYLATION AND CELL MOTILITY}

Chapter 2 is published, see reference below,

Rodriguez, M., Kim, B., Lee, N., Veeranki, S. and Kim, L. 2008. MPL1, a novel phosphatase with leucine rich repeats, is essential for proper ERK2 phosphorylation and cell motility. Eukaryotic Cell, Vol. 7, pp. 958-966

\subsection{Summary}

The novel Dictyostelium phosphatase Mpll contains six Leucine-Rich-Repeats at the amino-terminal end and a phosphatase domain at the carboxyl end. Similarly architectured phosphatases exist among other protozoa such as Entamoeba histolytica, Leishmania major, and Trypanosoma cruzi. Mpll was strongly induced after 5 hours of development; ablation by homologous recombination led to defective streaming and aggregation during development. In addition, cAMP pulsed $m p l 1^{-}$cells showed reduced random and directional motility. At the molecular level, $\mathrm{mpll}^{-}$cells displayed higher prestimulus and persistent post-stimulus ERK2 phosphorylation in response to cAMP stimulation. Consistent with their phenotype of persistent ERK2 phosphorylation, $\mathrm{mpll}^{-}$ cells also displayed an aberrant pattern of cAMP production, resembling that of the $\operatorname{reg} A^{-}$ cells. Reintroduction of a full length $\mathrm{Mpll}$ into $\mathrm{mpll}^{-}$cells restored aggregation, ERK2 regulation, random and directional motility, and cAMP production similar to wild type cells. We propose that Mpl1 is a novel phosphatase essential for proper regulation of ERK2 phosphorylation and optimal motility during development. 


\subsection{Introduction}

Mitogen Activated Protein (MAP) kinases are central in the regulation of proliferation, differentiation, and cell migration in diverse eukaryotic cells (Wang et al.1998; Kolch 2000; Roux and Blenis, 2004; Tsai et al. 2004; Vindis et al, 2003; Huang et al. 2003;). MAP kinase ERK2 also plays critical roles during Dictyostelium development. ERK2 is essential for initiation and propagation of periodic cAMP pulses during aggregation and differentiation. Chemoattractants, such as cAMP, induce ERK2 activation. Activated ERK2 subsequently inhibits the intracellular cAMP specific phosphodiesterase RegA, resulting in an increase in the cytosolic cAMP level (Laub and Loomis, 1998; Maeda et al. 2004; Sawai et al. 2005).

erk2 $2^{-}$cells, starved for 8 hours, exhibited a decrease in motility and a severe chemotaxis defect toward cAMP gradient. Aberrancy in chemotaxis was aggravated in the presence of a strong cAMP gradient $(2 \mu \mathrm{M})$ compared to a weak one $(0.1 \mu \mathrm{M})$ (Wang et al. 1998). erk2 cells also display defective cytoskeletal remodeling in response to chemoattractant stimulation. A polarized wild type cell typically displays a single dominant leading edge enriched with F-Actin. Myosin II localizes to the lateral side and back of a polarized cell, where it functions to suppress lateral pseudopods and provides tractional force to the back. This single dominant leading edge disintegrates but forms again after 7 minutes in response to global cAMP stimulation (Wang et al. 1998). In contrast, erk2- cells, under the same condition, displayed multiple crown-like membranous protrusions, which were enriched not only in F-Actin but also in Myosin II (Wang, et al., 1998). This aberrant structure, which was proposed to be less stable and 
unable to provide necessary traction force for cells to move, is believed to be the reason why erk2 ${ }^{-}$cells are less motile than wild type cells (Wang, et al. 1998).

It is well established that the dual phosphorylation of threonine ${ }^{176}$ and tyrosine ${ }^{178}$ residues of the ERK2 activation loop, often called the TEY motif, mediates activation of ERK2 kinase activity. This dual phosphorylation on the TEY motif of ERK2 peaks around 1 minute after cAMP stimulation, but virtually no phosphorylation of the ERK2 remains after 2 3 minutes (Kosaka and Pears, 1997, Wang et al. 1988). Adaptation of ERK2 is thus likely mediated by a phosphatase that can de-phosphorylate phosphates from both threonine ${ }^{176}$ and tyrosine ${ }^{178}$ residues. In Dictyostelium, several tyrosine phosphatases (PTP1, PTP2, and PTP3) have been characterized (Early et al. 2001; Gamper et al. 1996; Gamper et al. 1999, Howard et al. 1992; Howard et al. 1994). These phosphatases are involved in cell differentiation or stress response signaling, but it is not known if ERK2 is regulated by any of these tyrosine phosphatases. Currently, the phosphatase responsible for dephosphorylating ERK2 in Dictyostelium is unidentified.

In mammalian systems, several phosphatases are known to decrease MAPK phosphorylation and activity. These MAPK phosphatases belong to the Dual Specificity Phosphatase (DSPase) family, which dephosphorylate both phospho-Serine/Threonine and phospho-Tyrosine residues. Two well-characterized examples of DSPases are Cdc25 and MAP Kinase Phosphatase (MKP). Cdc25 dephosphorylates and activates cell cycle dependent kinases (cdks) to promote cell cycle progression. MKP dephosphorylates and inactivates MAP kinase signaling at the level of MAP Kinase (Ducruet et al. 2005; Lyon et al. 2002; Rintelen et al. 2003). A number of mammalian MKPs contain MAP Kinase 
Binding (MKB) domain, but no such domain can be found in the Dictyostelium genome by homology domain search (NCBI, Conserved Domains Search Blast).

We have isolated and characterized the function of Mpl1, a novel Dictyostelium phosphatase with a Leucine-Rich-Repeat (LRR) domain. Mpl1 phosphatase domain contains the conserved, functionally critical signature sequence of DSPases: $\operatorname{Dx}_{26}(\mathrm{~V} / \mathrm{L}) \mathrm{x}(\mathrm{V} / \mathrm{I}) \mathrm{HCxAG}(\mathrm{I} / \mathrm{V}) \operatorname{SRSxT}(\mathrm{I} / \mathrm{V}) \mathrm{xxAY}(\mathrm{L} / \mathrm{I}) \mathrm{M}$ (x can be any amino acids). This sequence constitutes a unique structure that enables DSPase to dephosphorylate all three types of phospho-amino acids (Theodosiou and Ashworth, 2002; Keyse, 2000). Mpl1 contains LRR domain in its $\mathrm{N}$-terminal region composed of six LRR sequences matching the consensus sequence of $\operatorname{Lx} \operatorname{LxLxxN} / \mathrm{CxL}$ ( $x$ can be any amino acids and $\mathrm{L}$ can be Leucine, Isolecine, and Phenylalanine). The LRR domain often forms a horseshoe shape domain capable of mediating diverse protein-protein interactions in many eukaryotes (Kobe and Kajava, 2001, Enkhbayar et al., 2004). The combination of potential DSPases with LRR domains can be found not only in Dictyostelium, but also in other parasitic unicellular eukaryotic organisms such as Entamoeba histolytica, Leishmania major, and Trypanosoma cruzi (Loftus, et al., 2005, Fig.1A).

Ablation of Mpll resulted in higher prestimulus and persistent post-stimulus ERK2 phosphorylation upon cAMP stimulation. Furthermore, $\mathrm{mpll}^{-}$cells displayed strong defects in motility. Similar to $\mathrm{reg}^{-}$cells, $\mathrm{mpll}^{-}$cells displayed more rapid cAMP production during the 2-minutes window after the stimulation with cAMP compared to wild type cells. Considering that ERK2 is a negative regulator of RegA, persistent activation of ERK2 would have resulted in a persistent RegA inhibition in $\mathrm{mpll}^{-}$cells. Consistently, reintroduction of the full length $\mathrm{Mpll}$ in $\mathrm{mpll}^{-}$cells restored ERK2 
regulation, motility, and cAMP production. We propose that Mpl1 is a novel phosphatase essential for proper regulation of ERK2 phosphorylation and effective cell movement during Dictyostelium development.

\subsection{Materials and Methods}

\subsubsection{Dictyostelium culture and development}

Dictyostelium cells were grown in axenic media (7.15g Peptone \#3 (DIFCO), 7.15

g Thiotone E Peptone (Becton Dickinson), $7.15 \mathrm{~g}$ Yeast extract, $15.4 \mathrm{~g}$ glucose $0.525 \mathrm{~g}$ $\mathrm{Na}_{2} \mathrm{HPO}_{4} \cdot 7 \mathrm{H}_{2} \mathrm{O}, 0.48 \mathrm{~g} \mathrm{KH}_{2} \mathrm{PO}_{4}$ in 1 liter of water) Cells were developed on nitrocellulose filters at $1 \times 10^{7}$ cells $/ \mathrm{cm}^{2}$ in DB buffer (10 mM sodium phosphate, $\mathrm{pH}$ 6.4, $2 \mathrm{mM} \mathrm{MgCl} 2$, and $0.2 \mathrm{mM} \mathrm{CaCl}_{2}$ ) or about one hundred actively growing Dictyostelium cells were mixed with $200 \mu \mathrm{l}$ of a saturated overnight culture of Klebsiella aerogenes, and plated on a $100 \mathrm{~mm}$ SM agar plate (10g Glucose, $10 \mathrm{~g}$ BactoPeptone, $1 \mathrm{~g}$ Yeast extract, $1 \mathrm{~g} \mathrm{MgSO}{ }_{4} \cdot 7 \mathrm{H}_{2} \mathrm{O}, 1.9 \mathrm{~g} \mathrm{K \textrm {KH } _ { 2 }} \mathrm{PO}_{4}, 0.6 \mathrm{~g} \mathrm{~K}_{2} \mathrm{HPO}_{4}, 20 \mathrm{~g}$ Agar in 1 liter of water).

\subsubsection{Full length $M p l 1$ cloning}

The full length Mpll cDNA is 2,505 base pairs (bp) long and contains single EcoRI site at +405 , SpeI site at +652 and StyI site at +1742 (http://dictybase.org, sequence information for DDB0190671). The 662 bp partial Mpll cDNA fragments encoding the 5' end of the gene (fragment I; +1 to +662 ), was generated by PCR using the forward primer 5' CGGGATCCATGATATTTAAAAAATTATTTTCAAAAGG 3' and the reverse primer 5' GGGAAACTAGTGAATTGATTAATAC 3', and subcloned into pBluescript II KS (-) (pKS(-), Stratagene) vector using BamHI and SpeI sites. The 3' end of the gene (fragment II; +1742 to +2505 ), 763 bp in length was generated by PCR using the forward primer 5'GAATGCGGCCGCGCCAAGGAAAGATTCAGC 3' and 
the reverse primer 5' CGAGCTCTTATTTTGATAAATCTTTTTCAAATTTTTTTAAT TGG 3', and subcloned into the pKS (-) vector containing the fragment I using NotI and SacI sites. The third partial cDNA encoding the central Mpll cDNA region (fragment III; +663 to +1741$)$ was generated by RT-PCR using the forward primer 5', GTATTAATCAATTCACTAGTTTCCC $3^{\prime}$ and the reverse primer 5' GCTGAATCTTTCCTTGGCTTTC 3'. The full length Mpll was generated by inserting the fragment III into the pKS (-) vector containing the two partial Mpll genes described above using SpeI and StyI sites.

The Flag tag was added to the 5' end of the full length Mpll by PCR using the forward primer 5' ATAAGCTTTAATAAAAAATGGACTACAAGGACGACGATGA CAAGATGATATTTAAAAAATTATTTTCAAAAGG 3' and the reverse primer 5' GGAATTTCATAGAATTCCATATAG 3'. The PCR product was digested with HindIII and EcoRI, and subcloned into the pKS (-) vector containing full length Mpll. Then, the construct was digested with XhoI and SacI and subcloned into the pCR 2.1-TOPO vector (Invitrogen) using the same sites. A positive clone was digested with HindIII and subcloned into an empty pKS (-) vector to introduce new restriction sites. Clones having BamHI at the 5' side and XhoI at the 3' side were selected, digested with the same enzymes, and subcloned into the pEXP4(+) vector (Dynes et al., 1994) previously digested with BclII and XhoI. All PCR products were confirmed by sequencing both strands after each subcloning step.

\subsubsection{Generation of $\mathrm{mpl1}^{-}$cells and northern blot analysis of $\mathrm{Mpl1}$}

The blasticidin-resistance cassette was subcloned between the LRR and Phosphatase (PPase) domain (Gly 583) of Mpll (Filled arrowhead in Fig. 1B). 
Transformants were prescreened by PCR (the forward primer 5' GCATCTGATAATAC TGATGAGGC 3' and the reverse primer 5' TTCAAGTTGCTGAATCTTTCC 3'). Genomic DNAs from the knockout candidates were isolated and $5 \mu \mathrm{g}$ of each sample were digested with EcoRV (Fig. 3A). Knockout cells were analyzed by genomic Southern blot. The Mpll expression pattern was determined by northern blot analysis using a partial Mpll cDNA encoding the phosphatase domain. The levels of the residual partial Mpll transcripts in $\mathrm{mpll}^{-}$cells were compared to that of wild type cells by RTPCR using the forward primer 5' ATGATATTTAAAAAATTATTTTCAAAAGG 3' and the reverse primer 5' GGGAAACTAGTGAATTGATTAATAC 3', resulting in a product that is 662 base pairs in length upstream of the blasticidin cassette insertion point. $1 \mathrm{ng}$ of total RNA from either wild type or $\mathrm{mpll}^{-}$cells was used for RT-PCR template for Mpll amplification. $\lg 7$ transcripts were amplified using the forward primer 5, GGTGAGCGAAAGCCGAGGAGAG 3' and the reverse primer 5' GCAACAGTTAC GGGTTCCGCC 3' as a control. $10 \mathrm{pg}$ of total RNA form either wild type or $\mathrm{mpll}^{-}$cells were used for RT-PCR template for $\operatorname{Ig} 7$ amplification.

\subsubsection{Recombinant Mpl1-Phosphatase and Phosphatase Assay}

Mpl1 phosphatase domain was initially amplified by RT-PCR with the forward primer 5' CCAAGGAAAGATTCAGCAAC 3' and the reverse primer 5' TTATTTTGA TAAATCTTTTTCAAATTTTTTTAATTGG 3', and cloned into the pCR2.1-TOPO vector. Positive clones were selected after sequencing the whole region. GST-MpllPPase was generated by subcloning the Mpll phosphatase domain into $p G E X$ 4T-2 (Pharmacia Inc.) after EcoRI digestion and filling-in with Klenow. Clones containing the 
phosphatase domain were screened first by PCR and confirmed by fusion protein expression of $53 \mathrm{kD}$ upon IPTG induction.

GST and GST-Mpl1-PPase proteins were purified with Gluthatione-Sepharose beads (Pharmacia Inc.), and analyzed by western blot using anti-GST antibody. Mpl1

phosphatase activities were determined by measuring $p$-NP generation from $p$-NPP (Enzolyte $p N P P$ Phosphatase assay kit, AnaSpec). The generation of $p$-NP was determined by monitoring absorption values at $405 \mathrm{~nm}$.

\subsubsection{Submerged aggregation assay}

For submerged aggregation experiments, log phase cells were harvested, washed and placed under DB buffer at indicated cell densities on a 24 well plate (Falcon 353047 , Becton Dickinson). After 12 hours at $20^{\circ} \mathrm{C}$, cell migration, streaming, and aggregation were monitored using Leica inverted microscope (DM IRB).

\subsubsection{Chemotaxis and random motility analyses}

Log phase cells were differentiated with $50 \mathrm{nM}$ of cAMP pulses at 6 minutes intervals for $4 \mathrm{hrs}$. Pulsed cells were plated at a density of $3 \times 10^{4} \mathrm{cells} / \mathrm{cm}^{2}$ on a $35 \mathrm{~mm}$ tissue culture dish cover (Falcon 353001, Becton Dickinson). A Schmazu micromanipulator with a glass capillary needle (Eppendorf Femtotip) filled with either $0.1 \mu \mathrm{M}$ or $2 \mu \mathrm{M}$ cAMP solution was used for chemotaxis assay. For random motility analysis, cells were plated on the same tissue culture plate cover with no cAMP source, and their movements were recorded for 30 minutes. The responses of the cells were followed by time-lapse video recording with Openlab software.

Chemotaxing cells were analyzed as described previously (Loovers et al. 2006). An ellipsoid was constructed around the cell to allow the same centroid for both the 
ellipsoid and the contour. Chemotactic index, defined as the net distance moved to the direction of the pipette divided by the total distance moved, was computed from the centroid positions. The speeds of movement of cells were calculated from positions of the centroids. Statistical significance of differences between wild type and mutant cells were evaluated by obtaining P values using Student's t test.

\subsubsection{ERK2 activation by cAMP}

Both wild type and $m p l 1^{-}$cells $\left(10^{8}\right.$ cells $)$ were stimulated with $50 \mathrm{nM}$ cAMP pulses for 4 hours, treated with $2 \mathrm{mM}$ Caffeine for 30 minutes, and then stimulated with $0.1 \mu \mathrm{M}$ cAMP. Cells were harvested at each time point, and directly lysed with SDSPAGE loading dye for Western blot analysis using anti-phospho-ERK2 (Cell Signaling Inc.) or anti-Pan-Ras antibodies (Oncogene Research products).

\subsection{8 cAMP Assay}

cAMP levels were quantified by using a cAMP assay kit (Amersham). One hundred million cells were pulsed with $50 \mathrm{nM}$ cAMP for 5 hours $\left(20 \times 10^{6}\right.$ cells $\left./ \mathrm{ml}\right)$, washed, and resuspended with $\mathrm{DB}$ buffer at a density of $5 \times 10^{7}$ cells $/ \mathrm{ml}$. Before the activation, cells were preincubated with DB buffer containing $10 \mathrm{mM}$ dithiothreitol (DTT) for 10 minutes on ice. $1.8 \mathrm{ml}$ of cells was transferred into a cup on an orbital shaker for 2 minutes. $200 \mu \mathrm{l}$ of stimulation cocktail $(10 \mathrm{mM}$ DTT and $100 \mu \mathrm{M}$ of 2deoxy cAMP) was added to the cells. $100 \mu \mathrm{l}$ of samples were taken at each time point into $1.5 \mathrm{ml}$ Eppendorf tubes filled with $100 \mu \mathrm{l}$ of $3.5 \%$ perchloric acid (PCA). Samples were mixed thoroughly and incubated on ice for 30 minutes. $100 \mu \mathrm{l}$ of $50 \%$ saturated $\mathrm{KHCO}_{3}$ solution was added to the sample and incubated on ice for 30 minutes. After insoluble aggregates were removed by centrifugation, the supernatants were rapidly 
frozen using liquid nitrogen. Samples were evaporated in Speed-vac without heating for 15 hours, and resuspended with $110 \mu 1$ of Tris-EDTA buffer from the cAMP kit. Levels of cAMP were determined by following the manufacturer's instruction (Amersham Inc.).

\subsection{Results}

\subsubsection{Mpl1 is an active phosphatase with Leucine-Rich Repeats.}

A group of genes encoding a potential DSPase domain with Leucine-Rich Repeats (LRR) can be found in the genome of Dictyostelium and several protozoans such as Entamoeba histolytica, Leishmania major, and Trypanosoma cruzi (Fig. 1A). These hypothetical genes show a potential DSPase (PPase) and LRR domains, and sometime extra domains such as tandem serine/threonine kinase domains and/or Zn finger domains. No other similarly structured genes were found in the currently available genome of metazoa or plant.

We have cloned one such Dictyostelium gene, Mpll, which contains a carboxyl terminal phosphatase domain with conserved residues essential for dual specificity phosphatase function and six potential Leucine-Rich Repeats at the amino-terminal half of the protein (Fig. 1B). Mpll expression pattern was determined by northern blot analysis using a probe encoding the phosphatase domain as shown in Figure 1C. Mpll expression was significantly up-regulated upon starvation, reaching a maximum around 10 hours. Mpll expression subsequently declined but was present throughout development.

To ensure that Mpl1 is an active phosphatase, we generated a GST-fusion of the putative Mpl1 phosphatase domain (Mpl1-PPase; amino acids 580-834). GST and GST- 
Mpl1-PPase were expressed and purified from E. coli, using Gluthathione-Sepharose beads. Equivalent molar amounts of GST and GST-Mpl1-PPase were normalized by western blot using anti-GST antibody (Fig. 2A), and an equimolar amount of the proteins were incubated with $p N P P$. GST-Mpl1-PPase clearly demonstrated a phosphatase activity of pNPP dephosphorylation (Fig. 2B). It is, however, not known if Mpl1 is a bona fide dual specificity phosphatase.

\subsection{2.mpll cells are defective in aggregation.}

$\mathrm{mpll}^{-}$cells were created by homologous recombination as described in Figure 3A. Ablation of Mpll gene was screened by PCR analysis and genomic Southern blot using Mpll specific probe. To determine the level of a partial Mpll transcript in $\mathrm{mpll}^{-}$cells, transcripts were analyzed by RT-PCR using a primer set upstream of the blasticidin cassette insertion point. Compared to wild type cells, $\mathrm{mpll}^{-}$cells exhibited a significant decrease in the level of the partial Mpll transcript, while $I g 7$ control transcript levels were comparable (Fig. 3A). Although faintly visible, the residual level of the partial Mpll transcript did not interfere with the rescue of $\mathrm{mpll}^{-}$phenotypes by the reintroduction of the full length $\mathrm{Mpll}$ gene into $\mathrm{mpll}^{-}$cells (Fig. 4, 5, 6, 7). Aggregation minus (aggminus) phenotype was evident from $\mathrm{mpll}^{-}$cells developed on Klebsiella aerogenes (Ka) plates for seven days (Fig. 3B). Wild type cells formed a number of fruiting bodies, whereas most of $\mathrm{mpll}^{-}$cells failed to display visible structures on the plate. Occasionally, in less than $10 \%$ of plaques, $\mathrm{mpll}^{-}$cells formed various heterogeneous structures including aggregates and fruiting bodies. This agg-minus phenotype was rescued by the re-introduction of the full length Mpll (Fig. 3B). 
To determine whether $\mathrm{mpll}^{-}$cells are defective in cell migration, cells were plated to form territorial streams at various cell densities as described in Figure 3C. While wild type cells displayed eminent territorial streaming even at a density of $1.25 \times 10^{4} \mathrm{cell} / \mathrm{cm}^{2}$, $m p l 1^{-}$cells, in contrast, consistently failed to form territorial streams even at twenty times higher cell density. $\mathrm{mpll}^{-}$cells occasionally formed loose aggregates, which might have been formed by nearby cells coalescing together in the absence of directional cell migration.

\subsection{3 $\mathrm{mpl1}^{-}$cells are defective in chemotaxis.}

$m p l 1^{-}$cells were challenged with weak $(0.1 \mu \mathrm{M})$ and strong $(2 \mu \mathrm{M})$ gradients of cAMP for a duration of 60 minutes to fully examine their behavior. Cells were made responsive to the cAMP gradient by 4 hours of cAMP pulses, and were challenged for one hour with a cAMP gradient formed from a micropipette filled with $0.1 \mu \mathrm{M}$ or $2 \mu \mathrm{M}$ cAMP. During the initial 20 minutes $\mathrm{mpll}^{-}$cells exhibited severely compromised gradient sensing and reduced speed (Fig. 4B, 4D, 5B, 5D) compared with wild type cells (Fig. 4A, 4D, 5A, 5D). During the last 20 minutes duration, chemotaxis index of $\mathrm{mpll}^{-}$cells improved $\sim 75 \%$ compared to wild type under both conditions, but the degrees of the improvement in motility were lesser (Fig. 4D, 5D). Although statistically meaningful (P value, 0.012 ), the difference of motility under weak and strong gradient was modest. Behaviors of $\mathrm{mpll}^{-}$cells reintroduced with the full length $\mathrm{Mpll}$ were determined in the equivalent manner. Under $0.1 \mu \mathrm{M}$ cAMP, these cells displayed wild type-like chemotaxis index and motility (Fig. 4C, 4D, 5C, 5D). Behaviors of HS174 cells (Wang et al. 1998), which lack ERK2, were monitored for comparison with other cell types described in this report. HS174 cells displayed more severe defects in gradient sensing and directional 
motility compared to $\mathrm{mpll}^{-}$cells under both gradients (Fig. 4D, 5D). These results were obtained from three independent experiments and the average values are summarized in Figure $4 \mathrm{D}$ and $5 \mathrm{D}$.

To determine if Mpll function is necessary for general motility, cells were stimulated with cAMP pulses as the chemotaxis assay, and their movement was monitored in the absence of the cAMP gradient. Wild type, $\mathrm{mpll}^{-}$cells, $\mathrm{mpll}^{-}$cells reintroduced with the full length Mpll, and HS174 cells were pulsed as described earlier, and were analyzed by tracing their movement for 30 minutes at 1 minute intervals (Fig. 6A, 6B). Compared to wild type cells, $\mathrm{mpll}^{-}$cells consistently displayed compromised random motility $(\sim 60 \%)$, whereas $\mathrm{mpll}^{-}$cells re-introduced with the full length $\mathrm{Mpll}$ showed no significant difference from wild type cells (Fig. 6B). Cells lacking ERK2 seemed to have more problems than cells suffering from aberrant ERK2 phosphorylation (Fig.6B, 7A, 7B, 7C). These results showed that $\mathrm{mpll}^{-}$cells were compromised in both random and directional motility, and re-introduction of $\mathrm{Mpll}$ significantly restored both defects.

\subsubsection{Mpl1 regulates post-stimulus ERK2 adaptation.}

Considering that one of the major dual specific phosphatases are MAP kinase phosphatases (MKPs), we reasoned that $\mathrm{mpll}^{-}$cells may experience aberrant ERK2 phosphorylation. ERK2 phosphorylation in response to cAMP stimulation was tested by western blot analysis using an anti-phospho-ERK2 specific antibody (Cell Signaling Inc., Brzostowski and Kimmel, 2006). Cells were stimulated with pulsatile cAMP for 4 hours, treated with $2 \mathrm{mM}$ caffeine for 30 minutes, and then challenged with $0.1 \mu \mathrm{M}$ of cAMP. Under these conditions in wild type cells, ERK2 phosphorylation was virtually 
undetectable before cAMP stimulation, and reached its maximum at 1 minute after the stimulation. $\mathrm{mpll}^{-}$cells, however, not only displayed higher prestimulus ERK2 phosphorylation, but also persistent phosphorylation after cAMP stimulation over 4 minutes of duration (Fig. 7A). The same blot was stripped and reprobed with anti-PanRas antibody to confirm equal loading across the lanes. These data indicate that Mpl1 regulates both prestimulus and poststimulus ERK2 phosphorylation. Consistently, reintroduction of full length Mpll lowered prestimulus ERK2 phosphorylation to an undetectable level, and the post-stimulus level of phospho-ERK2 was similarly restored to that of the wild type (Fig. 7B, 7D). Western blot using anti-flag showed the expression of the full length Mpl1 (Fig. 7C).

One of the well-established phenotypes of erk2 cells is their inefficiency in cAMP generation in response to cAMP receptor activation. It is, however, not due to the defective activation of Adenylyl Cyclase, but rather due to the excessive activity of RegA, a cytoplasmic phosphodiesterase. Upon receiving cAMP stimulation, wild type cells typically display the initial two minutes of slower phase in cAMP production, which is missing in regA- cells (Maeda et al. 2004). This two-minute window coincides with the transient ERK2 activation. It is, therefore, plausible that $\mathrm{mpll}^{-}$cells also display lack of the initial 2-minute slower phase of cAMP production in response to the receptor stimulation. Production of cAMP from wild type and $m p l l^{-}$cells was analyzed by $\left[\mathrm{H}^{3}\right]-$ cAMP competition assay after cAMP pulsing. The typical 2-minute slower phase in cAMP production was lost in $m p l 1^{-}$cells (Fig. 7E), similar to that of the $\operatorname{reg} A^{-}$cells (Maeda et al. 2004). Furthermore, re-introduction of the full length Mpll restored cAMP 
production pattern comparable to that of the wild type (Fig. 7E), indicating that Mpl1 is also essential for proper cAMP production.

\subsection{Discussion}

\subsubsection{Phosphatases similarly architected to Mpl1 exist in other unicellular eukaryotes.}

Although multiple MAP Kinase Phosphatases (MKPs) and DSPases exist in mammals, none of the mammalian dual specificity phosphatases contain LRR domains. The MKPs interact with MAP kinases either directly through the phosphatase domain or indirectly through MAP Kinase binding (MKB) domain. No MKB domain was found in the Dictyostelium genome by NCBI homology domain search. There, however, exist several potential DSPases equipped with LRR domains in the genome of certain unicellular eukaryotic organisms such as Entameoba histolytica, Leishmania major, and Trypanosoma cruzi as described in Figure 1A. All these three organisms are potentially pathogenic, and thus understanding Mpl1 function may shed new insight on the biology

of these parasitic organisms. It will be interesting to determine if the Mpll like genes of Entameoba histolytica, which are highly homologous to Mpll in domain organization, are also essential for ERK2 regulation and motility.

\subsubsection{Mpl1 is an essential regulator of ERK2 function.}

In this report, we showed that Mpl1 is essential for proper ERK2 regulation. Considering that multiple phosphatases exist in vivo, it is significant to observe aberrantly high level of phospho-ERK2 in $\mathrm{mpll}^{-}$cells. In addition, the kinetics of cAMP production of $m p l l^{-}$cells resembled that of the $\operatorname{reg} A^{-}$cells, further supporting the notion that $\mathrm{mpll}^{-}$ 
cells have higher ERK2 activity (Fig. 7E). Furthermore, reintroduction of $M p l 1$ in $m p l 1^{-}$ cells restored ERK2 phosphorylation and cAMP production similar to that of the wild type (Fig. 7B, 7E). It can be said that Mpl1 is essential for proper ERK2 regulation, although it is not clear whether Mpl1 directly or indirectly dephosphorylates phosphoERK2.

In addition to RegA regulation, ERK2 has also been implicated in polarized cytoskeletal reorganization (Wang et al., 1998). Upon receiving cAMP stimulation during aggregation process, cells lose polarity by disintegrating the leading edge and become rounded up within a minute, and regain polarity by reforming a leading edge after 6 7 minutes. Cells lacking ERK2 fail to form the dominant F-Actin filled leading edge. In contrast, erk2 cells generated crown-like structures filled with both F-Actin and Myosin II. It seems, therefore, that transient activation of ERK2 during the early response period is essential for selective assembly of F-Actin from Myosin II in the leading edge after 6 minutes of signal integration.

Consistently, an elevation of prestimulus ERK2 phosphorylation and persistent poststimulus ERK2 phosphorylation in $\mathrm{mpll}^{-}$cells were paralleled with defective motility. Furthermore, the restoration of normal ERK2 regulation in $\mathrm{mpll}^{-}$cells by reintroduction of $\mathrm{Mpl} 1$ significantly improved random motility and directional motility. It seems conceivable that not only the deprivation, but also excessiveness of ERK2 activity could hamper dynamic F-Actin and Myosin II remodeling during cell movement. However, due to the short list of ERK2 substrates in Dictyostelium cells, it remains to be determined how deprivation or excess ERK2 activity regulates cytoskeletal remodeling during cell movement. 


\subsection{3 $\mathrm{mpl1}^{-}$cells were defective in cell migration.}

Quantitative analysis of the chemotaxis of $\mathrm{mpll}^{-}$cells revealed several defects. Compared to wild type, $m p l 1^{-}$cells displayed severely compromised chemotaxis index during the initial 20 minutes duration, which improved significantly when allowed for an additional 40 minutes under both weak and strong cAMP gradients. Considering their modest phenotype and delayed improvement in directionality of $\mathrm{mpll}^{-}$cells, it is unlikely that $\mathrm{Mpl} 1$ is the major determinant of gradient sensing.

In contrast, motility was more severely compromised during the first 20 minutes under both gradients. During the last 20 minutes, the motility improved modestly under both gradients. The degree of improvement was slightly better under the weak than the strong cAMP gradient. $m p l 1^{-}$cells may experience more problem in ERK2 adaptation under strong cAMP gradient, but the mechanism behind these observations is currently not clear.

In any case, $m p l 1^{-}$cells displayed a more severe defect in motility than the directionality. Re-introduction of the full length $\mathrm{Mpll}$ in $\mathrm{mpll}^{-}$cells significantly restored multiple defects in aggregation, chemotaxis, random motility, ERK2 regulation, and cAMP production, which underscored the significance of Mpl1 in these processes.

\subsection{Acknowledgment}

Marbelys Rodriguez is a RISE student supported by NIH. Sudhakar Veeranki is FIUPresidential fellow. We thank Dr. Lisa Kreppel and Ms. Lorraine Acevedo for their technical help and Dr. Lisa Schneper for critical reading and discussions. 


\subsection{Figures}

A

Figure 1

Dictyostelium discoideum

Mpl1
\begin{tabular}{|l|l|l|l|l|}
\hline & \multicolumn{2}{|c|}{ LRR } & & \\
\hline \multicolumn{3}{|c|}{$\mid{ }_{\text {LRR }}$} & & DSPC \\
\hline
\end{tabular}
\begin{tabular}{|l|l|l|l|}
\hline & LRR & & DSPC \\
\hline
\end{tabular}

834 (XP_646404)

856 (XP_642370)

695 (XP_646403)

Entamoeba histolytica

Leishmania major

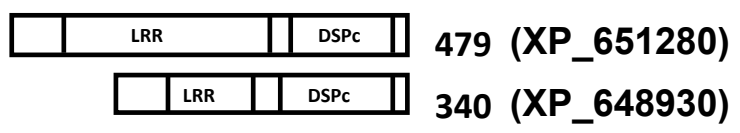

\begin{tabular}{|l|l|l|l|l|l|l|l|}
\hline & PK & & PK & & LRR & & DSPC \\
\hline & PK & & PK & & LRR & DSPc \\
\hline
\end{tabular}

1382(XP_0016863

Trypanosoma cruzi

\begin{tabular}{|c|c|c|c|c|c|}
\hline & PK & PK & & LRR & DSPC \\
\hline & PK & PK & $\mathrm{Zn}$ & LRR & DSPC \\
\hline & $\overline{\mathrm{PK}}$ & $\overline{\mathrm{PK}}$ & $\mathrm{zn} \mid$ & LRR & DSPC \\
\hline
\end{tabular}

1286(XP_844396)

1285(XP_821800)

1285(XP_804043) 


\begin{tabular}{l|l|l|l|l}
\hline Mpl1 & & LRR & & DSPc \\
\cline { 2 - 4 } & & &
\end{tabular}

MIFKKLFSKGSTSPTTRPRGATFSGTFPTDVLSDDGSGTNTNGLSNSTTNPSSIHSTPTTPTTTASTNLTNSN KLSTLAPITNGNRSLRGSKDGSGTTKESKKKVLTLNEKQKLLLKSMEY I KGSGTYYGNYMEFYEIPIQIYVGT EPSETYPSLSYNTELRSLILDFNKITEIPEQIGLLPNLKHLSLAANQLSQVPEFLSQLKSLESLELGINQFTS FPLNICKI KSLTLLRLETNNI KSLPDDF INLENLKDLSLLDNQLKEI PDSLPNN IEKLNLGCNDI INSYSKSL IRISHSLTTLNLSENKIEVLDESLSCLVNVKTLILDCNMI KVI PGSVLGSWKSLVTLNLPHNF I SDLPAEIVT LDNLRI IDLRGNNFEFCKNYPSSESSS I LFKIEEF I KDKEKLKSLI LKENLEI LSKLKDDNSTTTTTNINSNL DVPIIITTNIETIPTTSTTATTTETTNDITFKISDITEI IEKTDTTTTTTTTNQTDNVKLEEKVYEKQENDEN NSVTLETTTTISIASDNTDEASIQI PQKEDGDKENLENDDKLLQESFSENNNNNNNEKQQEQQENPLKESQGK IQQLEEELEKLEQKQLELKDKIRLEKI KYQE IQQQSPRLSQQENNQEA IVVNTQPSSPPPTI IVNEQKSEKLE NEKPTKREQPMVVVTKNNNKAEVEMTAPNQLIFWQSIVPDLI IDKLYLGCRECAMNKSWLKDNNVTHILTVAN FKPLYPDLFKYLIINIDDVDEANIYQYFKEMNTFIDEGREKGGVLIHCRAGVSRSATATIAYIMMKNSVKFQE AFDITIKGRSRIYPNRGFLNQLKKFEKDLSK

C

$\begin{array}{lllllll}0 & 5 & 10 & 15 & 20 & 24 & \mathrm{hr}\end{array}$

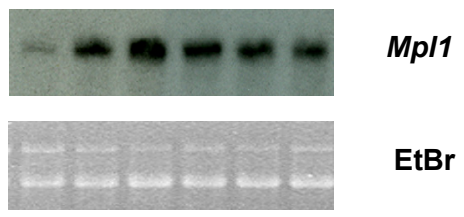

Figure 1. Dual specificity phosphatases with Leucine-Rich Repeats.

(A) Two other Mpl1 like genes exist in Dictyostelium discoideum genome. A blast search for Mpll like genes resulted in potential DSPase with LRRs in several unicellular protozoans such as Entamoeba histolytica, Leishmania major, and Trypanosoma cruzi. Serine/Threonine protein kinase (PK) and $\mathrm{Zn}$-finger motifs $(\mathrm{Zn})$ are found in several genes listed. Combination of potential DSPase and LRR seems to be unique to protozoans, some of which are well known parasites that could cause serious illness. Diagrams of these potential DSPases are shown with their amino acids lengths and their gene access numbers at the right side. (B) Full length Dictyostelium Mpl1 sequence is shown. Six conserved Leucine-Rich Repeats (LRR) are underlined, and the potential dual specific phosphatase (PPase) domains are in bold with essential conserved sequences 
underlined. The insertion point of the Blasticidin cassette in $\mathrm{mpll}^{-}$cell is marked with a filled arrowhead. (C) Northern blot analysis showed that Mpll expression was low in vegetative stage cells and highly enhanced during development. Maximum expression was observed around 10 hours and declined slightly thereafter.

A

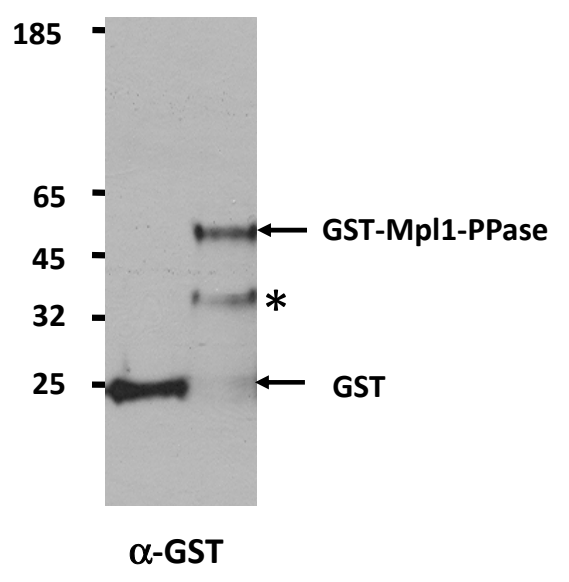

B

\begin{tabular}{|c|c|c|}
\hline & GST & GST-Mpl1 \\
\hline $\mathrm{A}_{405} *$ & $\mathbf{0 . 0 2} \pm \mathbf{0 . 0 3}$ & $\mathbf{0 . 1 8} \pm \mathbf{0 . 0 2}$ \\
\hline
\end{tabular}

Figure 2

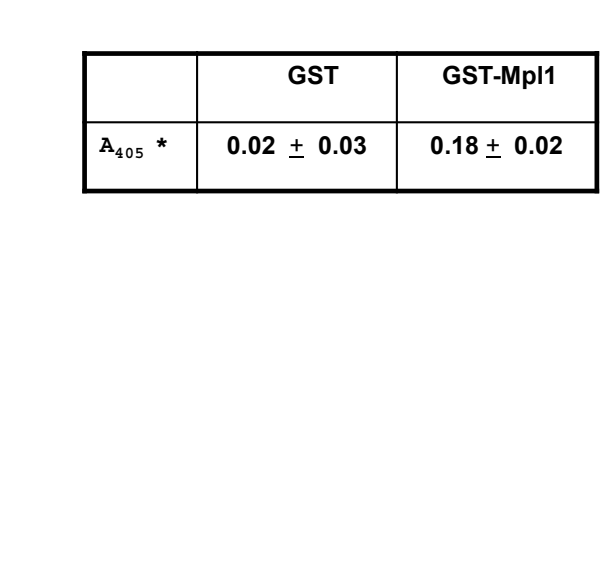

Figure 2. Mpl1 encodes an active phosphatase.

(A) GST and GST-Mpl1-PPase were expressed and purified from E. coli. A major $\sim 53 \mathrm{kD}$ band (GST-Mpl1-PPase) and a minor degradation product $(*)$ were detected by western blot using anti-GST antibody. (B) Phosphatase activities were compared from purified proteins after normalization by western blot. GST alone displayed negligible background, whereas GST-Mpl1-PPase exhibited a significant increase in absorption by dephosphorylation of $p N P P$. Absorption of $p-N P$ at $405 \mathrm{~nm}$ was from $1 \mathrm{mg}$ of protein incubated at room temperature for an hour. Average values with standard deviations are shown from three independent experiments. 

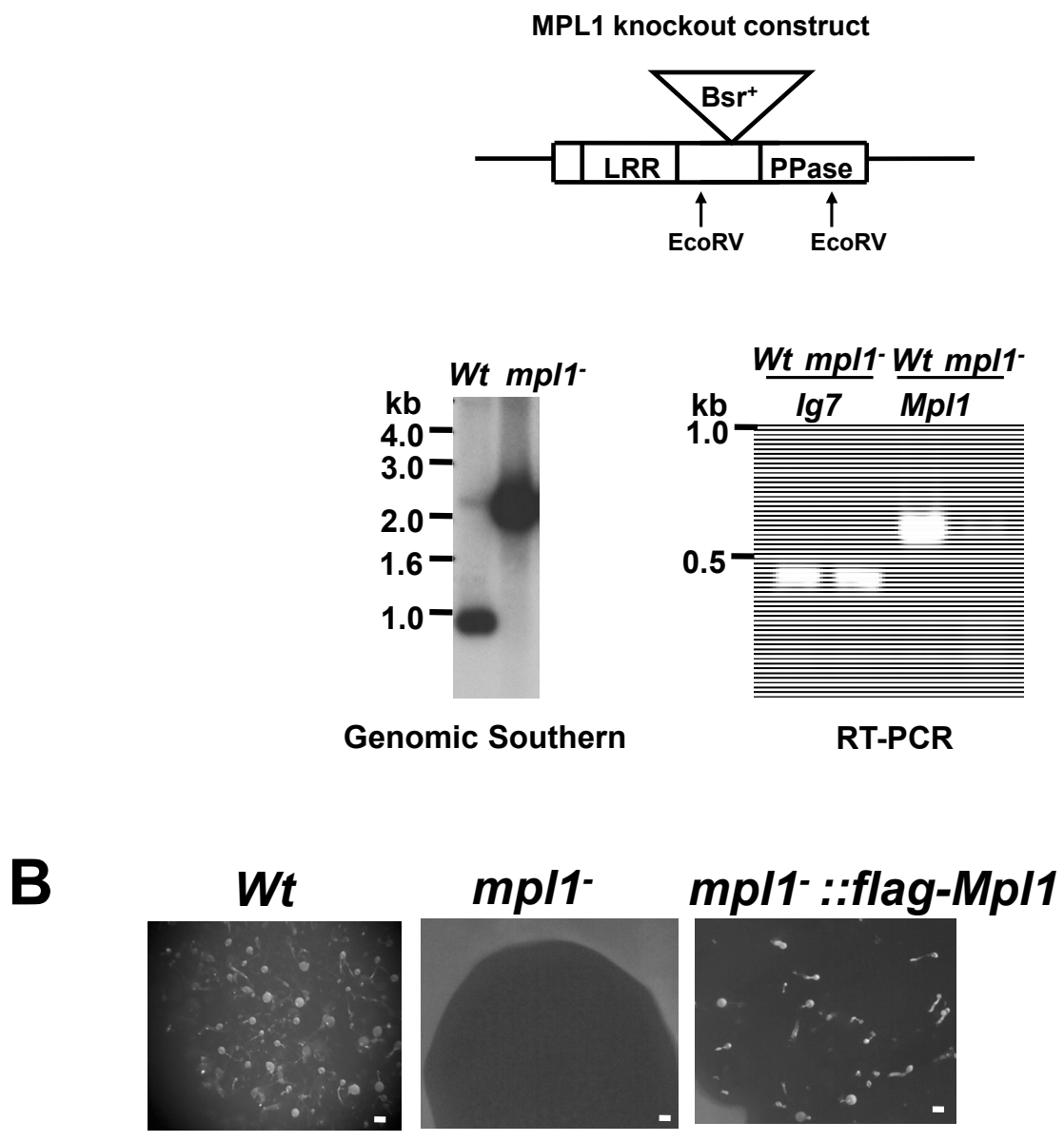

C
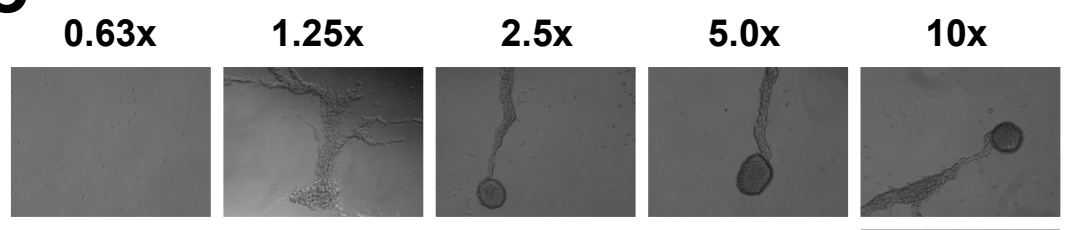

$20 \times 10^{4} \mathrm{cells} / \mathrm{cm}^{2}$

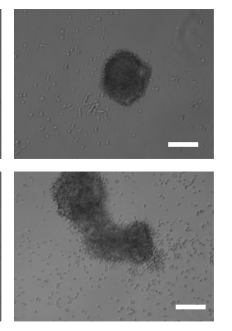

Wt

mp/1-

Figure 3. Generation of $m p l 1^{-}$cells and phenotype characterization.

(A) The blasticidin resistance cassette was subcloned between LRRs and the PPase domain. Initial screening was performed with PCR, and the selected knock-out 
candidates were confirmed by genomic Southern blot analysis as described in Materials and Methods. Levels of Mpll messages were compared by RT-PCR, using primers specific for amino-terminal region before the blasticidin cassette insertion. $\operatorname{Ig} 7$ transcripts were utilized as an internal control for RT-PCR reaction. (B) Cells were developed on bacterial (Klebsiella aerogenes) lawn plates for 7 days. Wild type cells produced numerous fruiting bodies, whereas few multicellular structures were detected from plaques from $\mathrm{mpll}^{-}$cells. Reintroduction of the full length $\mathrm{Mpll}$ restored fruiting body formation. $1 \mathrm{~mm}$ scale bars are shown. (C) Wild type and $\mathrm{mpll}^{-}$cells were developed under DB buffer for 12 hours at densities as marked. $\mathrm{mpll}^{-}$cells occasionally coalesced together to form loose aggregates at cell densities over $5 \times 10^{4} \mathrm{cells} / \mathrm{cm}^{2}$, yet most of them stayed as individual cells at densities where wild type cells efficiently streamed. Scale bars are $100 \mu \mathrm{m}$.

\section{A}

Figure 4

Wt $0.1 \mu M$ cAMP

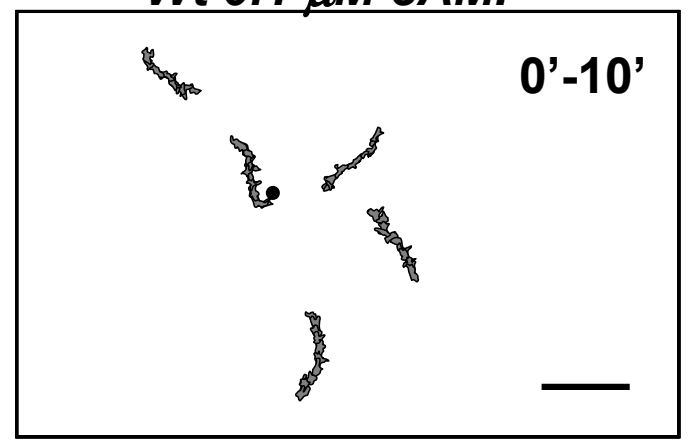


B

mpl1- cells

$0.1 \mu$ M cAMP

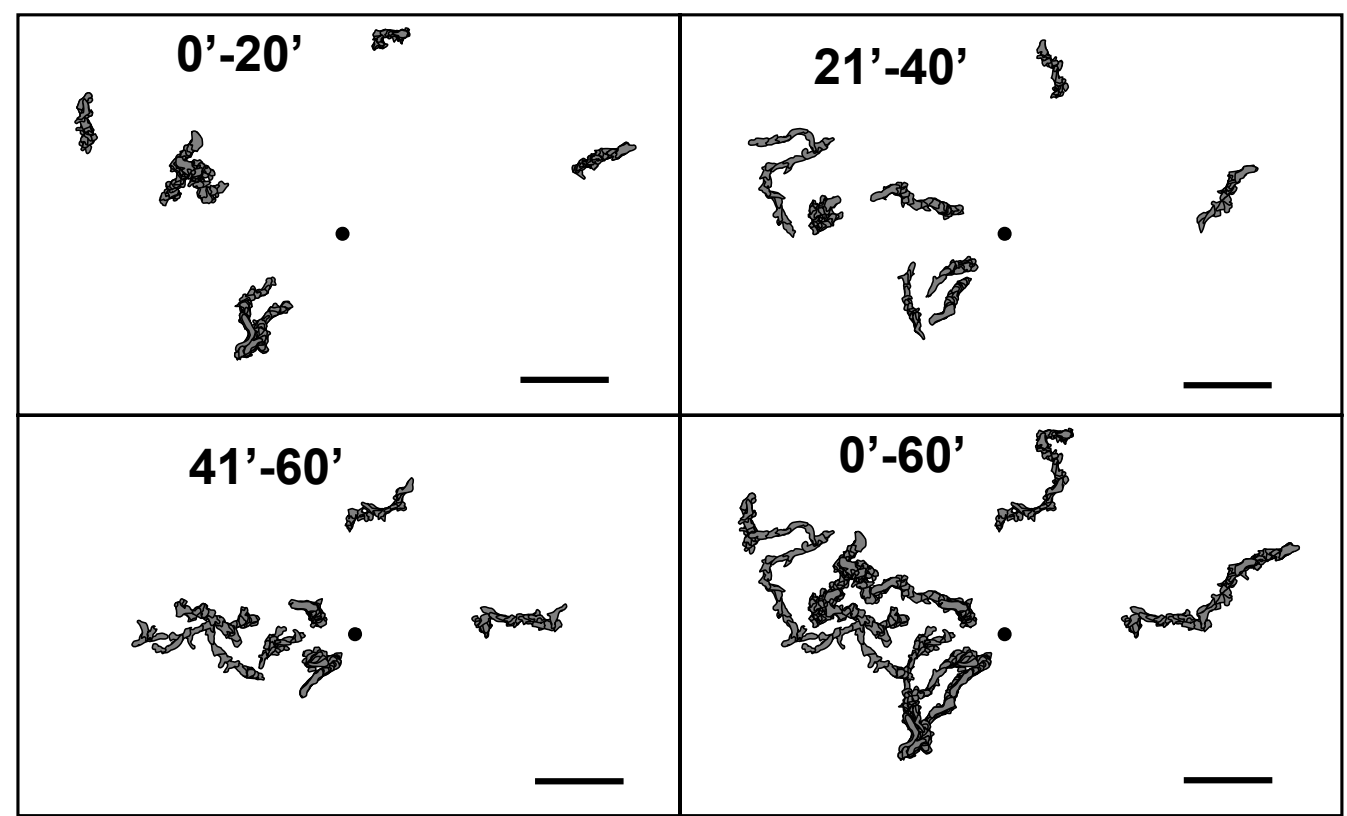

C

mpl1:: flag-Mpl1

$0.1 \mu M$ cAMP

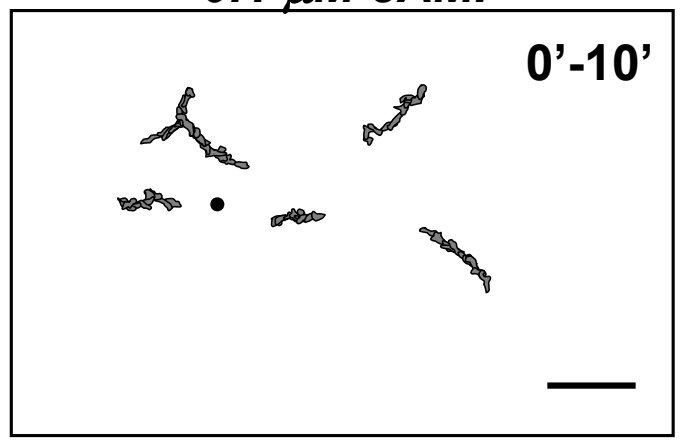




\section{D}

\begin{tabular}{|c|c|c|c|c|c|}
\hline & cAMP & & $0^{\prime}-20^{\prime}$ & $21^{\prime}-40^{\prime}$ & $41^{\prime}-60 '$ \\
\hline \multirow{2}{*}{$W t$} & $0.1 \mu \mathrm{M}$ & $\mathrm{Cl}$ & $0.79 \pm 0.13$ & - & - \\
\cline { 3 - 6 } & & Speed & $9.5 \pm 2.6$ & - & - \\
\hline \multirow{2}{*}{$m p / 1-$} & $0.1 \mu \mathrm{M}$ & $\mathrm{Cl}$ & $0.41 \pm 0.39^{*}$ & $0.55 \pm 0.26$ & $0.60 \pm 0.33$ \\
\cline { 3 - 6 } & & Speed & $2.6 \pm 0.8^{*}$ & $3.3 \pm 2.0$ & $4.2 \pm 1.9$ \\
\hline $\begin{array}{c}m p / 1 \cdots f l a g- \\
\text { Mp/1 }\end{array}$ & $0.1 \mu \mathrm{M}$ & $\mathrm{Cl}$ & $0.63 \pm 0.22^{* *}$ & - & - \\
\cline { 3 - 6 } & & Speed & $8.7 \pm 3.3^{* *}$ & & \\
\hline erk2- & $0.1 \mu \mathrm{M}$ & $\mathrm{Cl}$ & $0.06 \pm 0.36^{*}$ & $0.06 \pm 0.38$ & $-0.02 \pm 0.33$ \\
\cline { 3 - 6 } & & Speed & $3.1 \pm 1.1^{*}$ & $2.9 \pm 1.3$ & $2.2 \pm 0.9$ \\
\hline
\end{tabular}

Figure 4. mpl1 ${ }^{-}$cells are inefficient in chemotaxis under $0.1 \mu \mathrm{M}$ cAMP gradient.

Log phase cells of both wild type (A), $m p l 1^{-}$cells (B), $m p l 1^{-}$cells re-introduced with the full length Mpl1 (C) were stimulated with $50 \mathrm{nM}$ cAMP pulses for 4 hours and challenged with a micropipette filled with $0.1 \mu \mathrm{M}$ cAMP. Time-lapse images of cellular responses to the cAMP gradient were captured with OpenLab software. Tracing images of chemotaxing cells were arranged to demonstrate relative directional movement, cell shape, and distances traveled toward the cAMP point source (a filled circle) with $100 \mu \mathrm{m}$ scale bars. Shown in (A) is a stack of 10 tracings, at 1 minute intervals, of wild type cells. $m p l 1^{-}$cells were monitored for 60 minutes, and shown as three consecutive 20 minute stacks and one whole 60 minute tracing. Stack of ten images of $\mathrm{mpll}^{-}$cells re-introduced with the full length Mpll is shown (C). Data were from three independent experiments for each cell types. (D) Chemotactic index, defined as the net distance of cell movement in the direction of the pipette divided by the total distance moved, was computed from the centroid positions (Loovers et al. 2006). Average values with standard deviations were obtained from three independent experiments. One of the three wild type chemotaxis movies was analyzed for 20 minutes, and two other wild type and three rescue movies 
were analyzed for 10 minutes, by which several cells already migrated to the tip of the micropipette. Chemotaxis indices and speed of movement for cells lacking ERK2 (HS174, Wang et al. 1998) is included for comparison. erk2 cells were pulsed for 4 hours before challenged with cAMP gradient. *, $\mathrm{P}<0.001$ compared with wild type control, student's t test. **, $\mathrm{P}>0.05$ compared with wild type control, student's t test.

A

Figure 5

Wt $2.0 \mu M$ cAMP

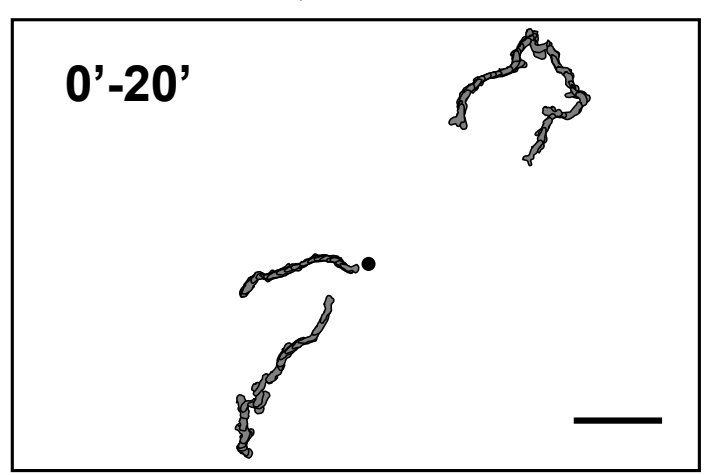




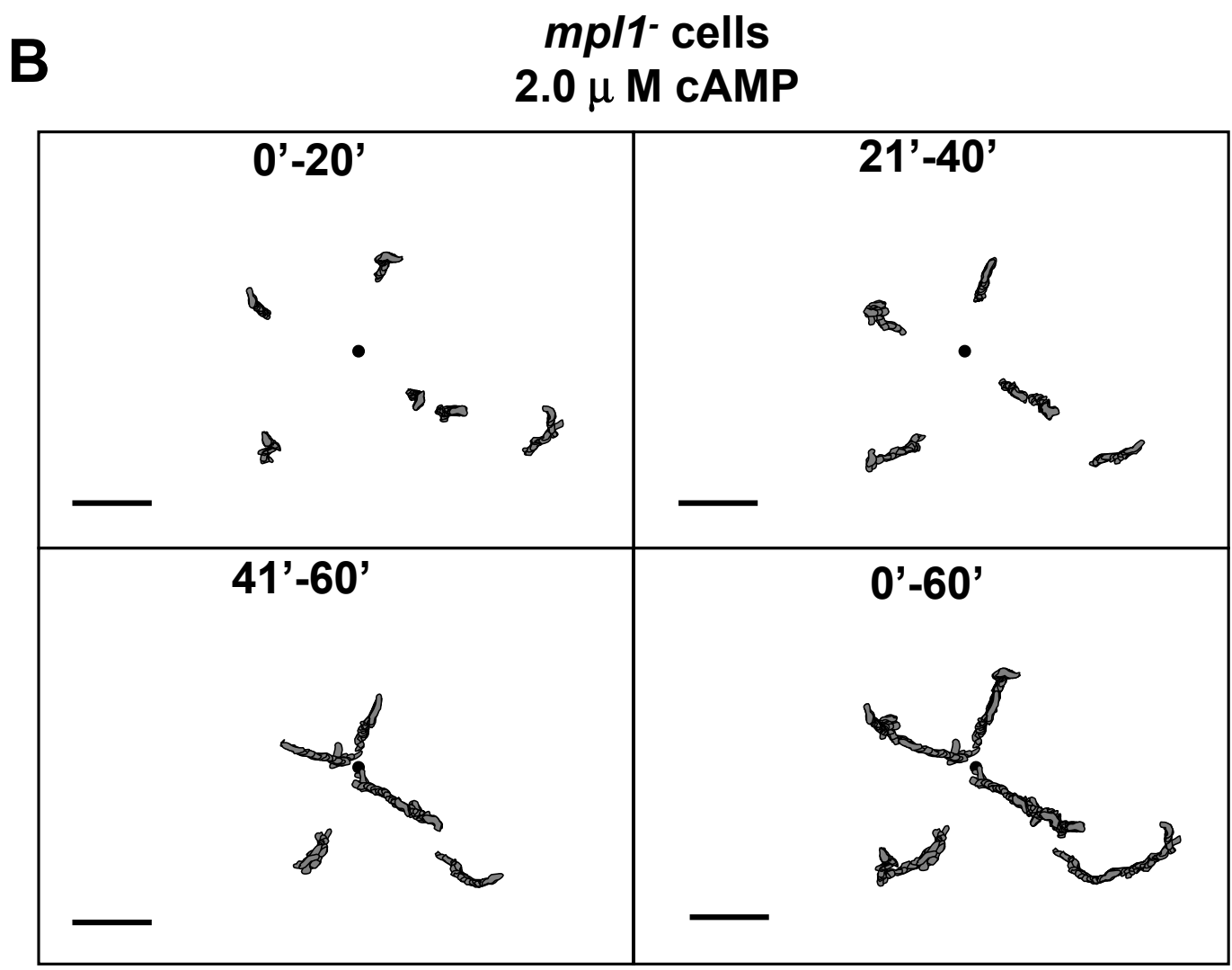

C

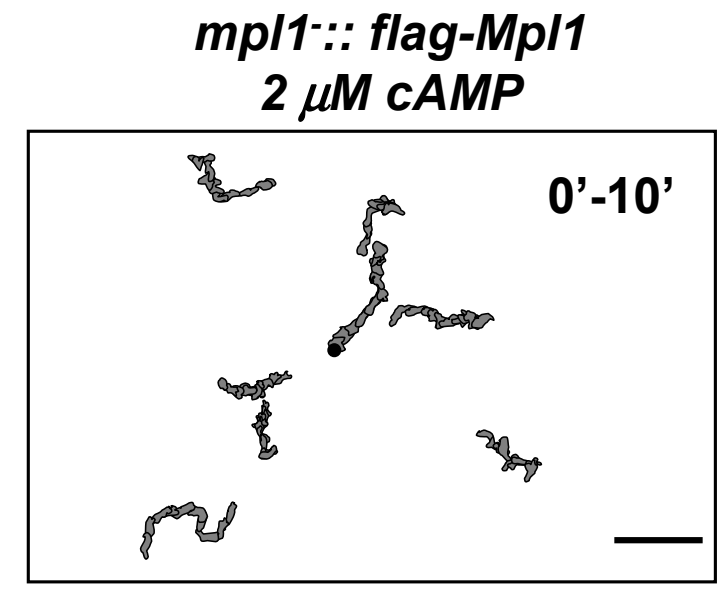


D

\begin{tabular}{|c|c|c|c|c|c|}
\hline & cAMP & & $0^{\prime}-20^{\prime}$ & $21^{\prime}-40^{\prime}$ & $41^{\prime}-52^{\prime}$ \\
\hline \multirow{2}{*}{$W t$} & $2.0 \mu \mathrm{M}$ & $\mathrm{Cl}$ & $0.82 \pm 0.12$ & - & - \\
\cline { 3 - 6 } & & Speed & $9.6 \pm 2.4$ & - & - \\
\hline \multirow{2}{*}{$m p / 1^{-}$} & $2.0 \mu \mathrm{M}$ & $\mathrm{Cl}$ & $0.41 \pm 0.34^{*}$ & $0.65+0.25$ & $0.58+0.36$ \\
\cline { 3 - 6 } & & Speed & $2.5 \pm 1.2^{*}$ & $3.3 \pm 1.8$ & $2.8 \pm 1.3$ \\
\hline \multirow{2}{*}{$\begin{array}{c}m p / 1 \cdots f f a g- \\
\text { Mp/1 }\end{array}$} & $2.0 \mu \mathrm{M}$ & $\mathrm{Cl}$ & $0.63 \pm 0.17^{*}$ & - & - \\
\hline \multirow{2}{*}{\begin{tabular}{c} 
erk2- \\
\cline { 3 - 6 }
\end{tabular}} & $2.0 \mu \mathrm{M}$ & Speed & $8.2 \pm 3.3^{* *}$ & - & - \\
\cline { 3 - 6 } & & $\mathrm{Cl}$ & $-0.03 \pm 0.44^{*}$ & $-0.05 \pm 0.31$ & $-0.06 \pm 0.53$ \\
\cline { 3 - 6 } & & Speed & $2.8 \pm 1.3^{*}$ & $2.2 \pm 1.1$ & $1.7 \pm 1.0$ \\
\hline
\end{tabular}

Figure 5. mpl1 cells displayed aggravated chemotactic responses toward $2 \mu \mathrm{M}$ cAMP gradient compared to $0.1 \mu \mathrm{M}$ cAMP gradient.

Chemotactic responses of wild type (A) $\mathrm{mpll}^{-}$cells (B), and $\mathrm{mpll}^{-}$cells re-introduced with the full length $\mathrm{Mpll}$ (C) in response to cAMP gradient formed by a micropipettes filled with $2 \mu \mathrm{M}$ cAMP were analyzed similar to Figure 4. (D) Average values with standard deviations of chemotaxis indices and speeds were obtained from three independent experiments. ${ }^{*}, \mathrm{P}<0.001$ compared with wild type control, student's t test. **, $\mathrm{P}>0.05$ compared with wild type control, student's t test. 
A

Figure 6

\begin{tabular}{|c|c|c|c|}
\hline & \\
\hline
\end{tabular}

Figure 6. mpl1 cells were also defective in random motility.

Random motility of cAMP pulsed wild type, $m p l 1^{-}$cells, and $m p l 1^{-}$cells re-introduced with the full length Mpll were traced for 30 minutes with 1 minute intervals and the migratory paths are shown in (A). Scale bars are $100 \mu \mathrm{m}$. (B) Average values with standard deviations from three independent experiments are shown. A total of 39 wild type, $34 \mathrm{mpll}^{-}$cells, $26 \mathrm{mpll}^{-}$cells re-introduced with the full length $\mathrm{Mpll}$, and $30 \mathrm{erk} 2^{-}$ cells were analyzed. *, $\mathrm{P}<0.001$ compared with wild type control, student's t test. **, $\mathrm{P}>0.05$ compared with wild type control, student's t test. 
A
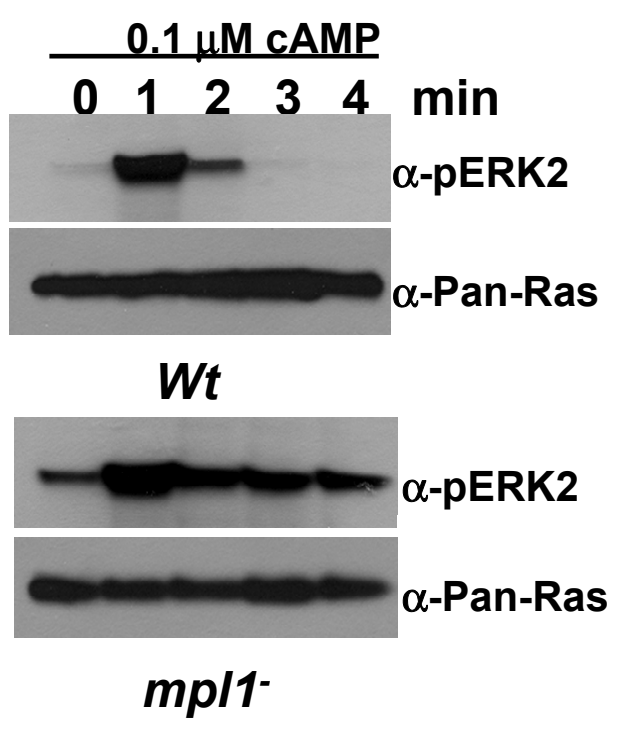

Figure 7

B

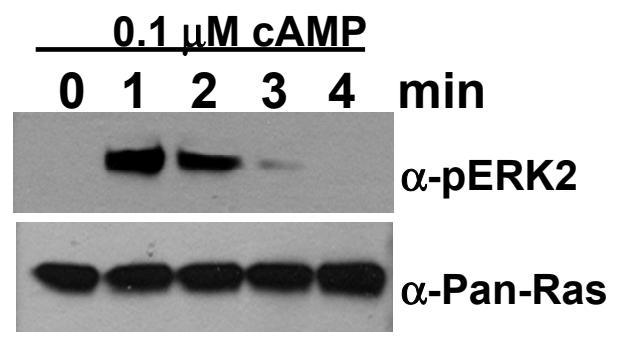

Flag-Mpl1::mp/1-

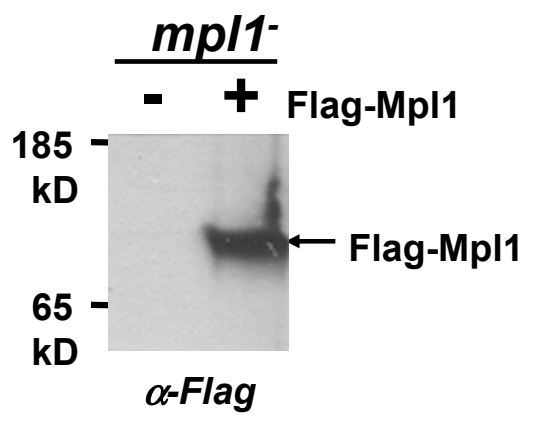

D

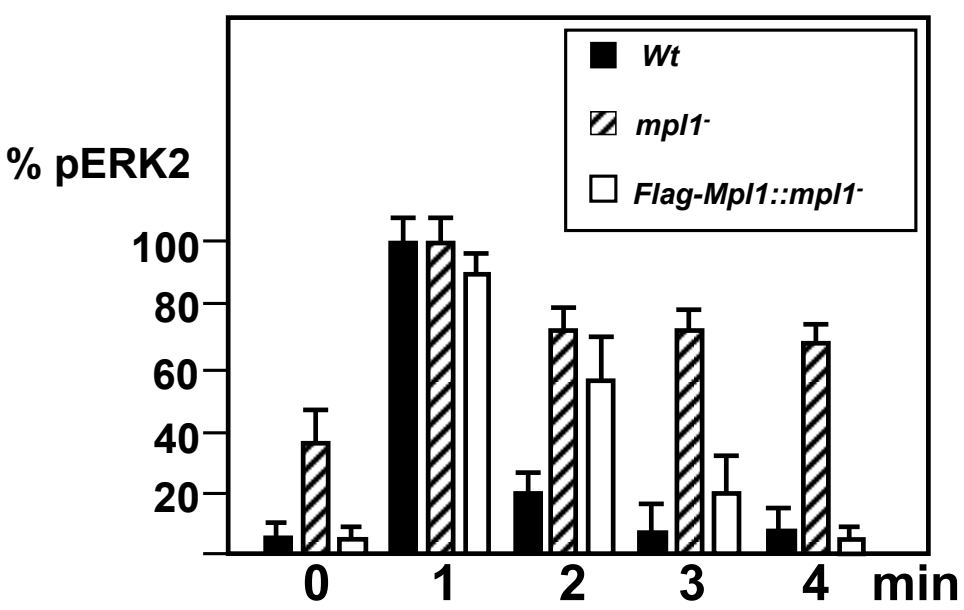

Figure 7. Mpl1 regulates ERK2 phosphorylation in Dictyostelium.

(A) Both wild type and $m p l 1^{-}$cells $\left(10^{8}\right.$ cells) were stimulated with 50nM cAMP pulses for 4 hours, treated with $2 \mathrm{mM}$ caffeine for 30 minutes, and further stimulated with 0.1 
$\mu \mathrm{M}$ cAMP. Cells were taken at each time point, and directly lysed with SDS-PAGE loading dye for Western blot analysis using phospho-ERK2 specific antibody and PanRas antibody (loading control). Wild type cells displayed maximal ERK2 activation around 1 minute, whereas phopho-ERK2 persisted over 4 minutes in $\mathrm{mpll}^{-}$cells. Basal phosphorylation of ERK2 is also higher at time zero in $\mathrm{mpll}^{-}$cells than in wild type cells. (B) $\mathrm{mpll}^{-}$cells expressing flag-Mpll were pulsed and stimulated with cAMP and analyzed as described in (A). (C) Western blot using anti-flag antibody confirmed the expression of flag-Mpl1, which migrated as $\sim 90 \mathrm{kD}$ protein as expected. (D) Levels of ERK2 phosphorylation levels were compared between wild type, $\mathrm{mpll}^{-}$cells, and $\mathrm{mpll}^{-}$ cells re-introduced with $M p l l$ were shown in (D). (E) cAMP production was measured from cAMP pulsed wild type, $\mathrm{mpll}^{-}$cells, and $\mathrm{mpll}^{-}$cells re-introduced with $\mathrm{Mpl1.} \mathrm{mpll}^{-}$ cells overproduced cAMP during the initial 2 minutes of the poststimulus period, which resembled that of the $\operatorname{reg} A^{-}$cells. In contrast, $\mathrm{mpll}^{-}$cells re-introduced with $\mathrm{Mpll}$ displayed essentially wild type-like pattern in cAMP production. *, $\mathrm{P}<0.001$ compared with wild type control, student's t test. **, $\mathrm{P}<0.05$ compared with wild type control, student's $t$ test. t, $\mathrm{P}>0.05$ compared with wild type control, student's t test. 


\subsection{References}

Brzostowski JA, Kimmel AR. (2006) Nonadaptive Regulation of ERK2 in Dictyostelium: Implications for Mechanisms of cAMP Relay. Mol Biol Cell. 17, 4220-7.

Ducruet AP, Vogt A, Wipf P, Lazo JS. (2005). Dual specificity protein phosphatases: therapeutic targets for cancer and Alzheimer's disease. Annu Rev Pharmacol Toxicol. 45, 725-50.

Dynes JL, Clark AM, Shaulsky G, Kuspa A, Loomis WF, Firtel RA. (1994). LagC is required for cell-cell interactions that are essential for cell-type differentiation in Dictyostelium. Genes Dev. 8, 948-58.

Early, A., Gamper, M., Moniakis, J., Kim, E., Hunter, T., Williams, J. G. and Firtel, R. A. (2001). Protein tyrosine phosphatase PTP1 negatively regulates Dictyostelium STATa and is required for proper cell-type proportioning. Developmental Biology 232, 233-245.

Enkhbayar P, Kamiya M, Osaki M, Matsumoto T, Matsushima N. (2004) Structural principles of leucine-rich repeat (LRR) proteins. Proteins. 54, 394-403.

Gamper, M., Howard, P. K., Hunter, T. and Firtel, R. A. (1996). Multiple roles of the novel protein tyrosine phosphatase PTP3 during Dictyostelium growth and development. Molecular and Cellular Biology 16, 2431-2444.

Gamper, M., Kim, E., Howard, P. K., Ma, H., Hunter, T. and Firtel, R. A. (1999). Regulation of Dictyostelium protein-tyrosine phosphatase-3 (PTP3) through osmotic shock and stress stimulation and identification of pp130 as a PTP3 substrate. Journal of Biological Chemistry 274, 12129-12138.

Howard, P. K., Sefton, B. M. and Firtel, R. A. (1992). Analysis of a Spatially Regulated Phosphotyrosine Phosphatase Identifies Tyrosine Phosphorylation as a Key Regulatory Pathway in Dictyostelium. Cell 71, 637-647.

Howard, P. K., Gamper, M., Hunter, T. and Firtel, R. A. (1994). Regulation by ProteinTyrosine-Phosphatase Ptp2 Is Distinct from That by Ptp1 during Dictyostelium Growth and Development. Molecular and Cellular Biology 14, 5154-5164.

Huang, Y. Z., Zang, M. W., Xiong, W. C., Luo, Z. J. and Mei, L. (2003). Erbin suppresses the MAP kinase pathway. Journal of Biological Chemistry 278, 1108-1114.

Keyse, S. M. (2000). Protein phosphatases and the regulation of mitogen-activated protein kinase signalling. Current Opinion in Cell Biology 12, 186-192.

Kobe, B. and Kajava, A. V. (2001). The leucine-rich repeat as a protein recognition motif. Current Opinion in Structural Biology 11, 725-732. 
Kolch, W. (2000). Meaningful relationships: the regulation of the Ras/Raf/MEK/ERK pathway by protein interactions. Biochemical Journal 351, 289-305.

Kosaka C, Pears CJ. (1997). Chemoattractants induce tyrosine phosphorylation of ERK2 in Dictyostelium discoideum by diverse signaling pathways. Biochem J. 324, 347-352.

Laub MT, Loomis WF. (1998). A molecular network that produces spontaneous oscillations in excitable cells of Dictyostelium. Mol Biol Cell. 9, 3521-32.

Loftus B, Anderson I, Davies R, Alsmark UC, Samuelson J, Amedeo P, Roncaglia P, Berriman M, Hirt RP, Mann BJ, Nozaki T, Suh B, Pop M, Duchene M, Ackers J, Tannich E, Leippe M, Hofer M, Bruchhaus I, Willhoeft U, Bhattacharya A, Chillingworth T, Churcher C, Hance Z, Harris B, Harris D, Jagels K, Moule S, Mungall K, Ormond D, Squares R, Whitehead S, Quail MA, Rabbinowitsch E, Norbertczak H, Price C, Wang Z, Guillén N, Gilchrist C, Stroup SE, Bhattacharya S, Lohia A, Foster PG, Sicheritz-Ponten T, Weber C, Singh U, Mukherjee C, El-Sayed NM, Petri WA Jr, Clark CG, Embley TM, Barrell B, Fraser CM, Hall N. (2005). The genome of the protist parasite Entamoeba histolytica. Nature. 433, 865-868.

Loovers HM, Postma M, Keizer-Gunnink I, Huang YE, Devreotes PN, van Haastert Peter JM. (2006). Distinct Roles of PI(3,4,5) $\mathrm{P}_{3}$ during Chemoattractant Signaling in Dictyostelium: A Quantitative In Vivo Analysis by Inhibition of PI3-Kinas e. Mol Biol Cell 17, 1503-1513.

Lyon MA, Ducruet AP, Wipf P, Lazo JS. (2002). Dual-specificity phosphatases as targets for antineoplastic agents. Nature Reviews Drug Discovery. 1, 961-976

Maeda M, Lu S, Shaulsky G, Miyazaki Y, Kuwayama H, Tanaka Y, Kuspa A, Loomis WF. (2004). Periodic signaling controlled by an oscillatory circuit that includes protein kinases ERK2 and PKA. Science. 304, 875-8.

Rintelen F, Hafen E, and Nairz K. (2003). The Drosophila dual-specificity ERK phosphatase DMKP3 cooperates with the ERK tyrosine phosphatase PTP-ER. Development. 130, 3479-3490.

Roux, P. P. and Blenis, J. (2004). ERK and p38 MAPK-activated protein kinases: a family of protein kinases with diverse biological functions. Microbiology and Molecular Biology Reviews 68, 320-344.

Sawai S, Thomason PA, Cox EC. (2005). An autoregulatory circuit for long-range selforganization in Dictyostelium cell populations. Nature. 433, 323-6.

Theodosiou A and Ashworth A. (2002) MAP kinase phosphatases. Genome Biol. 3(7)

Tomchik KJ, Devreotes PN. (1981). Adenosine 3',5'-monophosphate waves in Dictyostelium discoideum: a demonstration by isotope dilution -- fluorography. Science. 212. 443-446. 
Tsai, H. R., Yang, L. M., Tsai, W. J. and Chiou, W. F. (2004). Andrographolide acts through inhibition of ERK1/2 and Akt phosphorylation to suppress chemotactic migration. European Journal of Pharmacology 498, 45-52.

Vindis, C., Cerretti, D. P., Daniel, T. O. and Huynh-Do, U. (2003). EphB1 recruits c-Src and p52 (Shc) to activate MAPK/ERK and promote chemotaxis. Journal of Cell Biology $162,661-671$.

Wang Y, Liu J and Segall JE. (1998) MAP kinase function in amoeboid chemotaxis. Journal of Cell Science 111, 373-383. 


\section{CHAPTER 3: THE PP2A REGULATORY SUBUNIT, B56, AND THE GLYCOGEN SYNTHASE KINASE-3 REGULATE PROTEIN KINASE B- RELATED 1 ADAPTATION IN DICTYOSTELIUM CELLS}

\subsection{Summary}

The members of the AGC protein kinase superfamily have been shown to play an important role in cytoskeleton remodeling and reorganization. A member of the Dictyostelium AGC protein kinase family, the Protein Kinase B-related 1 (PKBR1), has been shown to regulate chemotaxis in Dictyostelium cells. In response to cAMP stimulation, PKBR1 becomes rapidly activated in a Ras dependent mechanism and induce phosphorylation of multiple downstream effectors. Activation of PKBR1 requires two phosphorylation events, one at the active loop (AL) by the phosphoinositide dependent kinase (PDKA) and another at the hydrophobic motif (HM) site by the Tor complex 2 (TorC2). The known upstream regulators of PKBR1 have been the focus of recent studies, but its adaptation is not fully characterized. Here we report that the PP2A regulatory subunit, B56, and the Glycogen Synthase Kinase 3 (GSK3) are necessary for PKBR1 adaptation in Dictyostelium cells. Cells lacking B56, psr $A^{-}$cells, exhibited high basal and persistent post stimulus levels of activated PKBR1, increased phosphorylation of PKBR1 substrates, and aberrant motility. Furthermore, we propose the existence of a novel role of GSK3 in PKBR1 regulation. The overexpression of a dominant negative form of GSK3 (GSK3DN) and treatment of cells with the GSK3 inhibitor, Lithium Chloride $(\mathrm{LiCl})$, resulted in increased basal levels of activated PKBR1, in a RasD dependent, but B56 independent mechanism. Altogether, these results suggest that PKBR1 adaptation is regulated by GSK3 and another by PP2A/B56. 


\subsection{Introduction}

Motility is process involving multiple signaling pathways designed to allow cells to receive and interpret environmental signals, and subsequently coordinate appropriate and robust response. Misregulation of some of the signaling pathways that reduce cell motility could provide a novel insight to control pathological conditions in which motility is critical, such as tumor metastasis and acute inflammation. Further understanding and characterization of these signaling cascades would be essential in treating such diseases. Several of the key regulators of motility found in mammalian cells are conserved in Dictyostelium cells, making it a great model system to further characterize these signaling pathways.

Cellular migration is an important component of the life cycle of Dictyostelium cells. When the conditions are nutritional favorable, Dictyostelium cells exist as single cells that prey on bacteria and/or yeast (Chisholm, R. and Firtel, R., 2004; MüllerTaubenberger, A. et al. 2013). Dictyostelium cells effectively forage their prey because of their ability to sense and chemotax towards very shallow gradients of byproducts and/or signals originated from the prey (Swaney, K. et al. 2010). Upon starvation, individual Dictyostelium cells come together guided by a gradient of cAMP generated by the cells resulting in the formation of an aggregate that differentiates into a motile slug and a fruiting body later (Chisholm,R. and Firtel, R. 2004). Directional cell migration guided by the cAMP gradient is an essential component of Dictyostelium development.

During the aggregation stage, the extracellular cAMP activates G-protein coupled receptors (GPCR) resulting in the dissociation of heterotrimeric G-proteins into Ga and G $\beta \gamma$ subunits. Since these receptors are uniformly distributed throughout the cell 
membrane, and the activation of cAMP receptors resemble the extracellular cAMP gradient pattern, it have been proposed that the signal becomes amplified downstream of receptor activation (Janetopoulos, C. et al. 2001; Ueda, M. et al. 2001; Sasaki, A. et al. 2004; Charest, P. C. and Firtel, R. 2007). The G $\beta \gamma$ subunit have been suggested to activate several members of the family of small GTPases, including Ras and Rac (Swaney, K. et al. 2010; Yan, J. and Jin, T. et al. 2012). Activation of proteins triggers the activation of phosphatidylinositol-3-kinase (PI3K) resulting in the local accumulation of phosphatidylinositol-3,4,5-triphosphate $\left(\mathrm{PIP}_{3}\right)$ on the side where cAMP concentration is the highest. Additionally, the $\mathrm{PIP}_{3}$ gradient is maintained by the translocation of the phosphatidylinositol-3-phosphatase, PTEN, from the front of the cell to the lateral sides and to the back of the cell. The mutual exclusion of PI3K and PTEN makes possible the local accumulation of $\mathrm{PIP}_{3}$ in the leading edge of the cell. In turn, $\mathrm{PIP}_{3}$ accumulation creates docking sites for several Pleckstrin homology $(\mathrm{PH})$-domain-containing proteins, several of which are crucial for pseudopod extension and F-actin polymerization (Charest, P. C. and Firtel, R. 2007; Swaney, K. et al. 2010).

An important family of kinases that modulates cytoskeletal remodeling in Dictyostelium is the AGC family of kinases, Akt/PKBA and Protein Kinase B-related (PKBR1). In response to cAMP stimulation, PKBA is rapidly recruited to the membrane via its $\mathrm{PH}$ domain. Once at the membrane, PKBA gets phosphorylated by phosphoinositide-dependent kinase A (PdkA) and by the Tor complex 2 (TorC2) in the active loop (AL) site and in the hydrophobic motif (HM) site, respectively (Meili, R. et al. 1999; Kamimura, Y. et al. 2008; Kamimura, Y. and Devreotes, P. 2010; Liao, X. et al. 2010; Cai, H., et al. 2010). Similarly to PKBA, PKBR1 gets activated upon cAMP 
stimulation by phosphorylation in both the Active Loop (AL) site by PdKA and in the Hydrophobic Motif (HM) site by TorC2 (Kamimura, Y. et al. 2008; Kamimura, Y. et al. 2010; Liao, X. et al. 2010; Cai, H., et al. 2010). In contrast to PKBA, PKBR1 does not have a PH domain; instead PKBR1 is permanently anchored at the membrane through a myristoylation site present on its N-terminus (Meili, R. et al. 2000). Interestingly, PKBR1 activation was found to occur independently of PI3K in contrast to PKBA, suggesting PKBR1 upstream regulation may be through other parallel signaling pathway (Kamimura, Y. et al. 2008; Liao, X. et al. 2010). Furthermore, recent evidence suggested that PKBA and PKBR1 activation is mediated by the small GTPase RasC, possibly through TorC2 regulation (Cai, H., et al. 2010). Studies showed that PKBR1 and PKBA activation was reduced in cells lacking $\operatorname{RasC}\left(\operatorname{ras} C^{\star}\right)$, and the activation was easily restored upon expression of either $\mathrm{RasC}$ or a constitutively active form of $\mathrm{RasC}$. However, a residual PKBR1 and PKBA activation remained in $\operatorname{ras} C^{-}$cells suggesting other upstream regulators of PKBA and PKBR1 are yet to be identified.

Although, PKBA and PKBR1 has been the focus of recent investigations, the adaptation mechanisms are not fully understood yet. Recently, Charest, and others described that a complex composed of scaffolding protein Sca1, Ras guanine exchange factors A (RasGEFA), Ras guanine exchange factor H (RasGEFH) and the catalytic and scaffolding subunits of the heterotrimeric threonine/serine phosphatase (PP2A) complex regulates PKBR1 and PKBA adaptation via a negative feedback mechanism (Charest, P. et al. 2010). The Sca $1 / \operatorname{RasGEFA} / \mathrm{RasGEFH} / \mathrm{PP} 2 \mathrm{~A} / \mathrm{RasC}$ complex was shown to rapidly translocate to the membrane of chemotaxing cells resulting in the activation of RasC at the front leading edge of the cell. The activation of RasC and PKBR1 were reduced 
dramatically in cells lacking Scal (scal-) suggesting that the Sca1/RasGEFA/RasGEFH/PP2A $/$ RasC complex contributes greatly to the activation of RasC, and as a result PKBA and PKBR1 activation (Charest, P. et al. 2010). Interestingly, Sca1 possesses a PKB phosphorylation consensus motif (motif R-X-R-X$\mathrm{X}-\mathrm{S} / \mathrm{T}-\mathrm{X}-\mathrm{X}$; Kamimura, Y. et al. 2008) that is rapidly phosphorylated with similar kinetics of PKBR1/PKBA activation. This phosphorylation event is greatly reduced in cells lacking both PKBA and PKBR1 ( $\left.k^{2} \mathrm{a}^{-} / \mathrm{pkbrl^{- }}\right)$ suggesting Sca1 function may be regulated by PKBA/PKBR1 phosphorylation (Charest, P. et al. 2010). Additionally, RasC activation was prolonged in cells lacking PKBR1 ( $\left.k b r l^{-}\right)$suggesting the existence of a negative feedback mechanism by which PKBA and PKBR1 regulate RasC activation and consequently their adaptation (Charest, P. et al. 2010).

In this report we show the PP2A regulatory subunit, B56, and the Glycogen synthase kinase 3 (GSK3) negative regulates PKBR1 activation in Dictyostelium cells, providing a novel insight into PKBR1 adaptation. Cells lacking B56, psr $A^{-}$cells, exhibited aberrantly high basal level of active PKBR1, reduced levels of PP2A activity (Lee, N. et al. 2008) and reduced levels of active Ras proteins; these defects resulted in higher levels of phosphorylated PKBR1 substrates and defective random and directional migration. Additionally, $p s r A^{-}$cells exhibited higher levels of active Glycogen synthase kinase 3 (GSK3) (Lee, N. et al. 2008), which has been shown in the past to be an important PKBR1 regulator (Teo, R. et al. 2010; Kölsch, V. et al. 2012). When we examined the levels of active PKBR1 in $p s r A^{-}$cells expressing dominant negative GSK3 (GSK3DN) or treated cells with Lithium Chloride $(\mathrm{LiCl})$, a further increase of active PKBR1 was observed in $p s r A^{-}$cells suggesting that GSK3 also negatively regulates 
PKBR1. Interestingly, ablation of either $\operatorname{Ras} C$ or $\operatorname{Ras} D$, but not B56, abolishes GSK3 effect on PKBR1 regulation in these cells suggesting RasC and RasD may mediate the effect. Altogether, PKBR1 adaptation regulation may be as complex as its activation, possibly mediated by at least two parallel signaling pathways, one by B56 and the other by GSK3/Ras.

\subsection{Material and Methods}

\subsubsection{Cell culture}

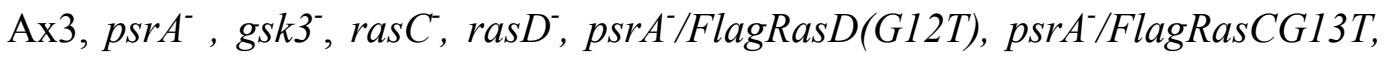
$\mathrm{psrA}^{-} / G S K 3 D N, W t / G S K 3 D N$ and $\mathrm{ras} D / G S K 3 D N$ cells were grown with axenic media (14.3g Peptone 3[Difco], 7.15g yeast extract [Oxoid], 15.4g glucose [Fisher Scientific], $0.525 \mathrm{~g} \mathrm{Na}_{2} \mathrm{HPO}_{4} \cdot 7 \mathrm{H}_{2} \mathrm{O}, 0.48 \mathrm{~g} \mathrm{KH}_{2} \mathrm{PO}_{4}, 0.53 \mathrm{~g} \mathrm{Na}_{2} \mathrm{HPO}_{4} \cdot 7 \mathrm{H}_{2} \mathrm{O}$ in 1 liter of water, $\mathrm{pH} 6.5-$ 6.9). The media was complemented with $5 \mathrm{mg} / \mathrm{ml}$ of Blasticidin (InvivoGen) for $p s r A^{-}$, ras $C^{\leftarrow}$, ras $D^{-}$and $g s k 3^{-}$strains. In addition, for $g s k 3^{-}$cells, $25 \mathrm{mg} / \mathrm{ml}$ of Thymidine (Acros Organics) was added to the media. For strains over-expressing FlagRasC, FlagRasD, FlagRasC(G13T), FlagRasD(G12T) or GSK3DN, $20 \mu \mathrm{g} / \mathrm{ml}$ of G418 (GIBCO) was used as a selective agent for the media.

\subsubsection{Generation of Flag-tagged RasD(G12T).}

Flag-tagged RasD(G12T) was generated using the Quick Change ${ }^{\circledR}$ Site-Directed Mutagenesis kit (Stratagene) with forward primer 5'GTtATTGTAGGTGGTACAGGTGTTGGTAAAAGTGCATTAAC-3' and reverse primer 5'-GTTAATGCACTTTTACCAACACCTGTACCACCTACAATAAC-3'. The

reaction was then treated with restriction enzyme Dpn-I at $37^{\circ} \mathrm{C}$ for 5 minutes followed 
by transformation into DH5a competent cells (Allele). Positive colonies were purified and construct was confirmed using sequencing.

Chemotaxis and Random Motility assays

Log-phase cells were starved at a concentration of $20 \times 10^{6}$ cells $/ \mathrm{ml}$ in DB buffer ( $2 \mathrm{mM} \mathrm{MgCl}_{2}, 0.2 \mathrm{mM} \mathrm{CaCl}_{2}, 7.4 \mathrm{mM} \mathrm{NaH}_{2} \mathrm{PO}_{4}, 4 \mathrm{mMNa}_{2} \mathrm{HPO}_{4}$ ) for 1 hour followed by stimulation with 50nM cAMP every 6 minutes for a total of 4 hours at room temperature. Competent aggregate cells were plated at a density of $3 \times 10^{4} \mathrm{cells} / \mathrm{cm}^{2}$ on a $35-\mathrm{mm}$ tissue culture dish cover (Falcon 353001; Becton Dickinson) and left to settle down for 5-10 minutes at room temperature. To examine the chemotactic response, cells were exposed to a glass capillary needle filled with $10 \mu \mathrm{M}$ cAMP solution with a Schmazu micromanipulator. To maintain the external chemotactic gradient, the capillary needle containing cAMP was connected to an Eppendorf FemotoJet at an injection pressure of $20 \mathrm{hPa}$. A time-lapse video recording using OpenLab Software was used to follow the cell movement at 1 minute-intervals. To perform a random motility analysis, competent aggregate cells were plated as previously described and no source of external cAMP was used.

Chemotaxing cells were analyzed as previously described by Loovers, H. and his colleges (2006). An ellipse was constructed around the cell and the chemotactic index and velocity were calculated from the center of the ellipse. The chemotactic index is defined as the ratio between the net distance moved in the direction of the glass capillary needle and the total distance moved by the cell. The velocity was calculated as the total distance moved by the cell divided by the total amount of time. 


\subsubsection{Determining Ras Activation in response to cAMP stimulation}

To examine Ras activation in response to cAMP stimulation, first of all, log phase vegetative cells were starved for 1 hour and stimulated with 50nM cAMP at 6 minute interval for 4 hours at room temperature at a concentration of $20 \times 106$ cells $/ \mathrm{ml}$ in DB buffer. Competent aggregate cells were washed once with ice cold DB buffer and treated with $5 \mathrm{mM}$ caffeine at room temperature for 20 minutes at a concentration of $20 \times 106$ cells/ml. Following treatment, cells were washed with ice cold DB buffer once and resuspended with $5 \mathrm{ml}$ of DB buffer and shaken for 2 minutes at room temperature. Then, cells were stimulated with $10 \mu \mathrm{M}$ cAMP and immediately lysed with TTG buffer $(20 \mathrm{mM}$ TrisBase, $150 \mathrm{mM} \mathrm{NaCl}, \quad 0.1 \%$ Triton-X, 20\% Glycerol, 1mM EDTA, 0.1\% 2mercaptoethanol and protease inhibitor cocktail from Roche) at 5, 30, 60 and 90 seconds.

Secondly, GTP bound Ras proteins were purified from cells lysates using pulldown assays as previously described by Veeranki, S. et al. 2008. The activated forms of RasD and RasG were purified using recombinant GST-Ras binding domain (RBD) from mammalian Raf1 (GST-RBDRaf1) and the activated form of RasC was purified using recombinant GST-Ras Binding Domain of Byr2 from Schizosaccharomyces pombe (GST-RBDByr2). Cell extracts were mixed with purified $4 \mu \mathrm{g}$ of either GST-RBDRaf1 or GST-RBDByr2 and incubated at $4{ }^{\circ} \mathrm{C}$ for 90 minutes. Then, samples were washed three times using TTG buffer. SDS-containing sample buffer was then added to the pulldown reactions; samples were analyzed using a Tris-glycine-SDS-polyacrylamide gel, and the levels of active Ras were detected by western blot using anti-PanRas antibody (Calbiochem). 


\subsubsection{Determining PKBR1 activation in response to cAMP stimulation}

To examine PKBR1 activation, competent aggregate cells were washed once with ice cold DB buffer and treated with $5 \mathrm{mM}$ caffeine at room temperature for 20 minutes. After the treatment, cells were washed twice with ice cold PM buffer (5mM Na2HPO4, 5mM KH2PO4, 2mM MgSO4) and resuspended at 20x106 cells/ml in PM buffer followed by shaking for two minutes at room temperature, then cells were stimulated with $1 \mu \mathrm{M}$ cAMP followed by lysis with TTG buffer at 15,30 and 180 seconds. PKBR1 phosphorylation was detected with western blot using Phospho-PKC antibody (Cell Signaling 190D10) as previously described by Cai. H. and his/her collegues (2010). To detect the phosphorylation of PKBR1 substrates containing the motif R-X-R-X-X-S/T-X$\mathrm{X}$, western blot using anti-Phospho Akt Substrate (Cell Signaling) was done as previously described by Kamimura, Y. and his/her colleagues.

To analyze PKBR1 activation in the presence of $\mathrm{LiCl}$, competent aggregate cells were treated with $50 \mathrm{mM} \mathrm{LiCl}$ for one hour at room temperature while shaking; then cells were wash with ice-cold DB once followed by caffeine treatment and stimulation with $1 \mu \mathrm{M}$ cAMP as previously described.

\subsection{Results}

\subsubsection{B56 regulates cell motility}

Defective aggregation during development (data not shown), led us to characterize $p s r A^{-}$cell motility. During random motility, $p s r A^{-}$cells exhibited an average velocity that is $50 \%$ reduced compared to $W t$ cells (Fig. 8). 
When the cell motility of $p s r A^{-}$cells was examined in the presence of an external

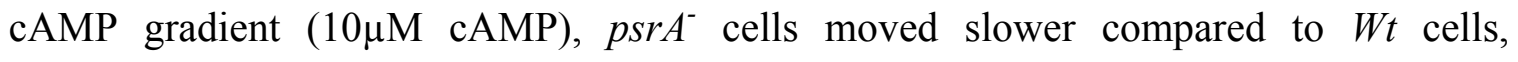
exhibiting an average velocity reduced by $60 \%$ compared to $W t$ cells (Fig. 8). Furthermore, $p s r A^{-}$cells displayed significantly compromised chemotaxis; $p s r A^{-}$cells exhibited an average chemotactic index (CI) of $0.4 \pm 0.4$, which is $50 \%$ of the average chemotactic index of $W t$ cells (Fig. 8). These results suggest that B56 is part of a regulatory network controlling both random and directional cell motility of Dictyostelium.

\subsubsection{B56 regulates Ras activation}

To determine the possible mechanism by which B56 regulates motility, we decided to examine Ras function in $p s r A^{-}$cells. Dictyostelium cells possess over eleven different Ras species and two Rap proteins; many of them, including RasG and RasC have been shown to be critical regulators of cellular migration (Kortholt, A. and van Haastert, P. 2008). RasG and RasC regulate the recruitment and activation of several downstream effectors involved in cellular motility, including PI3K and TorC2. Cells lacking either RasG or RasC exhibited compromised motility and cAMP-mediated signaling (Charest, P. and Firtel, R. 2007; Kortholt, A. and van Haastert, P. 2008).

To examine Ras activation, aggregation competent $p s r A^{-}$and $W t$ cells were stimulated with $10 \mu \mathrm{M}$ cAMP after treating cells with caffeine for 20 minutes. To detect RasG and RasD activation, the Ras Binding Domain of mammalian Raf1 (GST-RBD Rafl $_{1}$ ) fused with GST was used as previously described (Veeranki, S. et al. 2008). The levels of active RasG and RasD were detected in $W t$ cells at 5 seconds after cAMP stimulation persisting until 30-60 seconds and decreasing thereafter (Fig. 9A). Compared to Wt cells, 
$p s r A^{-}$cells exhibited lower levels of active RasG and RasD, exhibiting a weaker peak at 5 seconds after cAMP stimulation and rapidly decreasing afterwards. These results suggest $p s r A^{-}$cells have defective RasD and RasG activation. To determine RasC activation in response to cAMP stimulation, the Ras Binding Domain from Schizosaccharomyces pombe Byr2 (GST-RBD $\mathrm{Byr}_{\mathrm{r} 2}$ ) fused with a GST tag was used as previously described by Kae, H. and others (Kae, H. et al. 2004). Similarly to RasG and RasD, RasC activation at 5 seconds was lower than $W t$ cells, rapidly decreasing thereafter (Fig. 9B) suggesting in the absence of $\mathrm{B} 56$, the amplitude of $\mathrm{Ras} \mathrm{C}$ activation is compromised in response to cAMP stimulation.

\subsubsection{B56 is important for PKBR1 regulation}

Considering that $p s r A^{-}$cells have defective RasC activation and RasC have been shown to be an important regulator of the TorC2/PKBA and PKBR1 pathway, we hypothesized PKBR1 and PKBA activation may also be compromised in psr $A^{-}$cells. To examine PKBA and PKBR1 activation, aggregate competent cells were stimulated with $1 \mu \mathrm{M}$ cAMP and the phosphorylation levels of PKBR1 at the AL site were examined as previously described (Cao, H., et al. 2010). Upon cAMP stimulation, Wt cells rapidly exhibited phosphorylation at the AL site in PKBR1 and PKBA at 15 seconds, decreasing thereafter at 30 seconds and undetectable at 180 seconds after cAMP stimulation. The bands corresponding to phosphorylated PKBA or phosphorylated PKBR1 were absent in $p k b a^{-}$and $p k b r l^{-}$cells, respectively. Surprisingly, when PKBA and PKBR1 AL phosphorylation was examined in $p s r A^{-}$cells, we noted higher basal levels of phosphorylated PKBR1, but not PKBA, prior to cAMP stimulation in these cells compared to Wt cells; after stimulation, a shallow increase of in the levels of 
phosphorylated PKBR1 was observed at 15 seconds which persisted onto 180 seconds thereafter (Fig. 10A). These results suggest B56 plays an essential role in PKBR1 adaptation.

To further investigate the effect of B56 in PKBR1 adaptation, we examine the activation of putative PKBR1 substrates containing the motif R-X-R-X-X-S/T-X-X in psr $A^{-}$as previously described (Kamimura, Y., et al. 2008; Cao, H., et al. 2010). As expected, there were higher levels of phosphorylated PKBR1 substrates in psr $A^{-}$cells compared to $W t$ cells suggesting the inability of $p s r A^{-}$cells to regulate PKBR1 resulted in higher levels of active PKBR1 effectors (Fig. 10B).

\subsubsection{Repairing Ras activation in $p s r A^{-}$cells does not restore PKBR1 adaptation in these cells}

To examine the possibility that PKBR1 adaptation can be mediated by a RasCeffector, the PKBR1 activation was examined in $p s r A^{-}$cells overexpressing a constitutively active form of RasC (RasCG13T). When the levels of active PKBR1 were examined in these cells, we observed higher levels of phosphorylated PKBR1 at the AL site compared to $p s r A^{-}$cells (Fig. 10C). These results suggest the defective PKBR1 regulation present in $p s r A^{-}$cells cannot be improved by simply restoring RasC activation in $p s r A^{-}$cells. Possibly, the defective RasC activation present in these cells may not be the major cause of aberrant PKBR1 adaptation; possibly it may be a consequence of PKBR1 hyper-activation.

\subsubsection{RasD regulates PKBR1 and PKBA activation}

Similar to RasC, RasD activation was compromised in $p s r A^{-}$cells (Fig. 9A). To determine if RasD regulates PKBR1 adaptation we decided to introduce a constitutively 
active form of RasD (RasDG12T) in $p s r A^{-}$cells to restore RasD activation in these cells. When the PKBR1 activation was examined in $p s r A^{-}$cells overexpressing RasD(G12T), it was found to be higher than $p s r A^{-}$cells (Fig. 10D). These results suggest RasD may have a positive role in PKBR1 activation similar than RasC. When the PKBR1 activation was observed in cells lacking RasC, a reminiscent PKBR1 activation was observed in these cells suggesting the presence of other proteins regulating PKBR1 activation (Cai, H., et al. 2010). We propose RasD along with RasC regulates PKBR1 activation in Dictyostelium cells.

Interestingly, $p s r A^{-}$cells overexpressing $\operatorname{Ras} \mathrm{D}(\mathrm{G} 12 \mathrm{~T})$ exhibited aberrantly higher levels of phosphorylated PKBA at the AL site compared to $p s r A^{-}$cells and $p s r A^{-}$cells overexpressing $\operatorname{Ras} \mathrm{C}(\mathrm{G} 13 \mathrm{~T})$. Therefore, this may indicate RasD may also have a positive effect in PKBA activation and possibly a higher specificity towards PKBA compared to PKBR1. In addition, when PKBR1 and PKBA activation were determine in cells lacking RasD ( $r a s D^{-}$cells), lower levels of active PKBR1 and no detectable levels of PKBA were observed compared to $W t$ cells (Fig. 11C). However, it is not known whether RasD regulates PKBR1 and PKBA through the TorC2 complex with RasC. Also, it is not known if RasD-mediated activation of PKBA is dependent on PI3K activation or whether it occurs through an unknown parallel pathway yet to be described.

\subsubsection{GSK3 regulates PKBR1 activation}

Glycogen Synthase Kinase 3 has been shown in the past to be an important regulator of Dictyostelium development, playing a crucial role in the differentiation of pre-stalk and pre-spore cells (Harwood, A.J. et al. 1995; Kim, L. et al. 2000; Kim, L. et al. 2002; Schilde, C. et al. 2004; Lee, N. et al. 2008). In addition, PP2A/B56 was shown 
to regulate cell fate determination modulating GSK3 activity; $p s r A^{-}$cells exhibited abnormally high levels of active GSK3 and delayed expression of pre-stalk cell markers, Extracellular Matrix proteins A and B (ecmA and ecmB), and high expression of prespore cell markers, Spore Coat protein B (cotB) (Lee, N. et al. 2008).

Recent findings show that in addition to regulating development, GSK3 plays a role in chemotaxis; gsk3- cells exhibited defective Ras and PKBR1 regulation resulting in aberrant directional motility (Teo, R. et al. 2010; Kölsch, V. et al. 2012; Sun, T. et al. 2013). PKBR1 activation is impaired in gsk3- cells, showing no detectable levels of phosphorylated PKBR1 on the AL site in response to cAMP stimulation as previously reported by Teo, R. and his colleagues (Teo, R. et al. 2010) but in discrepancy with (Kölsch, V. et al. 2012); the reason for this difference may be in part for the utilization of strains with different genetic backgrounds or the utilization of distinct experimental conditions.

Because GSK3 is necessary for PKBR1 activation and GSK3 is aberrantly regulated in $p s r A^{-}$cells (Lee, N. et al. 2008), we reasoned the abnormal high basal levels of active PKBR1 observed in $p s r A^{-}$cells may be the consequence of the GSK3 hyperactivation present in these cells. To determine if B56 regulation of PKBR1 activation could be mediated by GSK3, we decided to reduce the levels of active GSK3 in psr $A^{-}$ cells by overexpressing a dominant negative form of GSK3 (GSK3DN) as previously described by Lee, N. and others (Lee, N. et al. 2008); as a control, GSK3DN was also overexpressed in $W t$ cells. To our surprise, when the PKBR1 activation was examined in psr $A^{-}$cells overexpressing GSK3DN, higher levels of basal phosphorylation in the AL site of PKBR1 were observed; similarly, higher levels of basal phosphorylated PKBR1 
were obtained in $W t$ cells, but at lower magnitudes compared to $p s r A^{-}$cells (Fig. 11A). Furthermore, the overexpression of GSK3DN resulted in persistent phosphorylation of PKBR1 substrates in these cells (Fig. 11B). Another possible way to reduce GSK3 activity in vivo is by treating cells with Lithium Chloride ( $\mathrm{LiCl})$, a well characterized GSK3 inhibitor. Similarly to GSK3DN overexpression, $50 \mathrm{mM} \mathrm{LiCl}$ treatment to either $W t$ or $p s r A^{-}$cells resulted in higher levels of active PKBR1 compared to non-treated cells (Fig. 12A). As expected, no significant increase in PKBR1 activation was observed in gsk3- cells treated with $\mathrm{LiCl}$ (Fig. 12B). These results suggest GSK3 negatively regulates PKBR1 activation in a B56 independent mechanism.

Recent reports suggests GSK3 negatively regulates Ras activation since ablation of Gsk3 resulted in persistent Ras activation (Kölsch, V. et al. 2012; Sun, T. et al. 2013). Considering Ras proteins are abnormally regulated in gsk3- cells and they are PKBR1 activators, we reasoned GSK3 negative regulation of PKBR1 activation may be mediated by Ras proteins. To determine if RasD is needed for GSK3-mediated PKBR1 regulation, we overexpressed GSK3DN in ras $^{-}$cells. When the PKBR1 activation was examined in ras $D^{-}$cells overexpressing GKS3DN the level of active PKBR1 remained comparable to that of ras $D^{-}$cells (Fig. 11C). Furthermore, when ras $D^{-}$or ras $C^{-}$cells were treated with LiCl, no significant increase in PKBR1 phosphorylation was observed compared to nontreated cells (Fig. 12C) in contrast to $W t$ and $p s r A^{-}$cells, which exhibited higher levels of PKBR1 activation after $\mathrm{LiCl}$ treatments (Fig. 12A). Altogether, these results suggest that GSK3 can affect PKBR1 activity in a RasC or RasD dependent mechanism.

On the basis of these results, GSK3 may have two different roles in PKBR1 regulation. One possible role being that GSK3 may be necessary for the transcription of 
a critical regulator of the PKBR1 activation pathway. Secondly, another role of GSK3 in PKBR1 regulation may be mediated by RasC or RasD. The down-regulation of GSK3 activity resulted in an increase of the basal levels of active PKBR1 in $W t$ and psr ${ }^{-}$cells suggesting GSK3 plays a negative role in PKBR1 activation, whereas no effect was observed in either ras $^{-}$or ras $D^{-}$cells, suggesting GSK3 role in PKBR1 adaptation occurs in a Ras dependent manner.

\subsection{Discussion}

\subsubsection{B56 regulates PKBR1 adaptation}

Dictyostelium is not the only organism that show B56 mediated adaptation of AGC kinases. A previous study performed on C. elegans showed PP2A/B56 plays an essential role in the adaptation of the AGC family kinase, Akt-1; similar finding were obtained in differentiated 3T3-L1 adipocytes cells, higher levels of activated Akt were observed upon knockdown of the PP2A regulatory subunit, B56 $\beta$ (Padmanabhan, S. et al. 2009).

In addition to exhibiting high basal levels of active PKBR1, psr $A^{-}$cells had reduced levels of Ras activation. On the basis of these observations, we hypothesized PKBR1 adaptation could be regulated by Ras proteins, possibly RasD. In the contrary to our expectations, upon expression of $\operatorname{RasD}(\mathrm{G} 12 \mathrm{~T})$ in $p s r A^{-}$cells, higher levels of phosphorylated PKBR1 and PKBA were observed in these cells suggesting RasD is a positive regulator of PKBR1 and PKBA. Furthermore, a previous report by Lee, N. and others showed $p s r A^{-}$cells displayed aberrant levels of active GSK3 resulting in defective cell differentiation during development (Lee, N. et al. 2008). GSK3 have been shown to 
regulate PKBR1 activation (Teo, R. et al. 2010; Kölsch, V. et al. 2012). Thus, the aberrantly high levels of active PKBR1 present in psrA- cells could be due to the GSK3 hyperactivation. Surprisingly, when the levels of active GSK3 were reduced in $p s r A^{-}$ cells, higher levels of PKBR1 were observed indicating GSK3 negatively regulates PKBR1 activation in a B56 independent manner (Fig. 13). Determining B56 subcellular localization may help us further understand B56 function in PKBR1 adaptation.

\subsection{2 $\mathrm{psr}^{-}$cells exhibit abnormal cellular motility}

The role of B56 in cellular motility may be the result of aberrant regulation of PKBR1, which have been shown to be an essential regulator of chemotaxis in Dictyostelium cells (Cai, H. et al. 2010). In the absence of B56, PKBR1 adaptation was compromised resulting in the higher basal levels of active PKBR1 and persistent phosphorylation of PKBR1 substrates (Fig. 10A and B). Sca1, was suggested to be regulated by PKBR1 phosphorylation resulting in reduce Sca1-mediated RasC activation (Charest, P. et al. 2010). Increased levels of active PKBR1 in psr $A^{-}$cells may result in increased levels of phosphorylated Scal and subsequently resulting in reduced RasC activation. This possibility is supported by the defective levels of activated RasC observed in $p s r A^{-}$cells (Fig. 9B). The cellular adhesion regulator, Talin, was also shown to be regulated by PKBR1 phosphorylation (Kamimura, Y. et al. 2008). In the absence of B56, the misregulation of Talin phosphorylation, due to high basal levels of active PKBR1, may result in abnormal adhesion regulation affecting cellular migration. B56mediated regulation of focal adhesions have been previously reported in mammalian cells, but in these case paxillin, another adhesion regulator, was the target of B56 (Ito, A. 
et al. 2000). It would be interesting to determine if paxillin function is also affected by B56 in Dictyostelium cells.

\subsubsection{RasD regulates PKBR1 activation}

Previously, PKBR1 activation has been reported to be regulated by $\mathrm{RasC}$ in response to cAMP stimulation (Cai, H. et al. 2010). Cells lacking RasC exhibited reduced levels of active PKBR1 compared to $W t$ cells. Considering that PKBR1 activation was not completely abolished in $\operatorname{ras} C^{-}$cells, there must be additional activators of PKBR1, possibly other Ras proteins (Kae, H. et al. 2004; Cai, H. et al. 2010).

RasD may regulate PKBR1 activation similarly to RasC. PKBR1 activation in response to cAMP is slightly reduced in ras $^{-}$cells by approximately $40 \%$ suggesting it may also regulate PKBR1 activation (Fig. 11C). Overexpression of $\operatorname{RasD}(\mathrm{G} 12 \mathrm{~T})$ similarly resulted in higher levels of active PKBR1. Interestingly, RasD(G12T) stimulated the activation of PKBA at a greater extent in $p s r A^{-}$cells compared to RasC(G13T). This suggests that RasD can activate both PKBR1 and PKBA. Additionally, RasD was found to interact with PKBA in vitro forming a signaling complex (Bandala-Sanchez, E. et al. 2006).

RasD also plays an essential role in Dictyostelium development (Reymond, C.D. et al. 1986; Louis, S.A., et al. 1997). During development, aggregating cells differentiate into two major types of cells, pre-stalk and pre-spores cells, which are the precursors of the stalk and spores cells, respectively (Chisholm, R.L. and Firtel, R.A. 2004). The overexpression of $\operatorname{RasD}(\mathrm{G} 12 \mathrm{~T})$ resulted in increased expression of pre-stalk cell markers, $e c m A$ and $e c m B$ and reduced expression of pre-spore cell marker $\cot C$ suggesting RasD may promote pre-stalk differentiation and inhibit prespore differentiation (Louis, S.A., et 
al. 1997). Similarly, PKBR1 regulates cell differentiation in Dictyostelium cells; $p k b r 1^{-}$ cells failed to developed efficiently possibly due to reduced expression of pre-stalk- and pre-spore-specific markers (Meili, R. et al. 1999; Ochiai, H., et al. 2011). It is likely that RasD affect differentiation through PKBR1. Furthermore, B56 may also affect Dictyostelium cell differentiation through both PKBR1 and GSK3.

\subsubsection{GSK3 regulates PKBR1 regulation}

Previous studies have shown GSK3 plays a role in PKBR1 regulation; gsk3- cells exhibit undetectable level of active PKBR1 in response to cAMP stimulation (Teo, R. et al. 2010; Fig. 12B) which is in conflict with previous observations reported by Kölsch, V. et al. 2012. These results suggest GSK3 have a positive role in PKBR1 activation. However, when the levels of active GSK3 are reduced in cells, either by the expression of GSK3DN or by treating cells with $\mathrm{LiCl}$, higher basal levels of phosphorylated PKBR1 on the AL site were observed. Furthermore, the effect of GSK3DN or LiCl on PKBR1 activation requires Ras proteins. The overexpression of GSK3DN on $\operatorname{ras}^{-}$cells showed comparable levels of active PKBR1 compared to ras $D^{-}$cells, in contrast to $\mathrm{psrA}^{-}$or $W t$ cells, which exhibited higher basal levels of active PKBR1 upon GSK3DN overexpression. Similarly, $\mathrm{LiCl}$ treatments on either $\operatorname{ras}^{-}$or $\operatorname{ras}^{-}$cells showed no significant difference among the levels of phosphorylated PKBR1 between treated and non-treated cells. Altogether, these results provide evidence of a novel mechanism of PKBR1 adaptation; GSK3 negatively regulates PKBR1 activity in a Ras dependent mechanism (Fig. 13). 


\subsection{Figures}

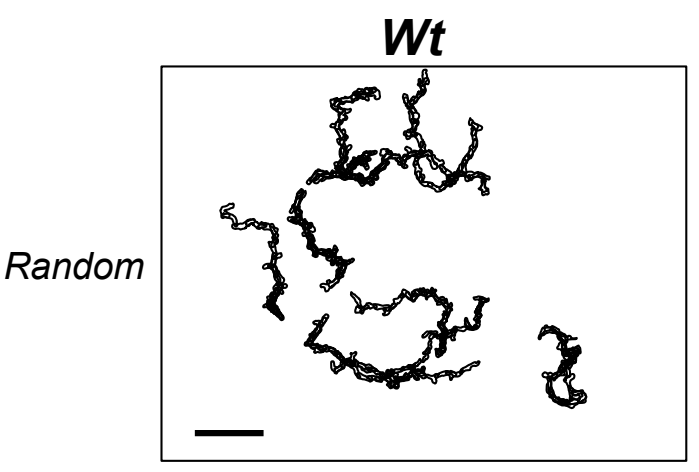

Speed: $9.6 \mu \mathrm{m} / \mathrm{min} \pm 1.7$

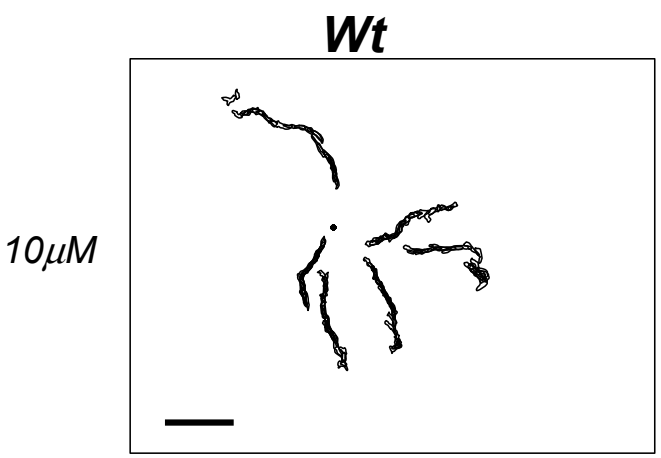

$\mathrm{Cl}: 0.8+0.1$

Speed: $8.4 \mu \mathrm{m} / \mathrm{min}+2.0$

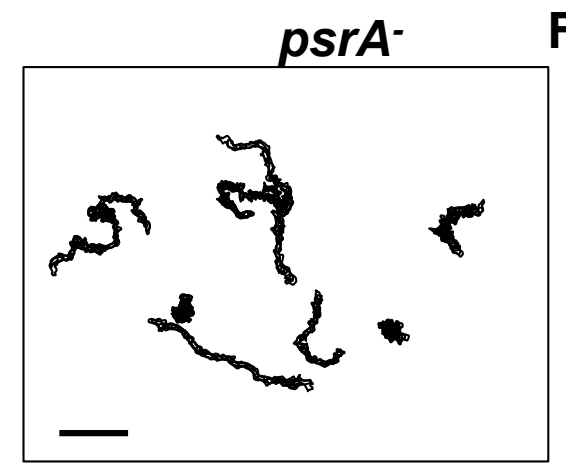

$5.4 \mu \mathrm{m} / \mathrm{min} \pm 2.1$

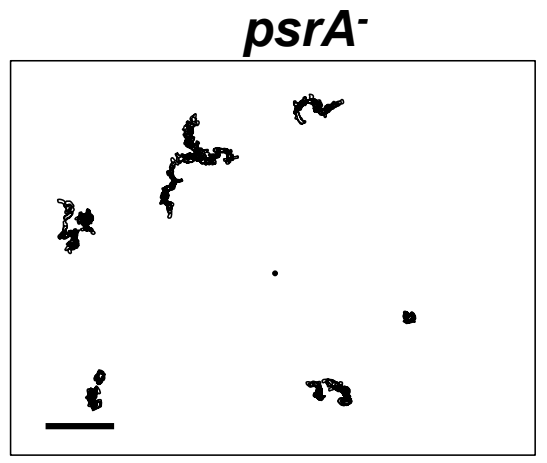

$\mathrm{Cl}: 0.4 \pm 0.4$

Speed: $2.7 \mu \mathrm{m} / \mathrm{min} \pm 1.0$

Fig 8

Figure $8 p s r A^{-}$cells have aberrant motility compared to $W t$ cells.

In the absence of an external chemotactic gradient, $p s r A^{-}$cells had in average lower velocities than $W t$ cells. Similarly, when exposed to an external chemotactic gradient $\left(10 \mu \mathrm{M}\right.$ cAMP), $p s r A^{-}$cells exhibited lower velocities compared to $W t$ cells. When the chemotactic index (CI) of $p s r A^{-}$cells was examined, as expected, $p s r A^{-}$cells had lower directionality in the presence of a cAMP gradient compared to $W t$ cells. 


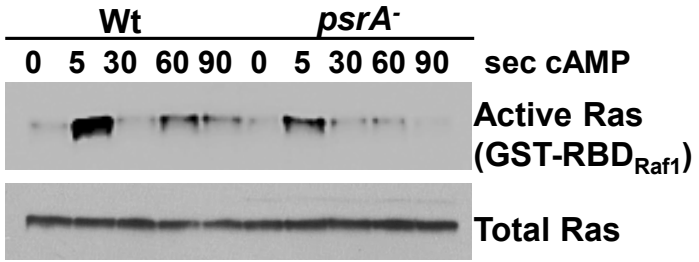

a-Pan-Ras

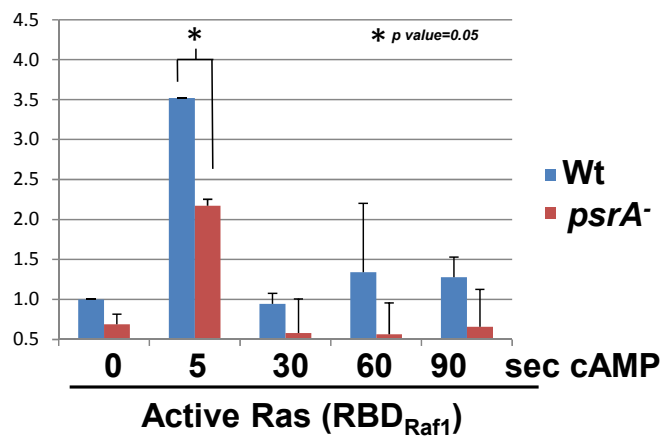

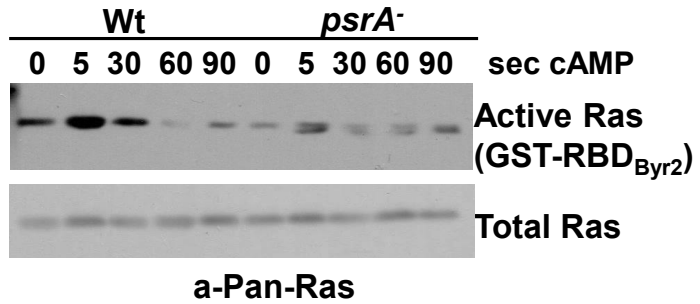

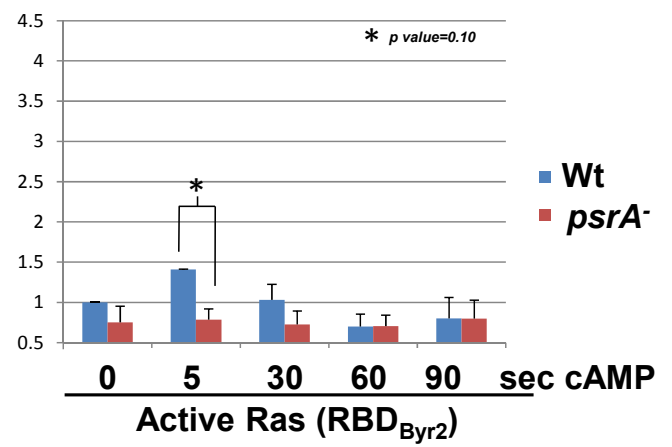

Figure 9. RasG, D and C activation in response to cAMP stimulation is defective in $\operatorname{psr} A^{-}$cells.

(A) $p s r A^{-}$cells have defective RasD and RasG activation. The levels of active RasD and

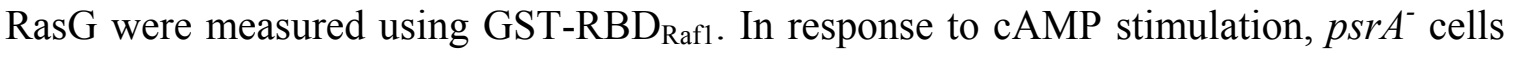
have lower levels of active Ras compared to $W t$ cells. Bar graph represents quantification of PKBR1 activation (mean + standard deviation) of two independent experiments that were obtained using UN-SCAN-IT gel software. (B) psr $A^{-}$cells have defective RasC activation. Cell extracts from $W t$ and $p s r A^{-}$cells were incubated with purified GST-RBD Byr2. Similar to RasD and RasG, RasC activation seems to be compromised in $p s r A^{-}$cells compared to $W t$ cells. Bar graph represents a quantification of PKBR1 activation (mean \pm standard deviation) of two independent experiments that were obtained using UN-SCANIT gel software. 
A

Fig 10

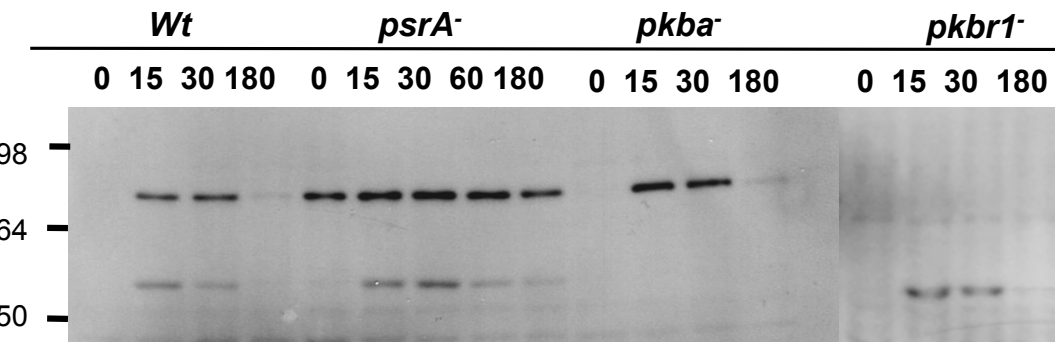

sec cAMP

PKBR1(TP309)

(AL site)

PKBA(Tp278)

(AL site)

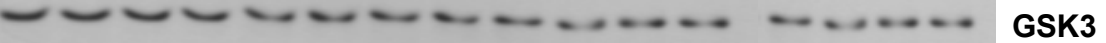

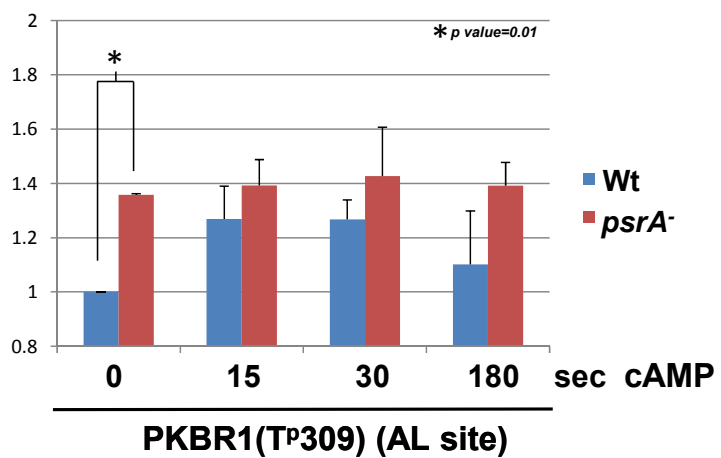

B
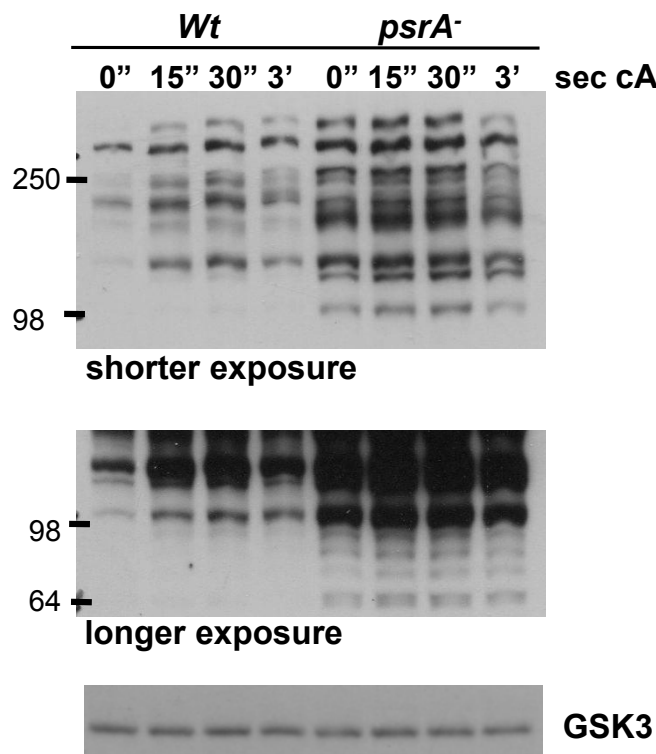
C
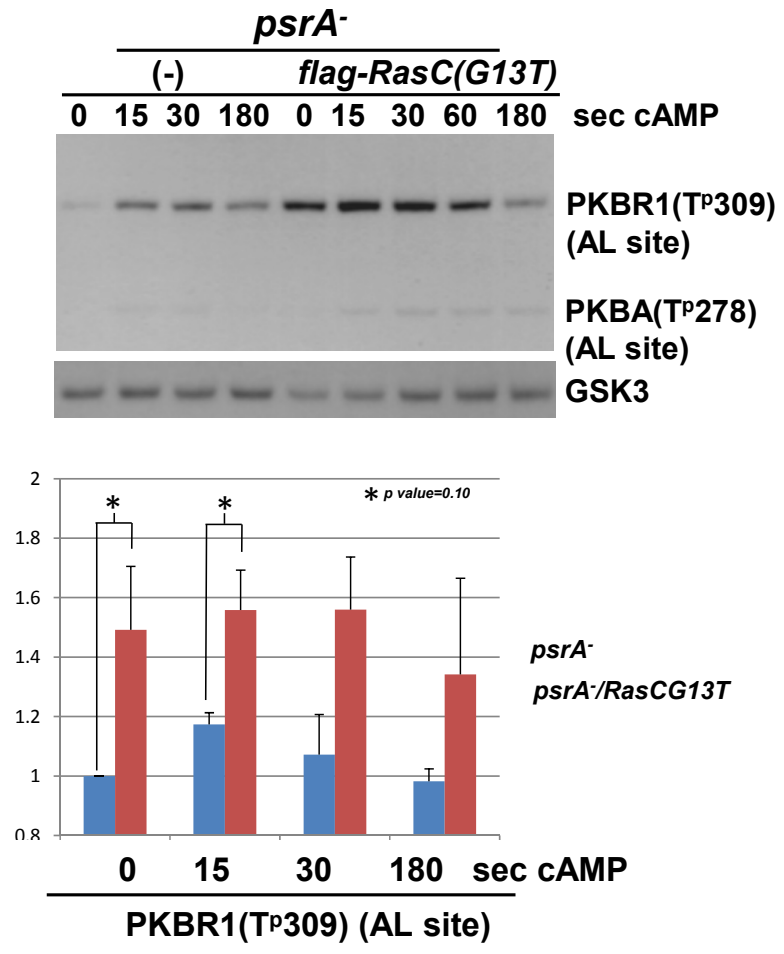
D
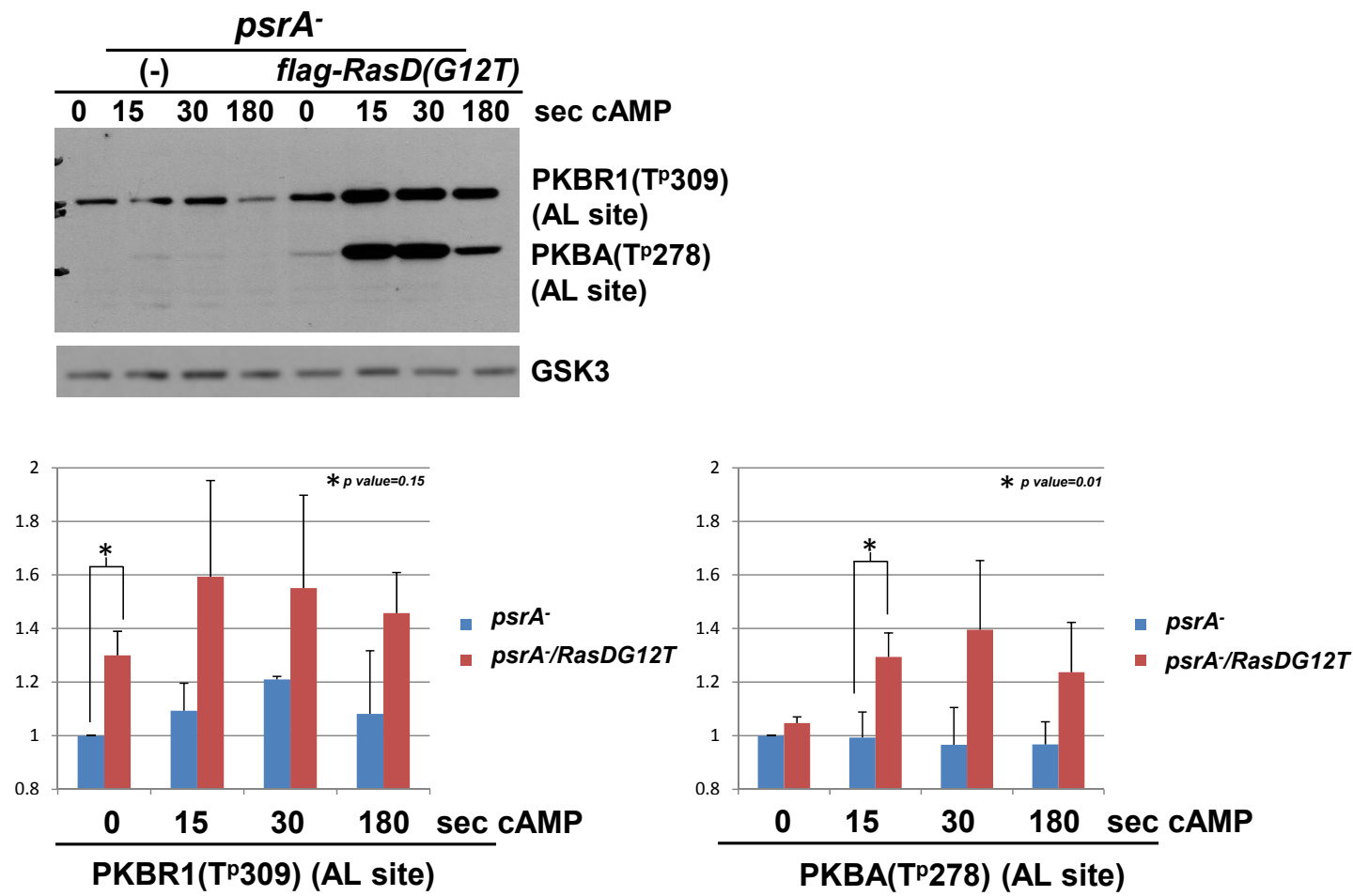

\section{Figure 10. $p s r A^{-}$cells aberrantly high levels of active PKBR1}

(A) PKBR1 and PKBA phosphorylation at the AL site was detected using anti-PhosphoPKC antibody (Cell Signaling 190D10). The absence of bands in $p k b a^{-}$and $p k b r l^{-}$cells confirmed that the antibody specifically detects phosphorylated PKBR1 and PKBA. Compared to $W t$ cells, $p s r A^{-}$cells exhibited abnormally high basal levels of phosphorylated PKBR1 at the AL site, and prolonged post-stimulus PKBR1 and PKBA phosphorylation. Bar graph represents a quantification of PKBR1 activation (mean \pm standard deviation) of three independent experiments that were obtained using UNSCAN-IT gel software. (B)Phosphorylation levels of PKBR1 substrates are significant higher in $p s r A^{-}$cells than that of $W t$ cells. The phosphorylation of PKBR1 substrates containing the motif R-X-R-X-X-S/T-X-X (Kamimura, Y. et al. 2008) was detected 
using the anti-Phospho Akt Substrate (Cell Signaling). Compared to $W t$ cells, $p s r A^{-}$cells have higher phosphorylation levels of PKBR1 substrates. (C) Overexpression of the constitutively active form of RasC (flag-RasCG13T) increased PKBR1 activation in $p s r A^{-}$cells. Bar graph shown was obtained with UN-SCAN-IT gel software and it represents the quantification of PKBR1 activation (mean + standard deviation) of three independent experiments. (D) Over-expressing flag-RasD(G12T) in $p s r A^{-}$cells resulted in higher PKBR1 and PKBA phosphorylation compared to $p s r A^{-}$cells, suggesting RasD stimulates PKBR1 and PKBA activation. Bar graphs shown were obtained with UNSCAN-IT gel software and represent the quantification of PKBR1 activation (mean \pm standard deviation) and PKBA activation of two independent experiments.

A
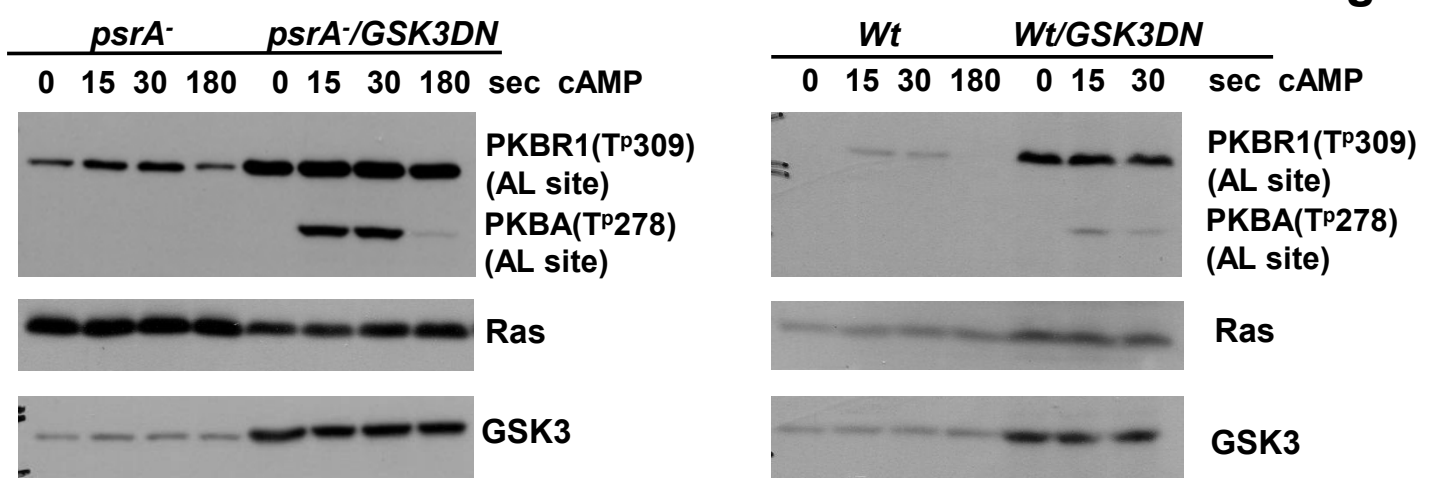

Ras
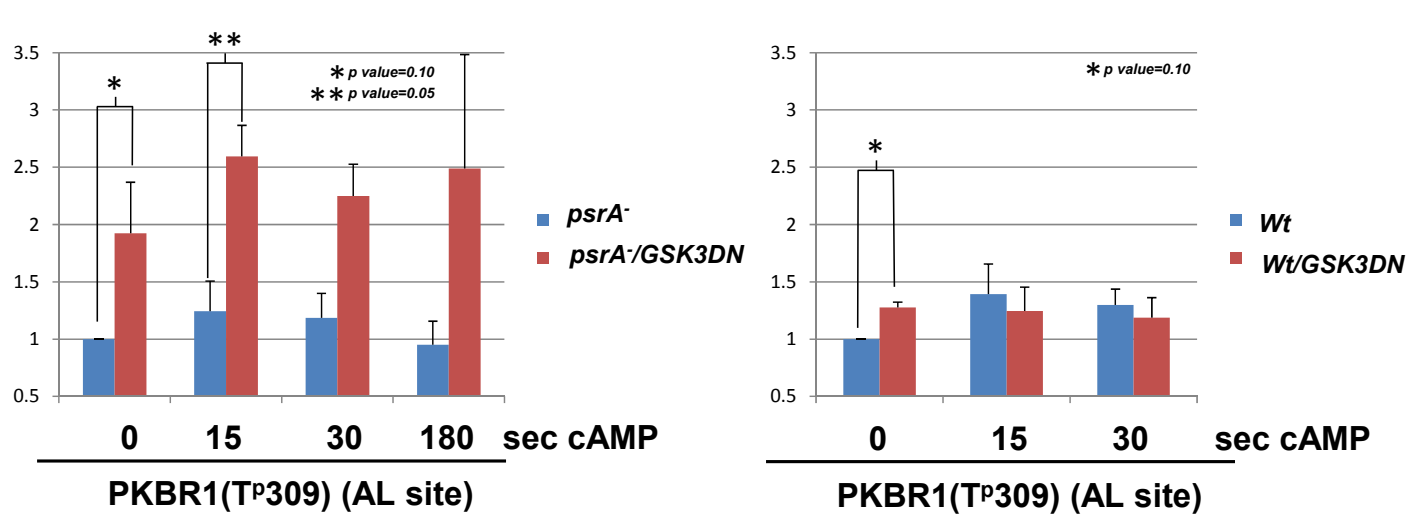
B

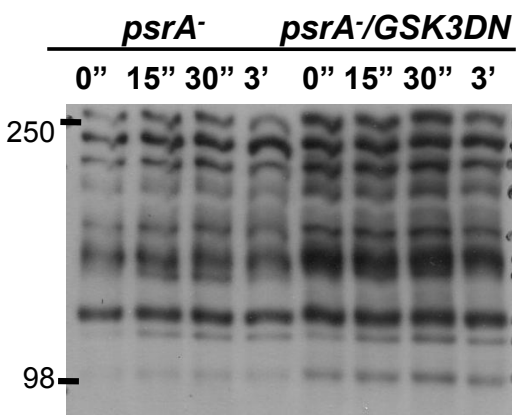

sec CAMP

shorter exposure

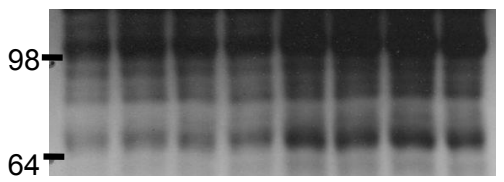

longer exposure
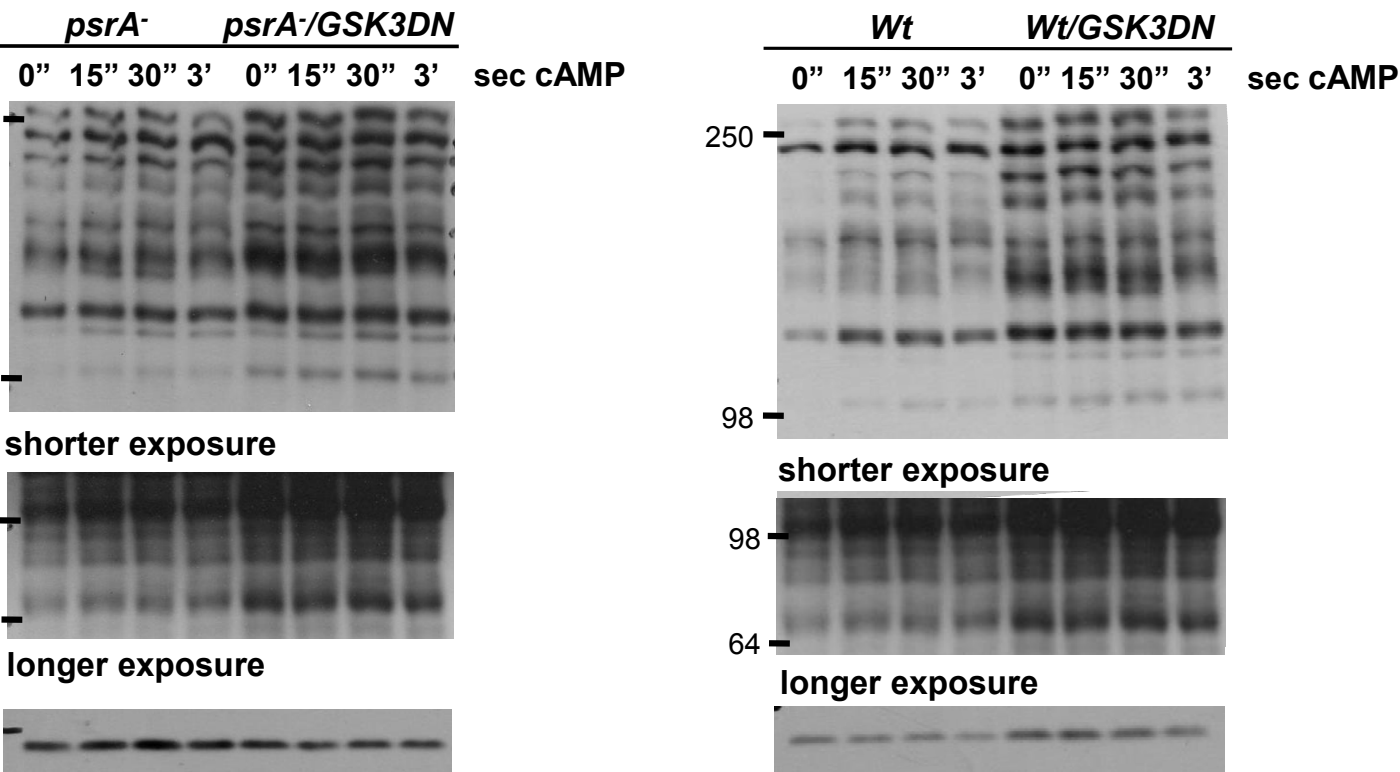

C

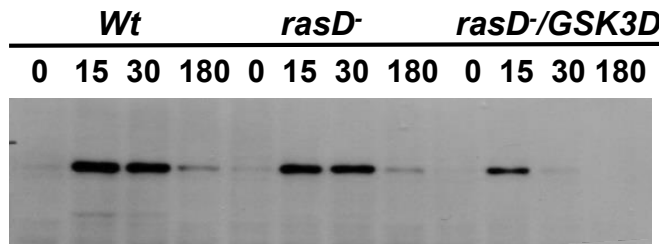

sec CAMP

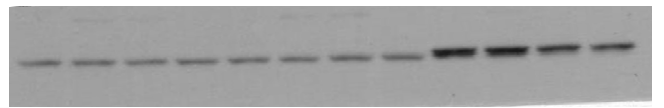

PKBR1(Tp309)

PKBA(TP278)

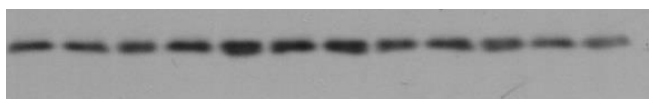

Ras

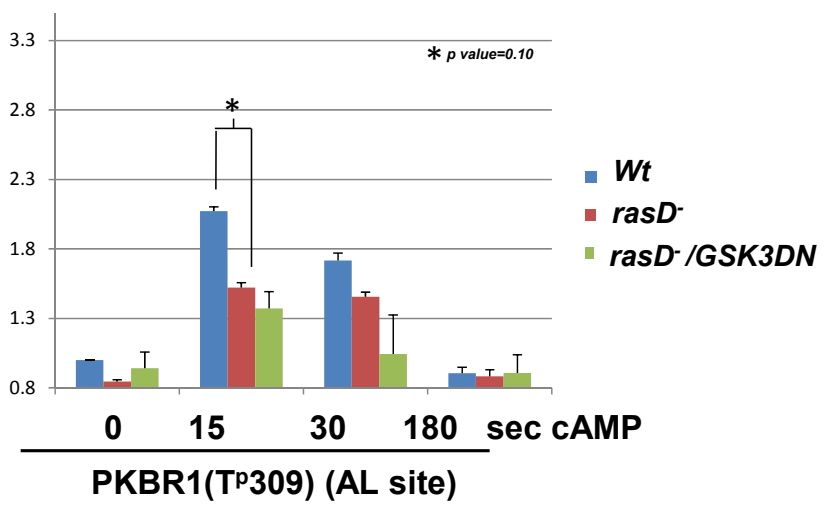

Figure 11. GSK3 negatively affects PKBR1 activity. 
(A) The overexpression of GSK3DN in $p s r A^{-}$and $W t$ cells resulted in higher levels of PKBR1 phosphorylation. These results suggest that GSK3 has a negative role in PKBR1 activation. Bar graph was obtained using UN-SCAN-IT gel software and they represent the quantification of PKBR1 activation (mean \pm standard deviation) of three independent experiments. (B) $p s r A^{-}$cells and $W t$ cells expressing GSK3DN displayed higher levels of PKBR1 substrate phosphorylation than that in the parental background. (C) The overexpression of GSK3DN in ras $D^{-}$cells did not increased PKBR1 activation in these cells suggesting GSK3-mediated inhibition of PKBR1 activation depends on RasD. Bar graphs shown were obtained with UN-SCAN-IT gel software and represent the quantification of PKBR1 activation (mean + standard deviation) and PKBA activation of two independent experiments.

A

Fig 12
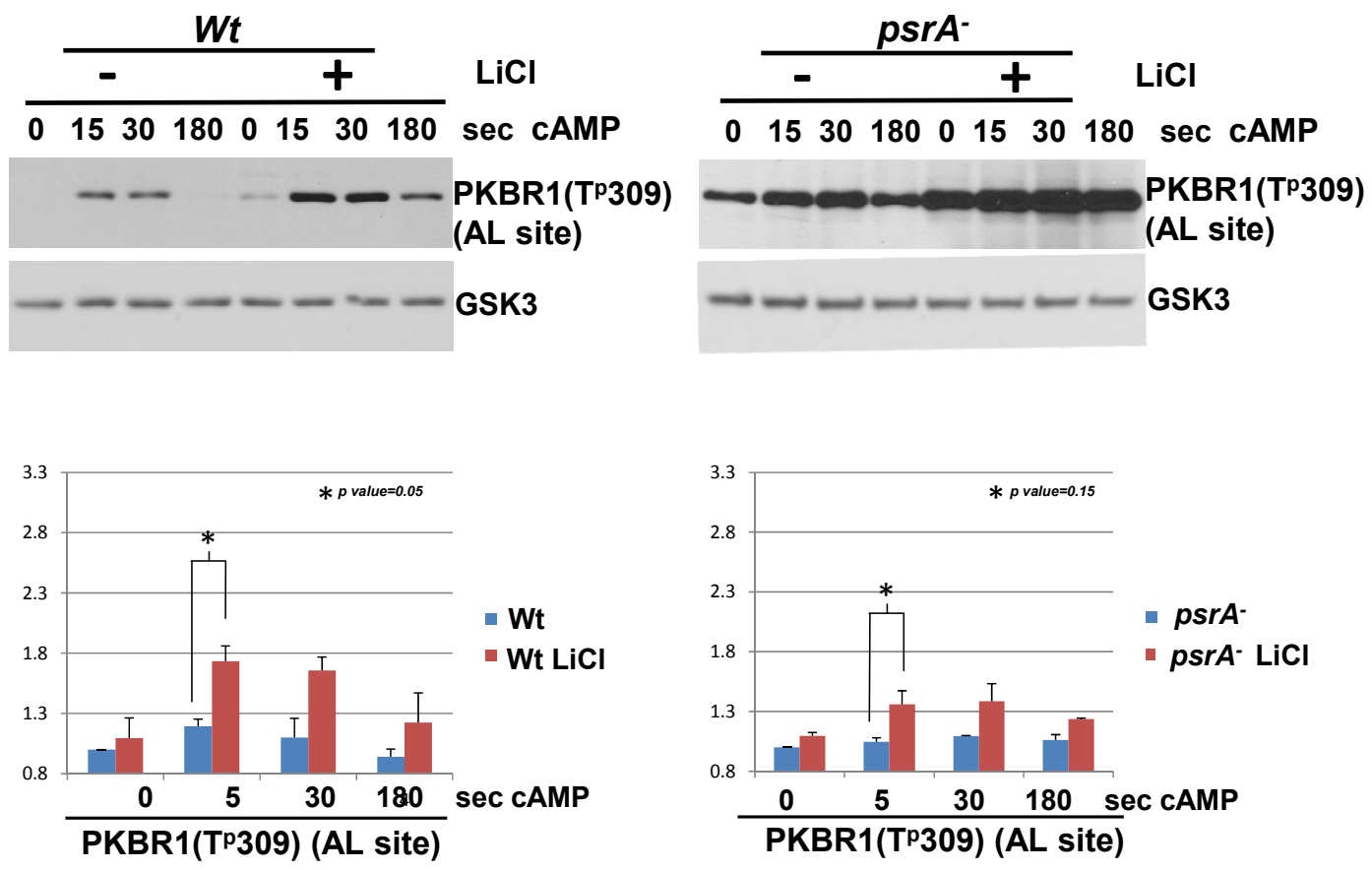
B
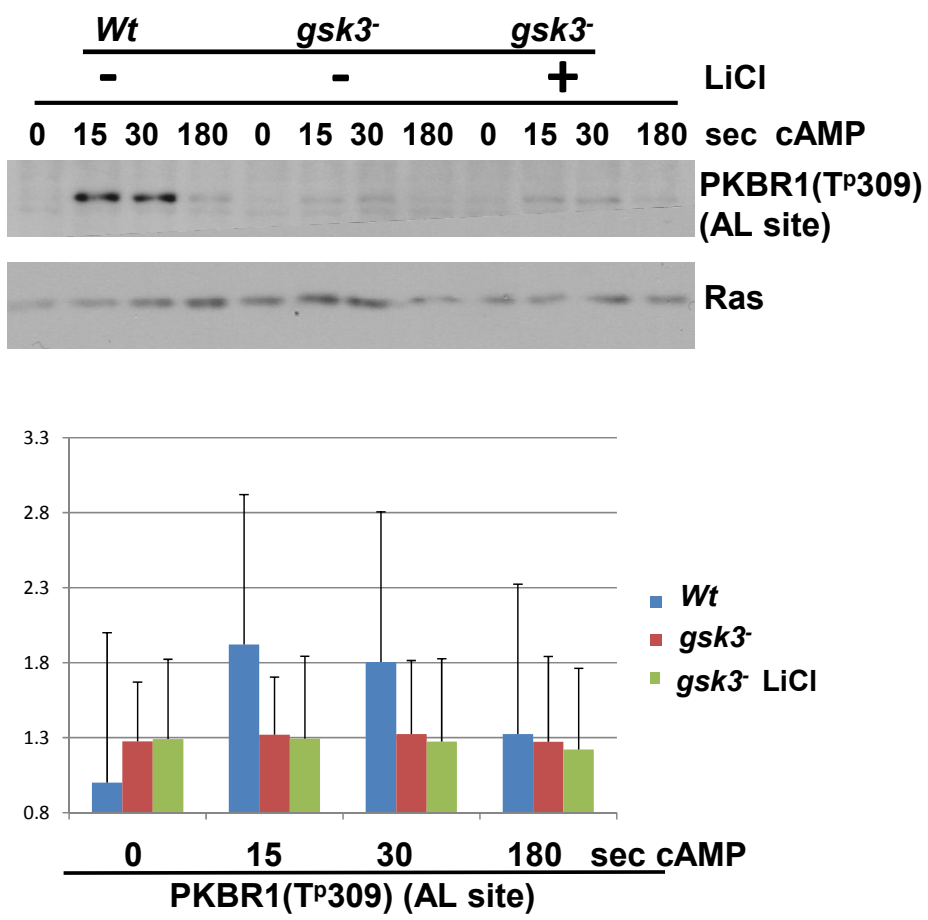

C
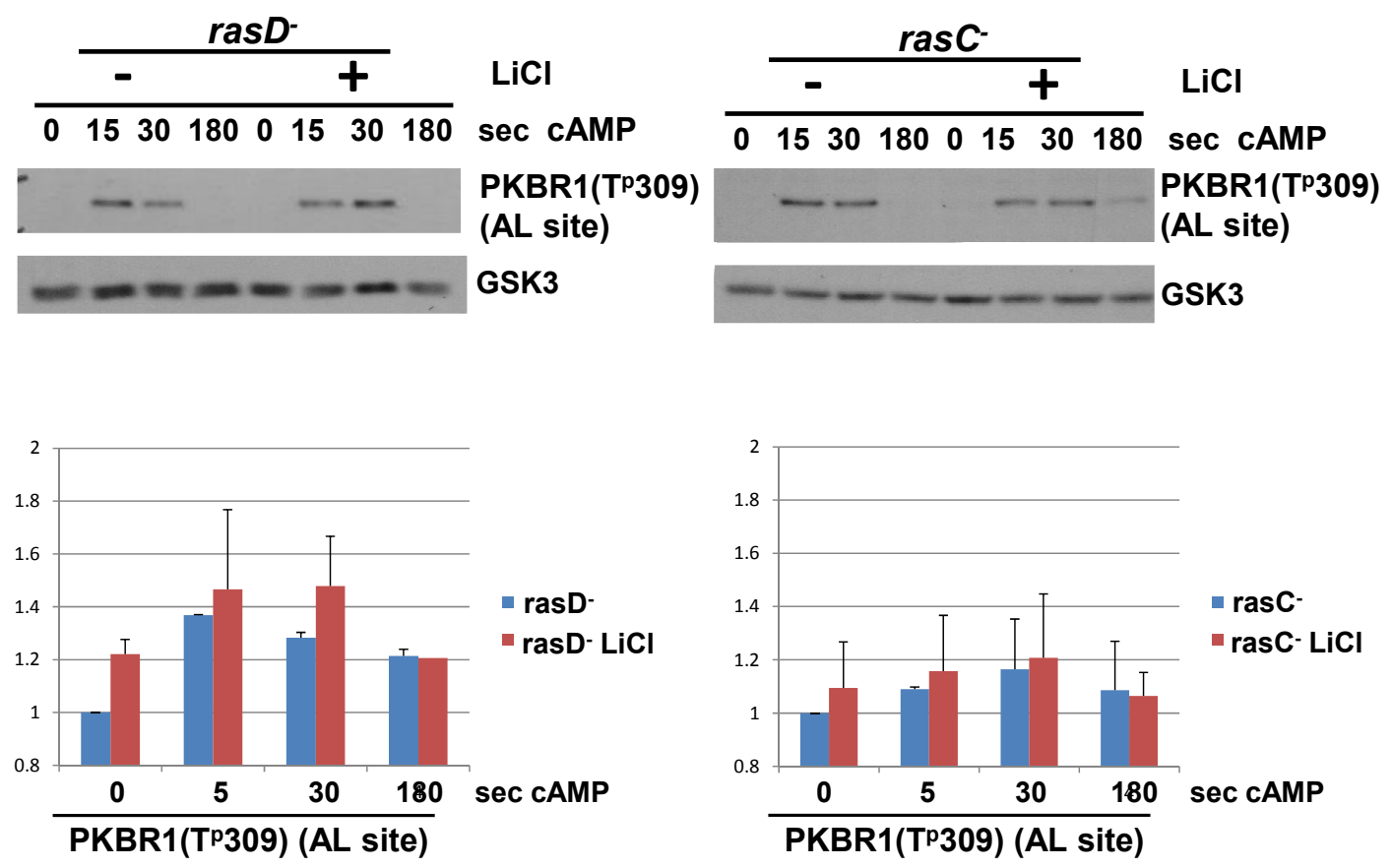

Figure 12. Lithium chloride ( $\mathrm{LiCl})$ treatments to cells results in increased PKBR1 activation 
(A) Cells treated with GSK3 inhibitor, $\mathrm{LiCl}$, showed increased PKBR1 activation compared to untreated cells. $\mathrm{LiCl}$ mediated effects on PKBR1 activation are comparable with those of GSK3DN. Bar graph was obtained using UN-SCAN-IT gel software and they represent the quantification of PKBR1 activation (mean \pm standard deviation) in response to cAMP stimulation of two independent experiments. Bar graphs shown were obtained with UN-SCAN-IT gel software and represent the quantification of PKBR1 activation (mean $\underline{+}$ standard deviation) of two independent experiments. (B) $\mathrm{LiCl}$ effect on PKBR1 activation requires GSK3. The effect of $\mathrm{LiCl}$ treatment in PKBR1 activation was absent in $g s k 3^{-}$cells. Bar graphs shown were obtained with UN-SCAN-IT gel software and represent the quantification of PKBR1 activation (mean + standard deviation) and PKBA activation of two independent experiments. (C) $\mathrm{LiCl}$ effect on PKBR1 activation requires Ras proteins. When $\operatorname{ras}^{-}$or $\mathrm{rasC}^{-}$cells were treated with $\mathrm{LiCl}$, there was no significant increase in increase of PKBR1 activation compared to that of the non-treated cells. These results suggest Ras proteins mediate GSK3 regulation of PKBR1. Bar graphs shown were obtained with UN-SCAN-IT gel software and represent the quantification of PKBR1 activation (mean $\underline{+}$ standard deviation) and PKBA activation of two independent experiments. 
Fig 13

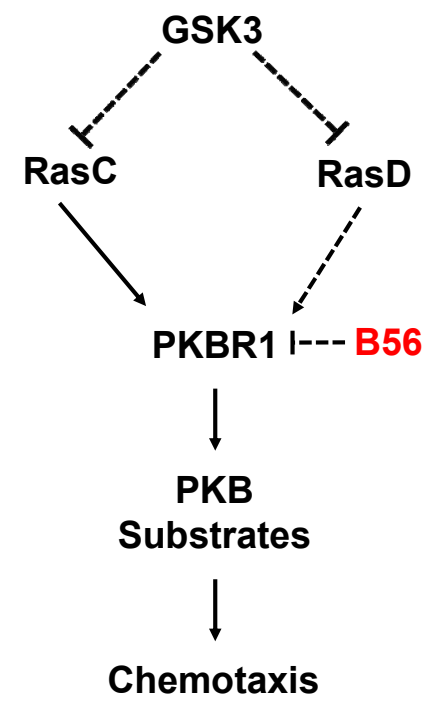

Figure 13. B56 and GSK3 regulate PKBR1 adaptation and chemotaxis.

PKBR1 adaptation is mediated by at least two mechanisms, one by B56 and another one through GSK3. 


\subsection{References}

Bandala-Sanchez, E., Annesley, S.J. and Fisher, P.R. 2006 A phototaxis signaling complex in Dictyostelium discoideum. European Journal of Cell Biology, Vol. 85, pp1099-1106

Cai, H., Das, S., Kamimura, Y., Long, Y., Parent, C., and Devereotes, P. 2010 Ras mediated activation of the TORC2-PKB pathway is critical for chemotaxis. JCB Vol. 190 No. 2, p233-245

Charest, P. G. and Firtel, R. A. 2007, Big roles for small GTPases in the control of directed cell movement. Biochem. J. Vol. 401:377-390

Charest, P., Shen, Z., Lakoduk, A., Sasaki, A., Briggs, S. and Firtel, R. 2010 A Ras signaling complex controls the RasC-TORC2 pathway and directed cell migration. Developmental Cell, Vol. 18, p737-749

Chisholm, R. and Firtel, R., 2004, Insights into Morphogenesis from a simple developmental system. Nature Reviews, 5:531-541

Harwood, A.J., Plyte, S.E., Woodgett, J., Strutt, H. and Kay, R.R. 1995 Glycogen Synthase Kinase 3 regulates cell fate in Dictyostelium. Cell, Vol. 80, p 139-148

Ito, A., Kataoka, T., Watanabe, M., Nishiyama, K., Mazaki, Y., Sabe, H., Kitamura, Y. and Nojima, H. 2000 A truncated isoform of the PP2A B56 subunit promotes cell motility through paxillin phosphorylation. The EMBO Journal, Vol. 19, pp562-571

Janetopoulos, C., Jin, T., and Devreotes, P. 2001. Receptor-mediated activation of heterotrimeric G-proteins in living cells. Science, Vol. 291:2408-2411

Janssens, V. and Goris, J. 2001. Protein phosphatase 2A: a highly regulated family of serine/threonine phosphatases implicated in cell growth and signaling.

Kae, H., Lim, C., J., Spiegelman, G. and Weeks, G. 2004 Chemoattractant-induced Ras activation during Dictyostelium aggregation. EMBO Reports Vol 5/No. 6 p602-606

Kamimura, Y., Xiong, Y., Iglesias, P., Hoeller, O., Bolourani, P., and Devereotes, P. 2008 PIP3-Indepenent Activation of TorC2 and PKB at the Cell's Leading Edge Mediates Chemotaxis. Current Biology Vol. 18, p1034-1043

Kamimura, Y. and Devreotes P.N. 2010 Phosphoinositide-dependent Protein Kinase (PDK) activity regulates phosphatidylinositol 3,4,5-triphosphate-dependent and independent Protein Kinase B activation and chemotaxis. The Journal of Biological Chemistry and Molecular Biology, Vol. 285, pp7938-7946. 
Khosla,M., Spegelman, G.B., Insall, R. and Weeks, G. 2000. Functional overlap of the Dictyoselium RasG, RasD and RasB proteins. Journal of Cell Science, Vol. 113, pp14271434

Kim, L. and Kimmel, A. 2000. GSK3, a master switch regulating cell-fate specification and tumorigenesis. Current Opinion in Genetics \& Development, Vol. 10 pp508-514

Kim, L., Harwood, A. and Kimmel, A. 2002. Receptor-dependent and tyrosine phosphatase-mediated inhibition of GSK3 regulates cell fate choice. Developmental Cell, Vol. 3 pp523-532

Kölsh, V., Shen, V., Lee, S., Plak, K., Lotfi, P., Chang, J., Charest, P., Lacal-Romero, J., Jeon, T., Kortholt, A., Briggs, S. and Firtel, R. 2012. Daydreamer, a Ras effector and GSK3 substrate, is important for directional sensing and cell motility. Cell and Developmental Biology, Vol. 24, pp100-114

Kortholt, A. and van Haastert, P. J.M 2008. Highlighting the role of Ras and Rap during Dictyostelium chemotaxis. Cellular Signaling, Vol. 20, pp1415-1422

Lee, Nam-Sihk., Veeranki, S., Kim, B. and Kim, L. 2008 The function of PP2A/B56 in non-metazoan multicellular development. Differentiation Vol. 76, p1104-1110

Liao, X., Buggey, J. and Kimmel, A.R. 2010 Chemotactic activation of Dictyostelium AGC-family kinases AKT and PKBR1 requires separate but coordinated function of PDK1 and TORC2. Journal of Cell Science, Vol. 123, pp983-992

Loovers, H.M., Postma, M., Keizer-Gunnink, I., Huang, Y.E., Devreotes, P.N. and van Haastert, P.J.M. 2006 Distinct Roles of PI(3,4,5) $\mathrm{P}_{3}$ during chemoattractant signaling in Dictyostlelium: a quantitative in vivo analysis by inhibition of PI3-Kinase. Molecular Biology of the Cell, Vol. 17, pp1503-1513

Louis, S.A., Spiegelman, G.B. and Weeks, G. 1997. Expression of an activated rasD gene changes cell fate decisions during Dictyostelium development. Molecular Biology of the Cell, Vol. 8, pp303-312

Meili, R., Ellsworth, C., Lee, S., Reddy, T.B.K., Ma, H., and Firtel, R. 1999 Chemoatractant-mediated transient activation and membrane localization of Akt/PKB is required for efficient chemotaxis to cAMP in Dictyostelium. The EMBO Journal Vol. 18 No. 8 pp.2092-2105

Meili, R., Ellsworth, C. and Firtel, R. 2000 A novel Akt/PKB-related kinase is essential for morphogenesis in Dictyostelium. Current Biology, Vol. 10, pp708-717

Müller-Taubenberger, A., Kortholt, A. and Eichinger, L. 2013 Simple system substantial share: The use of Dictyostelium in cell biology and molecular medicine. European Journal of Cell Biology, Vol. 92, P45-53 
Ochiai, H., Takeda, K., Fukuzawa, M., Kato, A., Takiya, S. and Ohmachi, T. 2011. Protein Kinase B gene homologue $p k b R l$ performs one of its roles at first finger stage on Dictyostelium. Eukaryotic Cell, Vol. 10, pp512-52

Padmanabhan, S., Mukhopadhyay, A., Narasimhan, S.D., Tesz, G., Czech, M.P. and Tissenbaum, H.A. 2009. A PP2A regulatory subunit regulates $C$. elegans Insulin/IGF-1 signaling by modulating Akt-1 phosphorylation. Cell, Vol. 136, pp939-951

Reymond, C.D., Gomer, R.H., Nellen, W., Theibert, A., Devreotes, P. and Firtel, R. 1986 Phenotypic changes induced by a mutated ras gene during the development of Dictyostelium transformants. Nature, Vol, 323, pp340-343

Sasaki, A., Chun, C., Takeda, K. and Firtel, R. 2004 Localized Ras signaling at the leading edge regulates PI3K, cell polarity, and directional cell movement. JCB Vol. 167, No. 3, p505-518

Schilde, C., Araki, T., Williams, H., Harwood, A. and Williams, J.G. 2004 GSK3 is a multifunctional regulator of Dictyostelium development. Development, Vol. 131, pp4555-4565

Swaney, K.F., Huang, C.H. and Devereotes, P. 2010 Eukaryotic chemotaxis: A network of signaling pathways control molity, directional sensing and polarity. Annu. Rev. Biophys. Vol. 39 p265-89

Sun, T., Kim, B. and Kim, L., 2013 Glycogen Synthase Kinase 3 influences cell motility and chemotaxis by regulating PI3K membrane localization in Dictyostelium. Develop. Growth Differentiation, Vol. 55, pp723-734

Teo, R., Lewis, K. J., Forde, J. E., Ryves, W.J., Reddy, J., Rogers, B. J., and Harwood, A., 2010 Glycogen Synthase Kinase-3 is required for efficient Dictyostelium chemotaxis. Molecular Biology of the Cell, Vol. 21, p2788-2796

Ueda, M., Sako, Y., Tanaka, T., Devreotes, P., and Yanagida, T. 2001. Single-molecule analysis in Dictyostelium cells. Science, Vol. 294:864-867

Veeranki, S., Kim, B. and Kim, L. 2008 The GPI anchored superoxide dismutase SodC is essential for regulating basal Ras activity and for chemotaxis of Dictyostelium discoideum. Journal of Cell Science, Vol. 121, pp3099-3108

Yan, J. and Jin, T. 2012 Signaling network from GPCR to the actin cytoskeleton during chemotaxis. BioArchitecture, Vol. 2, issue 1 p15-18 


\section{CHAPTER 4: DISCUSSION}

Signaling adaptation plays an essential role in the regulation of many signaling pathways. During directional motility, cells sense the chemoattractant gradient and bias their motility toward such a gradient. In Dictyostelium, adaptation allows cells to rapidly respond to changes in the environment by regulating the activation/deactivation of key regulators of motility. Cells in which some of the negative regulators are missing, for instance in $\mathrm{mpll}^{-}$or in $\mathrm{psrA}^{-}$cells, exhibit aberrant cellular migration due to hyperactivation of many signaling pathways including cAMP relay and cell polarization.

\subsection{MPL1 plays an essential role in ERK2 adaptation}

To regulate cAMP relay in Dictyostelium, cells use an orchestrated activation/deactivation of proteins, stimulating cAMP synthesis followed by cAMP degradation. These periodic activations and deactivations of the cAMP synthesis originate pulsing waves of cAMP that spread through the area resulting in the synchronization of the signaling pathways of nearby cells (Chisholm, R. and Firtel, R., 2004; Brzostowski, J. and Kimmel, A. 2006; Brzostowski, J. et al. 2013). It has been shown that ERK2 plays an essential role regulating the intracellular cAMP levels; ERK2 was proposed to inhibit RegA resulting in the cytosolic accumulation of cAMP and the activation of cAMP-dependent proteins, such as PKA (Madea, M. et al. 1995; Madea, M. et al. 2004). The misregulation of ERK2 results in compromised cAMP relay and directional motility (Brzostowski, J. and Kimmel, A. 2006; Brzostowski, J. et al. 2013).

The adaptation of ERK2 is not fully understood. The cAMP dependent protein, PKA, was suggested to negatively regulate ERK2 activation through a negative feedback 
mechanism (Laub,M.T. and Loomis, W. 1998; Madea, M. et al. 2004); however, ERK2 was found to adapt in $a c a^{-}$cells, which fail to activate PKA as a result of deficient cAMP synthesis (Brzostowski, J. and Kimmel, A. 2006). Therefore, other negative regulators of ERK2 must exist besides PKA. Ablation of Mpll, a member of the DSP family of phosphatases in Dictyostelium cells, results in persistent ERK2 phosphorylation. Additionally, $\mathrm{mpl1}^{-}$cells exhibit higher levels of cytosolic cAMP accumulation and defective directional and random motility. Altogether, these results suggest MPL1 plays an essential role in ERK2 regulation.

The regulation of MPL1 activation is currently unknown. It would be interesting to determine if MPL1 phosphatase activity is either activated in response to cAMP stimulation or whether MPL1 is constitutively active and transiently inhibited in response to cAMP stimulation. Previous reports showed that ERK2 remains phosphorylated in conditions where the cAR1 receptor remains activated, either because of constant cAMP levels or to decreased cAR1 phosphorylation (Brzostowski, J. and Kimmel, A. 2006; Brzostowski, J. et al. 2013). Examining MPL1 activity in these conditions can help us understand further ERK2 adaptation. Additionally, two other MPL1-like proteins exits in Dictyostelium; however, it is not known whether they play any role in the ERK2 adaptation, but if so, it may be a minor one considering the overexpression of MPL1 restored ERK2 adaptation in in $\mathrm{mpll}^{-}$cells similarly than $W t$. cells. Altogether, MPL1 role in ERK2 adaptation provides valuable insight regarding the adaptation mechanisms regulating Dictyostelium motility. 


\subsection{The PP2A regulatory subunit, B56, and GSK3 play an essential role in PKBR1 adaptation.}

Cellular polarization requires the localized activation of many signaling pathways. Ras proteins regulates the activation of members of the AGC protein kinase family, PKBA and PKBR1, which in turn regulate the activation of many cytoskeleton regulators, including Talin and PAKa (Chung, C. et al. 2001; Kamimura, Y. et al. 2008; Charest, P. et al. 2010). Similar to other members of the AGC family of kinases, PKBA and PKBR1 activation requires two phosphorylation events, one at the HM site by the TorC2 complex and another one at the AL site by PDKA (Meili, R. et al. 1999; Kamimura, Y. et al. 2008; Kamimura, Y. et al. 2010; Liao, X. et al. 2010; Cai, H., et al. 2010). PKBA and PKBR1 adaptation has not been fully characterized. Recent evidence suggests PKBR1 adaptation can be regulated through a negative feedback mechanism involving the scaffolding subunit, Sca1; PKBR1 inhibits Sca1-mediated RasC activation and subsequently reduced RasC-mediated PKBR1 activation (Charest, P. et al. 2010). Here we have described two additional components of PKBR1 adaptation, the PP2A regulatory subunit, B56, and GSK3.

Cells lacking the regulatory subunit B56 exhibited high basal levels of PKBR1 phosphorylation, not PKBA, suggesting PKBR1 adaptation was defective in these cells. Additionally, $p r s A^{-}$cells had reduced Ras activation compared to $W t$ cells. The decreased Ras activation observed in $p r s A^{-}$cells supports the notion of the presence of a negative feedback mechanism in which PKBR1 inhibits Sca1-mediated Ras activation resulting in decreased PKBR1 activation. The mechanism by which B56 regulates PKBR1 adaptation is not known. Previously, the PP2A catalytic subunit was found to interact with the Sca1 
complex regulating Sca1-mediated RasC activation; Sca1 mutants lacking the region in which PP2A interacts with Scal failed to activate RasC suggesting PP2A is necessary for Sca1-mediated RasC activation (Charest, P. et al. 2010). The PP2A regulatory subunits have been shown to regulate the phosphatase activity, cellular localization, and/or substrate specificity of the PP2A complex (Janssens, V. and Goris, J. 2001; Cho, U. S. and Xu, W. 2006; Lee, N. et al. 2008; Virshup, D.M. and Shenolikar, S. 2009); in the absence of B56, the Scal complex may encounter localization problems. Determining the B56 cellular localization will help elucidate the mechanism of B56-mediated PKBR1 adaptation.

In addition to B56, GSK3 also plays an essential role in PKBR1 adaptation. Previous reports show conflicting evidence regarding GSK3 role in PKBR1 regulation (Teo, R. et al. 2010; Kölsh, V., et al. 2012; Chapter 3). Upon reduction in the levels of active GSK3, either by the overexpression of GSK3DN or by treating cells with the GSK3 inhibitor, $\mathrm{LiCl}$, resulted in higher basal levels of active PKBR1 suggesting GSK3 plays a negative role in PKBR1 adaptation. Additionally, inhibition of PKBR1 activity by GSK3 is mediated by Ras proteins. When GSK3DN was overexpressed in $r a s D^{-}$cells, no changes in the basal levels of phosphorylated PKBR1 were observed in contrast to $W t$ and $p s r A^{-}$cells overexpressing GSK3DN. Similarly, no high basal levels were observed when $\operatorname{ras} D^{-}$or $\operatorname{ras} C^{-}$cells were treated with $\mathrm{LiCl}$, whereas $\mathrm{LiCl}$ treated $W t$ and $p s r A^{-}$cells exhibited higher basal levels of phosphorylated PKBR1. These observations suggest that GSK3 negatively regulates PKBR1 activity through Ras proteins. This possibility is supported by recent evidence suggesting GSK3 negatively regulate Ras activation (Kölsh, V., et al. 2012; Sun, T. et al. 2013). 
Altogether, B56 and GSK3 provide valuable insight into the mechanisms regulating PKBR1 adaptation in Dictyostelium cells. B56, possibly regulating Sca1 localization, and GSK3, by inhibiting Ras activation, ensure PKBR1 is transiently activated in response to cAMP stimulation. In turn, transient PKBR1 activation regulates the cytoskeleton rearrangements needed for efficient cell polarization and migration. B56 negative regulation of AGC protein kinases have been previously reported in C. elegans and in differentiated 3T3-L1 adipocytes cells (Padmanabhan, S. et al. 2009) suggesting B56 mediated PKBR1 adaptation may be conserved among metazoans. Further analyses are needed to determine if GSK3 regulation of PKBR1 adaptation is present in other organisms. 


\subsection{References}

Brzostowski, J. and Kimmel, A. 2006, Nonadaptive Regulation of ERK2 in Dictyostelium: Implications for Mechanisms of cAMP Relay. Molecular Biologof the Cell, 17: 4220-4227.

Brzostowski, J. A., Sawai, S. Rozov, O., Liao, X., Imoto, D., Parent, C.A. and Kimmel, A. 2013 Phosphorylation of chemoattractant receptors regulates chemotaxis, actin reorganization and signal relay. Journal of Cell Science, Vol. 126, pp4614-4626

Cai, H., Das, S., Kamimura, Y., Long, Y., Parent, C., and Devreotes, P. 2010 Ras mediated activation of the TORC2-PKB pathway is critical for chemotaxis. JCB Vol. 190 No. 2, p233-245

Charest, P., Shen, Z., Lakoduk, A., Sasaki, A., Briggs, S. and Firtel, R. 2010 A Ras signaling complex controls the RasC-TORC2 pathway and directed cell migration. Developmental Cell, Vol. 18, p737-749

Chisholm, R. and Firtel, R., 2004, Insights Into Morphogenesis From a Simple Developmental System. Nature Reviews, 5:531-541

Cho, U. S. and Xu, W. 2006. Crystal structure of a protein phosphatase 2A heterotrimeric holoenzyme. Nature, Vol. 445(7123):53-57

Chung, C. Y., Potikyan, G. and Firtel, R. 2001 Control of cell polarity and chemotaxis by Akt/PKB and PI3 Kinase through the regulation of PAKa. Molecular Cell, Vol. 7, pp937947

Janssens, V. and Goris, J. 2001. Protein phosphatase 2A: a highly regulated family of serine/threonine phosphatases implicated in cell growth and signaling. Biochemical Journal, Vol. 353, pp417-439

Kamimura, Y., Xiong, Y., Iglesias, P., Hoeller, O., Bolourani, P. and Devreotes, P. 2008 PIP3-Independent activation of TORC2 and PKB at the cell's leading edge mediates chemotaxis. Current Biology, Vol. 18, p1034-1043

Kamimura, Y. and Devreotes P.N. 2010 Phosphoinositide-dependent Protein Kinase (PDK) activity regulates phosphatidylinositol 3,4,5-triphosphate-dependent and independent Protein Kinase B activation and chemotaxis. The Journal of Biological Chemistry and Molecular Biology, Vol. 285, pp7938-7946

Kölsh, V., Shen, V., Lee, S., Plak, K., Lotfi, P., Chang, J., Charest, P., Lacal-Romero, J., Jeon, T., Kortholt, A., Briggs, S. and Firtel, R. 2012. Daydreamer, a Ras effector and GSK3 substrate, is important for directional sensing and cell motility. Cell and Developmental Biology, Vol. 24, pp100-114 
Laub, M.T. and Loomis, W. 1998. Role of PKA in the Timing of Developmental Events in Dictyostelium Cells. Microbiology and Molecular Biology Reviews, 62:684-694

Maeda, M., Aubry, L., Insall, R., Gaskins, C., Devreotes, P.N. and Firtel, R. 1995 Seven Helix Chemoattractant receptors transiently stimulate mitogen activated protein kinase in Dictyostelium. The Journal of Biological Chemistry, Vol. 271, pp3351-3354

Madea, M., Lu, S., Shaulsky, G., Miyazaki, Y., Kuwayama, H., Tanaka, Y., Kuspa, A. and Loomis, W., 2004, Periodic Signaling Controlled by an Oscillatory Circuit That Includes Protein Kinases ERK2 and PKA. Science 304: 875-878

Padmanabhan, S., Mukhopadhyay, A., Narasimhan, S.D., Tesz, G., Czech, M.P. and Tissenbaum, H.A. 2009. A PP2A regulatory subunit regulates C. elegans Insulin/IGF-1 signaling by modulating Akt-1 phosphorylation. Cell, Vol. 136, pp939-951

Sun, T., Kim, B. and Kim, L., 2013 Glycogen Synthase Kinase 3 influences cell motility and chemotaxis by regulating PI3K membrane localization in Dictyostelium. Develop. Growth Differentiation, Vol. 55, pp723-734

Teo, R., Lewis, K., Forde, J.E., Ryves, W.J., Reddy, J.V., Rogers, B.J. and Harwood, A.J. 2010. Glycogen Synthase Kinase 3 is required for efficient Dictyostelium chemotaxis. Molecular Biology of the Cell, Vol. 21, pp. 2788-2796

Virshup, D. M. and Shenolikar, S. 2009. From promiscuity to precision: protein phosphatases get a makeover. Molecular Cell, Vol. 33(5):537-545 
VITA

\section{MARBELYS RODRIGUEZ}

Born, Habana, Cuba

2000-2005 B.S., Biology

Florida International University

Miami, Florida

2000-2005 Merit scholarship

2007-2012 MBRS RISE fellowship

2009 Best graduate student oral presentation

MBRS Symposium

\section{PUBLICATIONS AND PRESENTATIONS}

Rodriguez, M., Kim, B., Lee, N., Veeranki, S. and Kim, L. MPL1, the novel phosphatase with leucine rich repeats, is essential for proper ERK2 phosphorylation and cell motility. Eukaryotic Cell (2008) 958-966.

Lee NS, Kim B, Rodriguez, M., and Kim L. The Dictyostelium kinase DPYK3 negatively regulates STATc signaling in cell fate decision. Development, Growth, and Differentiation (2008) 50, 607-613

Biology Symposium 2008

Rodriguez, M., Kim, B., Lee, N., Veeranki, S. and Kim, L. MPL1: a Dual Specific Phosphatase with Leucine-rich Domains.

MBRS Symposium 2008

Rodriguez, M., Kim, B., Lee, N., Veeranki, S., and Kim, L. MPL1 is essential for proper ERK2 phosphorylation and motility in Dictyostelium

American Society of Cell Biology 2008

Rodriguez, M., Kim, B., Lee, N., Veeranki, S. and Kim, L. Dictyostelium B56 is essential for both differentiation and cell migration

Tong, S., Rodriguez, M., and Kim L. Modulation of Cell Polarization with GSK3. Development, Growth, and Differentiation, (2009) 51,735-42

Comparative Immunology Symposium 2009

Rodriguez, M., Kim, B., Lee, N., Veeranki, S., and Kim, L.

MPL1 is essential for proper ERK2 phosphorylation and motility in Dictyostelium 
MBRS Symposium 2009

Rodriguez, M., Lee, N., Kim, B., Lee, N., Veeranki, S., and Kim, L. The serine/threonine phosphatase system, PP2A/B56, regulates cellular motility in Dictyostelium

Biology Symposium 2010

Rodriguez, M., Lee, N., Kim, B., Lee, N., Veeranki, S., and Kim, L. The serine/threonine phosphatase system, PP2A/B56, regulates cellular motility in Dictyostelium

MBRS Symposium 2010

Rodriguez, M., Lee, N., Kim, B., Lee, N., Veeranki, S., and Kim, L. PP2A/B56 Regulates Directional Migration in Dictyostelium Cells

American Society of Cell Biology 2010

Rodriguez, M., Kim, B., Castillo, B. and Kim, L. PP2A/B56 is essential for proper cell motility

Biology Symposium 2011

Rodriguez, M., Lee, N., Veeranki, S., Kim, B. and Kim, L. PP2A/B56 regulates cellular development in Dictyostelium cells

MBRS Symposium 2011

Rodriguez, M., Kim, B. and Kim, L. The PP2A Regulatory Subunit B56 Regulates Directional Motility in Dictyostelium cells

Biology Symposium 2012

Rodriguez, M., Kim, B. and Kim, L. The PP2A Regulatory Subunit B56 Regulates Chemotaxis in Dictyostelium cells

Rodriguez,M., Kim, B., and Kim L. B56 and GSK3 Regulate PKBR1 adaptation in Dictyostelium cells 2012 (2014) In preparation 